\title{
Natural Circulation in the Blanket Heat Removal System During a Loss-of-Pumping Accident (LOFA) Based on Initial Conceptual Design
}

by

L. L. Hamm

Westinghouse Savannah River Company

Savannah River Site

Aiken, South Carolina 29808

\author{
RECEIVED \\ OCT 301998 \\ OSTI
}

S. Y, Lee

M. A. Shadday

F. G. Smith III

This paper was prepared in connection with work done under the above contract number with the U.S. Department of Energy. By acceptance of this paper, the publisher and/or recipient acknowledges the U.S. Government's right to retain a nonexclusive, royalty-free license in and to any copyright covering this paper, along with the right to reproduce and to authorize others to reproduce all or part of the copyrighted paper. 


\section{NATURAL CIRCULATION IN THE BLANKET HEAT REMOVAL SYSTEM DURING A LOSS-OF- PUMPING ACCIDENT (LOFA) BASED ON INITIAL CONCEPTUAL DESIGN}

L. Larry Hamm

Si Young Lee

M. Andy Shadday

Frank G. Smith, III

Westinghouse Savannah River Company Savannah River Site

Aiken, SC 29808
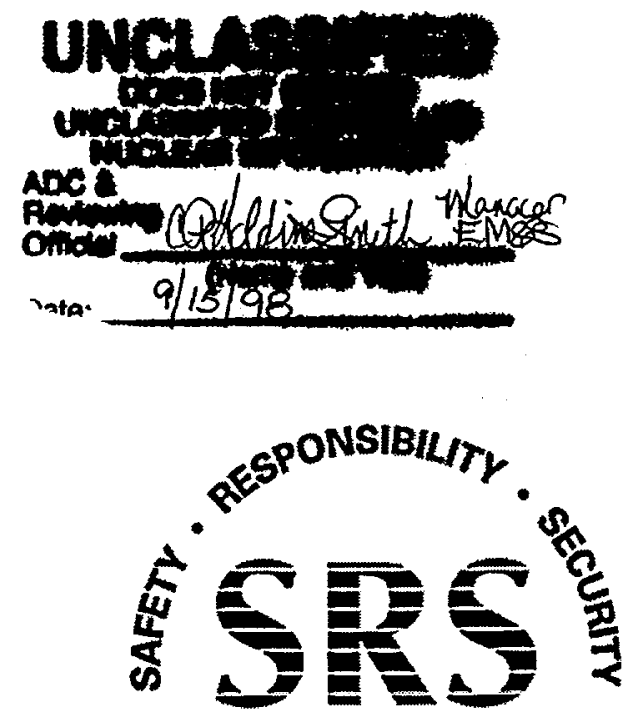


\section{DISCLAIMER}

This report was prepared as an account of work sponsored by an agency of the United States Government. Neither the United States Government nor any agency thereof, nor any of their employees, makes any warranty, express or implied, or assumes any legal liability or responsibility for the accuracy, completeness, or usefulness of any information, apparatus, product, or process disclosed, or represents that its use would not infringe privately owned rights. Reference herein to any specific commercial product, process, or service by trade name, trademark, manufacturer, or otherwise does not necessarily constitute or imply its endorsement, recommendation, or favoring by the United States Government or any agency thereof. The views and opinions of authors expressed herein do not necessarily state or reflect those of the United States Government or any agency thereof.

This report has been reproduced directly from the best available copy.

Available to DOE and DOE contractors from the Office of Scientific and Technical Information, P.O. Box 62, Oak Ridge, TN 37831; prices available from (615) 576-8401.

Available to the public from the National Technical Information Service, U.S. Department of Commerce, 5285 Port Royal Road, Springfield, VA 22161. 


\section{DISCLAIMER}

Portions of this document may be illegible in electronic image products. Images are produced from the best available original document. 


\section{WSRC-TR-98-00207}

KEYWORDS:

Accelerator Production of Tritium

Blanket System

Conceptual Design

TRAC Code

System Model

Evaluation Model

Safety Analysis

RETENTION - Permanent

\section{NATURAL CIRCULATION IN THE BLANKET HEAT REMOVAL SYSTEM DURING A LOSS-OF- PUMPING ACCIDENT (LOFA) BASED ON INITIAL CONCEPTUAL DESIGN}

SAVANNAH RIVER TECHNOLOGY CENTER

L. Larry Hamm

Si Young Lee

M. Andy Shadday

Frank G. Smith, III

Publication Date: July, 1998

Westinghouse Savannah River Company

Savannah River Site

Aiken, SC 29808

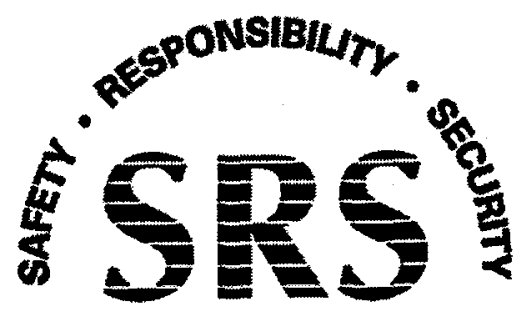

SAVANNAH RIVER SITE

Prepared for the U.S. Department of Energy under Contract No. DE-AC09-96SR18500 
TITLE: NATURAL CIRCULATION IN THE BLANKET HEAT REMOVAL SYSTEM DURING A LOSS-OF-PUMPING ACCIDENT (LOFA) BASED ON INITIAL CONCEPTUAL DESIGN

\section{APPROVALS}

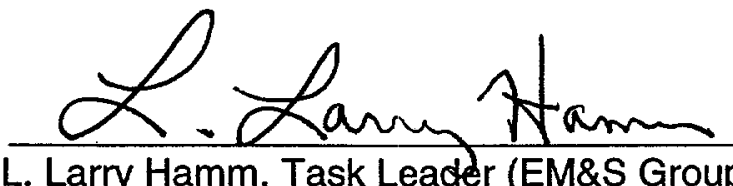

L. Larry Hamm, Task Leader (EM\&S Group/SRTC)
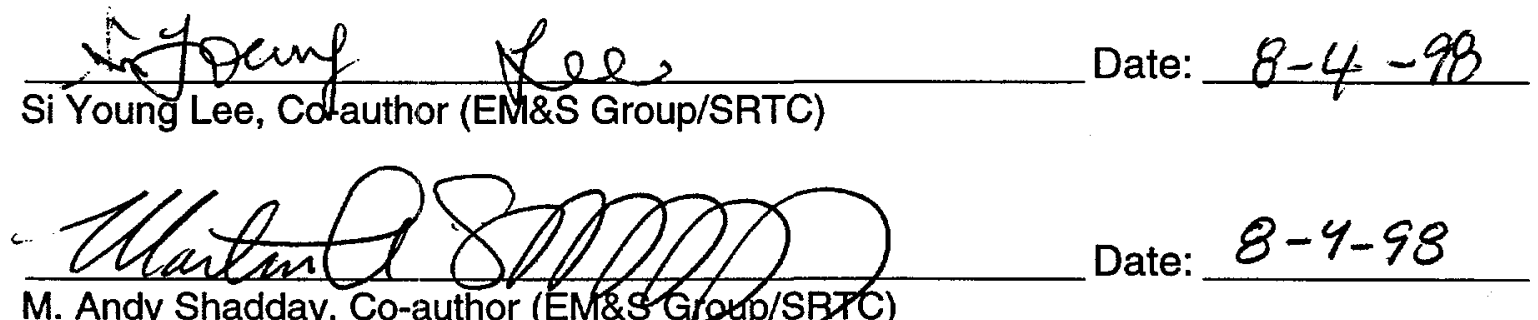

M. Andy Shadday, Co-author (EM\&SGtotp/SBTC)

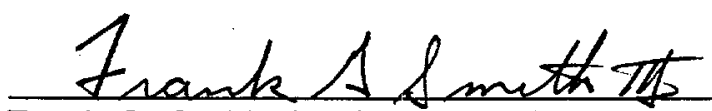

Date: $8-4-98$

Frank G. Smith, III, Co-author (PC\&C Group/SRTC)

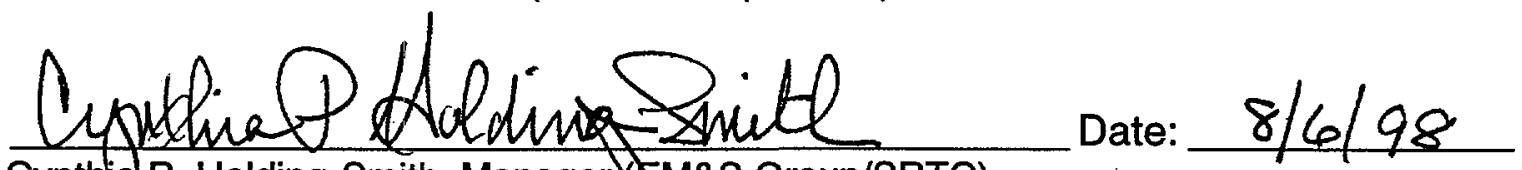

Cynthia P. Holding-Smith, Manager 1 \&S Group/SRTC)

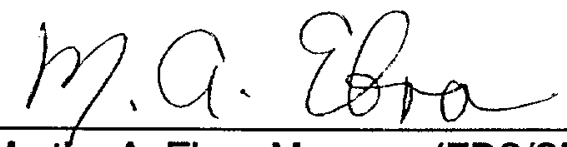

Martha A. Ebra, Manager (EDS/SRTC)

Date: $8-4-98$

Date: $8-4-98$

Date: $\frac{110 \log }{0}$

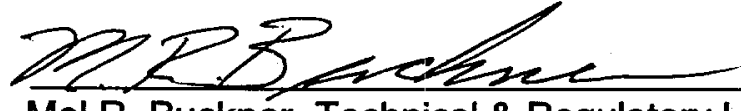

Mel R. Buckner, Technical \& Regulatory Lead (APT OPO)

Date: Sept 15,1998

The internal technical review function is being performed at the APT project level and is coordinated through LANL. 


\section{Table of Contents}

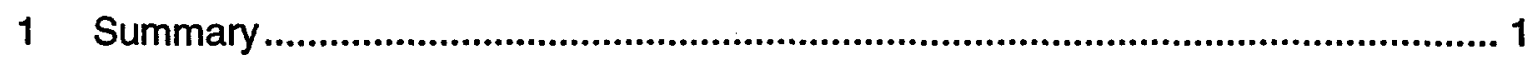

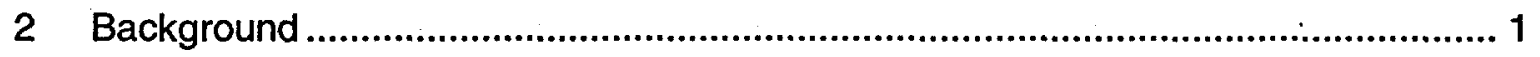

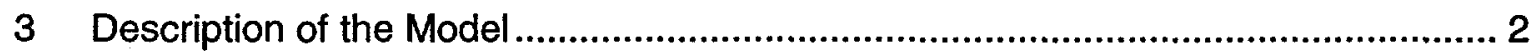

4 Vertical Mixed Convection Friction Factors ............................................................. 4

5 Discussion and Results .................................................................................. 4

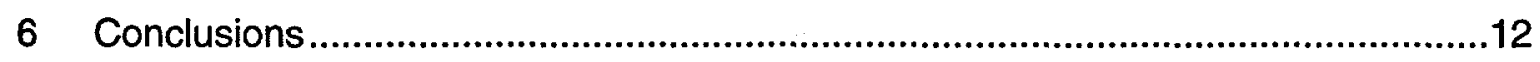

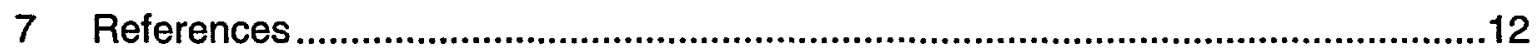

Appendix A: Derivation of the Governing Equations

Appendix B: Buoyancy-Assisted and Buoyancy-Opposed Friction Factor Multipliers

Appendix C: Sample Input Deck

Appendix D: Code Listing 


\section{List of Figures}

Figure 1 Schematic of the blanket primary HR system with three lumped modules and one lumped heat exchanger loop.

Figure 2

Natural circulation flowrates during a T/B LOFA

Figure 3

Expanded view of the flowrates during the flow reversal process.

Figure 4

Transient fluid temperatures of the two headers and the shell side

of the heat exchanger during a T/B LOFA.

Figure 5 Transient temperatures in the headers and Leg 1 during a T/B LOFA.

Figure 6

Transient temperatures in the headers and Leg 2 during a T/B LOFA.

Figure 7

Transient temperatures in the headers and Leg 3 during a T/B LOFA.

Figure 8

Transient temperatures in the headers and the tube side of the heat exchanger during a T/B LOFA.

Figure 9

Outlet header pressure during a T/B LOFA.

Figure 10

Natural circulation flowrates during a blanket only LOFA.

Figure 11

Transient fluid temperatures in the two headers and the shell side of the heat exchanger during a blanket only LOFA.

Figure A-1

Schematic of the blanket primary HR system with three lumped modules and one lumped heat exchanger loop.

Figure A-2

Schematic of one of the module legs of the natural convection network showing the control volumes used to derive the momentum equation.

Figure A-3

Schematic of the heat exchanger leg of the natural convection network. A3

Figure A-4

Schematic of the outlet header showing the mass flowrates. A4

Figure A-5

Schematic of the heat exchanger showing the heat transfer to the secondary side. A6

Figure B-1

Friction factor multipliers for buoyancy-assisted and buoyancyopposed mixed convection in vertical channels. B2

\section{List of Tables}

Table 1 Cruciform-type module descriptions showing NC model relationship.

Table 2

Normal operation deposited power levels. 


\section{Summary}

A transient natural convection model of the APT blanket primary heat removal (HR) system was developed to demonstrate that the blanket could be cooled for a sufficient period of time for long term cooling to be established following a loss-of-flow accident (LOFA). The particular case of interest in this report is a complete loss-of-pumping accident. For the accident scenario in which pumps are lost in both the target and blanket HR systems, natural convection provides effective cooling of the blanket for approximately 68 hours, and, if only the blanket HR systems are involved, natural convection is effective for approximately 210 hours. The heat sink for both of these accident scenarios is the assumed stagnant fluid and metal on the secondary sides of the heat exchangers.

\section{Background}

Loss of power could leave the APT Target/Blanket (T/B) Facility without running pumps resulting in no forced circulation in the primary and secondary heat removal systems for an extended period of time. Natural circulation (NC) would occur in the primary HR system; however, without circulation through the secondary sides of the heat exchangers there would not be an ultimate heat sink for the decay power in the blanket modules. To prevent some or all of the blanket modules from eventually overheating and losing structural integrity, either power would have to be restored or the cavity flood system would have to be activated. There would be a period of time following the loss of forced convection in the HR systems when the modules would be cooled by natural convection. The stagnant water in the secondary sides of the heat exchangers could serve as a temporary heat sink, diminishing in effectiveness as it heats up. A transient single-phase natural convection model of the primary HR system was developed to determine the duration of time of effective passive cooling of the modules. A special purpose fortran program was written, called NCLOFA, and a listing of the code is provide in Appendix D.

The accident under consideration is a facility loss-of-power that results in the simultaneous loss of both the T/B primary and secondary coolant pumps. This accident is unmitigated except for a beam shutdown. The primary HR systems would ultimately dry out by boiling off the coolant inventories, if corrective action is not taken. This would occur much sooner in the target system than the blanket because of the differences in both metal and coolant masses. The target can survive high temperatures where thermal radiation to the blanket is an acceptable heat removal mechanism; whereas, without cavity flooding, the blanket cannot maintain its structural integrity very long after dryout. Based on results presented in Ref. [1], the target is assumed to dry out twentyfour hours after the onset of the accident and the target decay power is then deposited in the Module 1 decouplers. The model is run until the HR system coolant reaches its saturation temperature. Beyond this point two-phase flow is established; however, the NC model chosen for this set of analyses is limited to single-phase conditions. Even though it is anticipated that significant cooling capability further exists once boiling begins. No formal credit for boiling capability is taken at this time, since a significant increase in modeling complexity would only extend the existing acceptable period of time available prior to taking corrective action.. The consequences of this accident 
scenario envelop those of the scenario where only the blanket primary and secondary coolant pumps are lost.

\section{Description of the Model}

The transient single-phase NC model of the primary HR system is based on a flow network with three lumped modules and one lumped heat exchanger, as shown in Fig. 1. The three lumped modules constitute three parallel legs between the fixed inlet and outlet headers, and the heat exchanger is in a fourth leg that forms the network into a closed loop. The various legs of the flow network that make up the NC model represent lumped flow paths. Table 1 provides a brief description of the 16 module cruciform-type units in the current blanket design (see Ref. [2] for further details). These modules are combined into lumped flow paths (referred to as legs) as listed below:

- "Leg 1" - the lateral Row-1/decoupler modules listed as Modules 1 and 4 in Table 1;

- "Leg 2" - the remaining vertical modules listed as Modules 2, 3, 5, 6, 7, 8, and 9 in Table 1;

- "Leg 3" - all horizontal modules listed as Modules 10, 11, 12, 13, 14, 15, and 16 in Table 1;

- "Hx leg" - blanket primary HR loop containing the two heat exchangers, two pumps, and piping from the outlet header back around to the inlet header closing the flow network.

Table 1 Cruciform-type module descriptions showing NC model relationship.

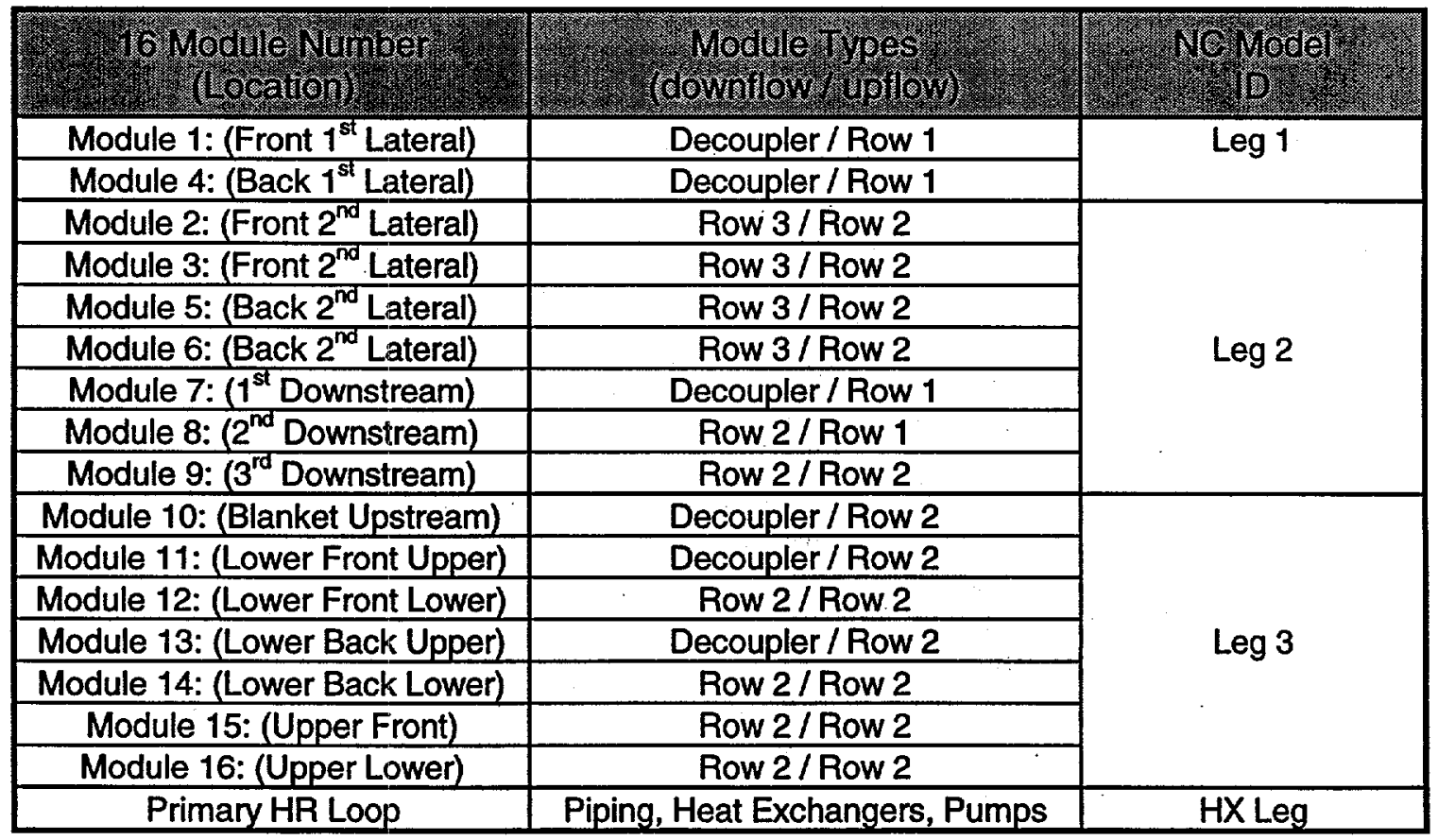


The labels above are also provided in Fig. 1 . The pressurizer is not modeled explicitly but does establish the network reference pressure at the inlet header. The heated upflow and downflow sections of a module are treated separately in the momentum equations, and the impact of buoyancy-assisted/opposed mixed convection flow is accounted for through a Rayleigh number dependent modification of the Darcy friction factor. The heated solid sections of the modules are lumped together with the coolant flowing through them in the thermal energy equations. The aluminum clad lead plates and the fluid in the adjacent channels are assumed to be isothermal. This is reasonable at the low metal power densities encountered under post beam shutdown conditions and with the high heated surface area to fluid volume ratios for the flow channels. This simplification avoids the necessity of solving conjugate heat transfer problems within the modules. There are four momentum equations, one for each leg in the loop and a continuity equation for the outlet header. These five equations are solved simultaneously for the four leg mass flowrates and the outlet header pressure each time step using a standard Newton-Raphson method. The inlet header pressure is a boundary condition that specifies the system reference pressure.

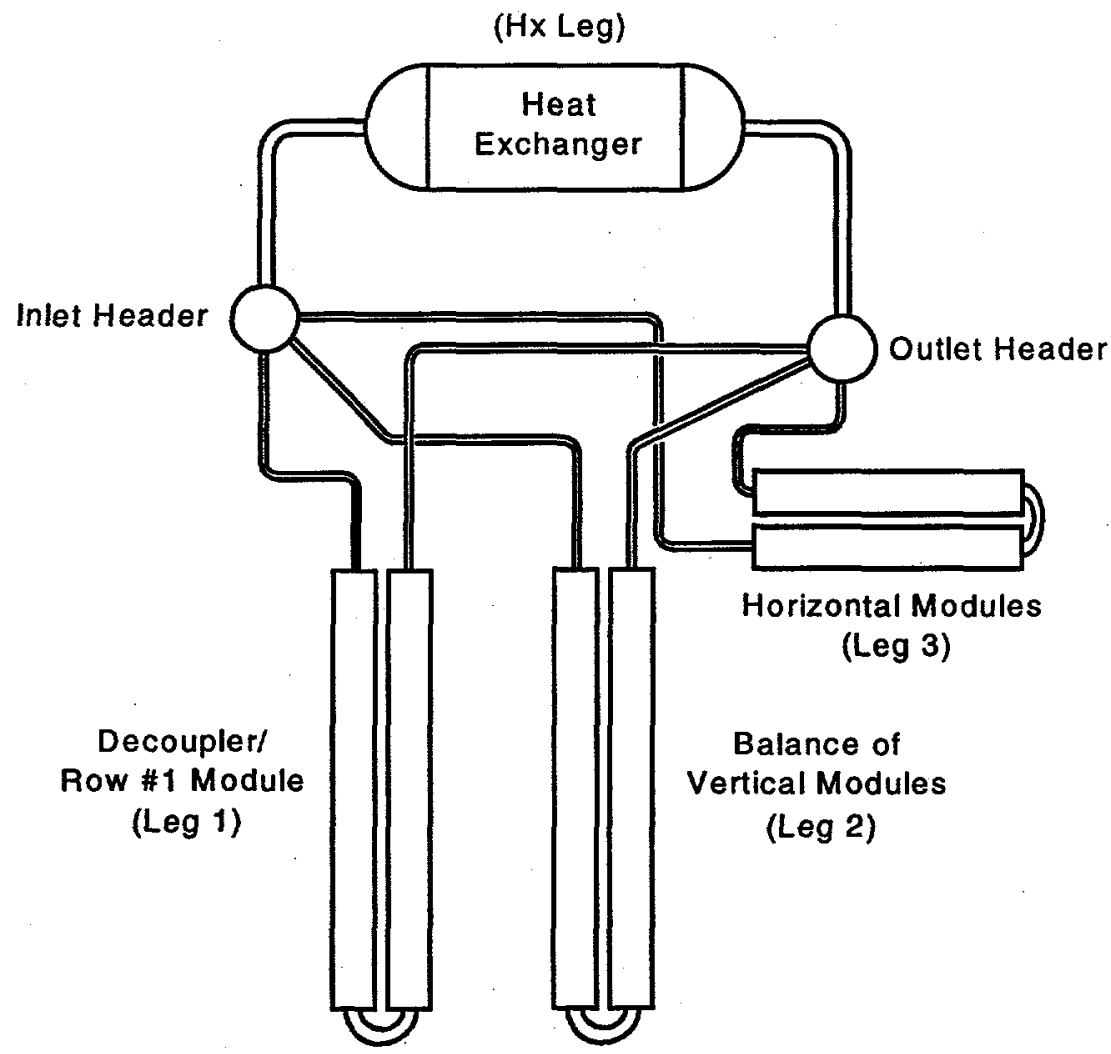

Figure 1 Schematic of the blanket primary HR system with three lumped modules and one lumped heat exchanger loop.

For determining the transient temperature distribution within the network, each of the module legs of the network is divided into five cells, while the heat exchanger leg is divided into three. Under low flow conditions for which this model is intended, this spatial resolution is adequate. A thermal energy equation is derived for each leg cell, each of the headers, and for the shell (or secondary) side of the heat exchanger. The energy equations are differenced in time allowing a varying degree of implicitness 
specified by the user. The energy equations are solved iteratively each time step in a two-step process. The two header temperatures and the temperature on the secondary side of the heat exchanger are updated. With these updated values, the network leg temperatures are updated by marching in the flow direction from the upstream to the downstream header for each leg. This process is repeated until convergence occurs. The momentum and thermal energy equations are derived in Appendix A.

The natural circulation is driven by the time dependent decay power in the heated sections of the module legs. After 24 hours have elapsed, the total target decay power is deposited in the decoupler section of Leg 1 . This is the heated section in Leg. 1 closest to the inlet header. This additional power is ramped in over a period of one hour. The NC simulation commences one hour after the onset of the accident and continues until the primary coolant reaches its saturation temperature. The model predicts the transient mass flowrates in the network legs, the outlet header pressure, the transient temperature distribution in the primary coolant, and the shell side heat exchanger temperature. Appendix $\mathrm{C}$ contains a sample-input file and Appendix $\mathrm{D}$ contains a code listing of the NCLOFA program.

\section{$4 \quad$ Vertical Mixed Convection Friction Factors}

The Darcy friction factors for mixed forced/free laminar convection through vertical passages can differ significantly from the forced convection values defined as sixty-four over the Reynolds number. In upflow through a heated vertical channel, buoyancy flattens the parabolic radial velocity profile and increases the wall velocity gradient, thereby, increasing the wall shear. In downflow, buoyancy decreases the radial velocity gradient at the wall and therefore the wall shear. The friction factor for heated upflow is increased, and for downflow it is decreased. No effect exists for horizontal flow paths.

Based on a plot of Fanning friction factors for buoyancy assisted and retarded flows between vertical flat plates in Ref. [3], correlations were developed for friction factor multipliers as functions of a modified Rayleigh number. These correlations are developed in Appendix B. They are used in the NC model to modify the friction factors in the heated sections of the two network vertical module legs.

\section{Discussion and Results}

Two facility loss-of-power accident scenarios were simulated with the NC model: a simultaneous loss of both the T/B primary and secondary coolant pumps, and a loss of only the blanket primary and secondary coolant pumps. The first scenario is the more interesting of the two because flow reversals occur. It is also the more limiting case because, with the addition of the target decay power, more power (approximately double) is transferred to the coolant. The results of this accident simulation are described first and in detail. The results for the latter scenario are described primarily by comparison and contrast with the results of the former.

Figure 2 shows, for the first accident scenario, the network mass flowrates for the three modules and the heat exchanger leg as functions of elapsed time. By definition, positive flow through the three module legs travels from the inlet header to the outlet header and return flow occurs through the heat exchanger leg. During normal operation (NO) and prior to the depositing of the target power in the decoupler, the flow is positive throughout the network. The target is assumed to dry out within twenty-four hours of the 
onset of the accident, and thereafter, the target decay power is dissipated by thermal radiation to the cooler adjacent blanket system decouplers. The blanket decouplers virtually surround the ladder assemblies, neutronically decoupling the target from the lead blanket. It is assumed that all thermal radiation emanating from the target ladders is deposited into the decouplers. This power is assumed to be ramped in over a period of one hour. With the addition of the target power, significantly more power is dissipated in the decoupler than in the Row-1 section of Leg 1, and buoyancy causes a flow reversal to occur. Deposited power levels under NO conditions are given in Table 2. Figure 3 shows an expanded view of the network mass flowrates during the period in which the flow reversals occur. Shortly after the flow reversal occurs in Leg 1 of the network, the flows reverse in Leg 3 and the Hx leg. The flow does not reverse in Leg 2. There are no preferred flow directions, due to buoyancy, in Leg 3 and the Hx leg of the network, so the flows in these legs readily reverse as consequences of the flow reversal in Leg 1. Buoyancy dictates the flow direction in Leg 2, and since the relative power distribution in this module doesn't change, neither does its flow direction.

Table 2 Normal operation deposited power levels.

\begin{tabular}{|c|c|c|}
\hline $10 \mathrm{mog}$ & 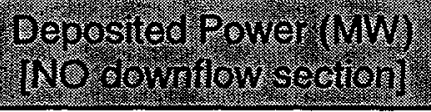 & 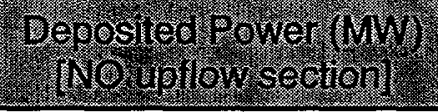 \\
\hline $\operatorname{Leg} 1$ & 8.222 & 15.768 \\
\hline $\operatorname{Leg} 2$ & 9.083 & 17.695 \\
\hline $\operatorname{Leg} 3$ & 0.0 & 5.712 \\
\hline HX Leg & 0.0 & 0.0 \\
\hline Totals & $\begin{array}{l}56.48 \text { (blanket) } \\
68.01 \text { (targets) }\end{array}$ & $\overline{-}$ \\
\hline
\end{tabular}

Figure 4 shows the temperatures of the two headers and the shell side of the heat exchanger. Prior to the flow reversals, the inlet header is colder than the outlet header, which is to be expected since the flows in all three modules are positive. After the flow reversals, the outlet header is colder than the inlet header. The shell side of the heat exchanger has the lowest of the three temperatures. This is the system heat sink. The increased heating rate of the fluid after the target power is deposited in the decoupler is evident from the slopes of the transient temperature plots. 


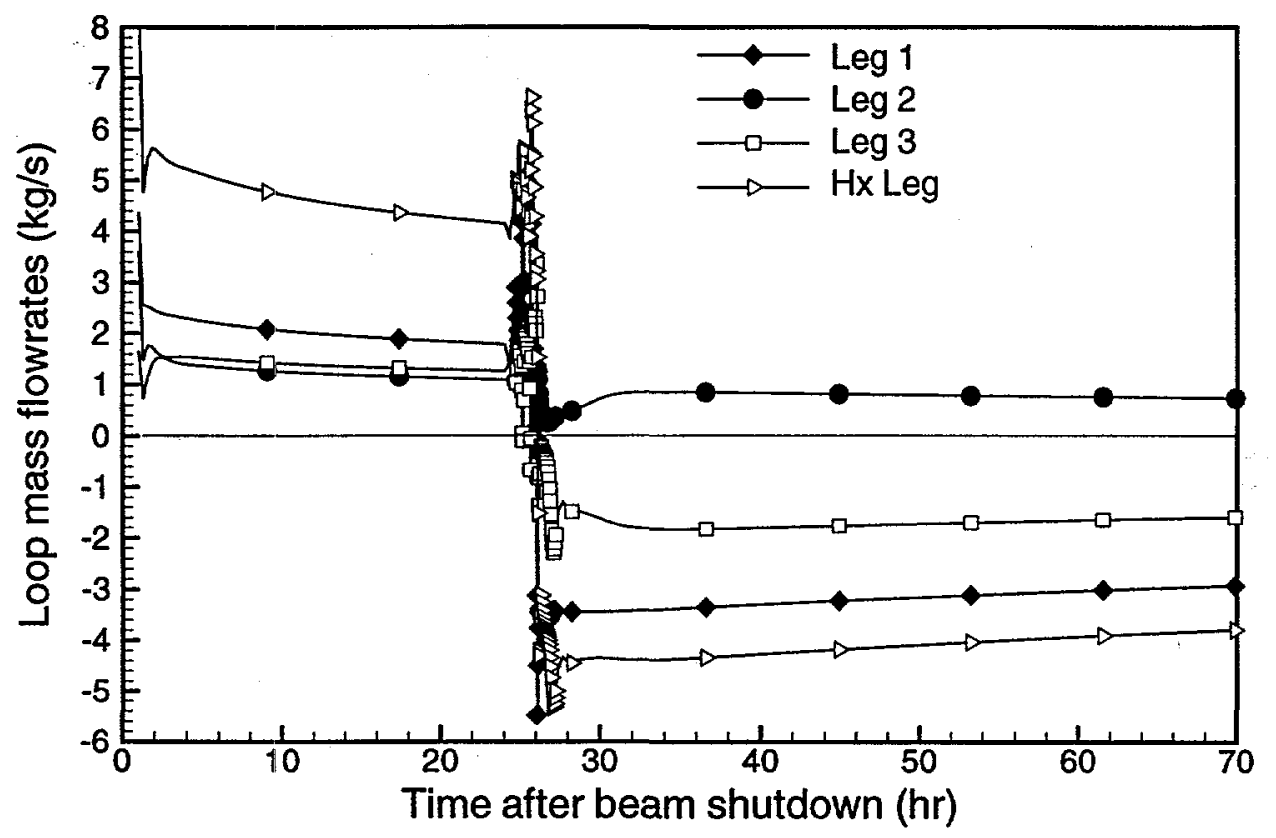

Figure 2 Natural circulation flowrates during a T/B LOFA.

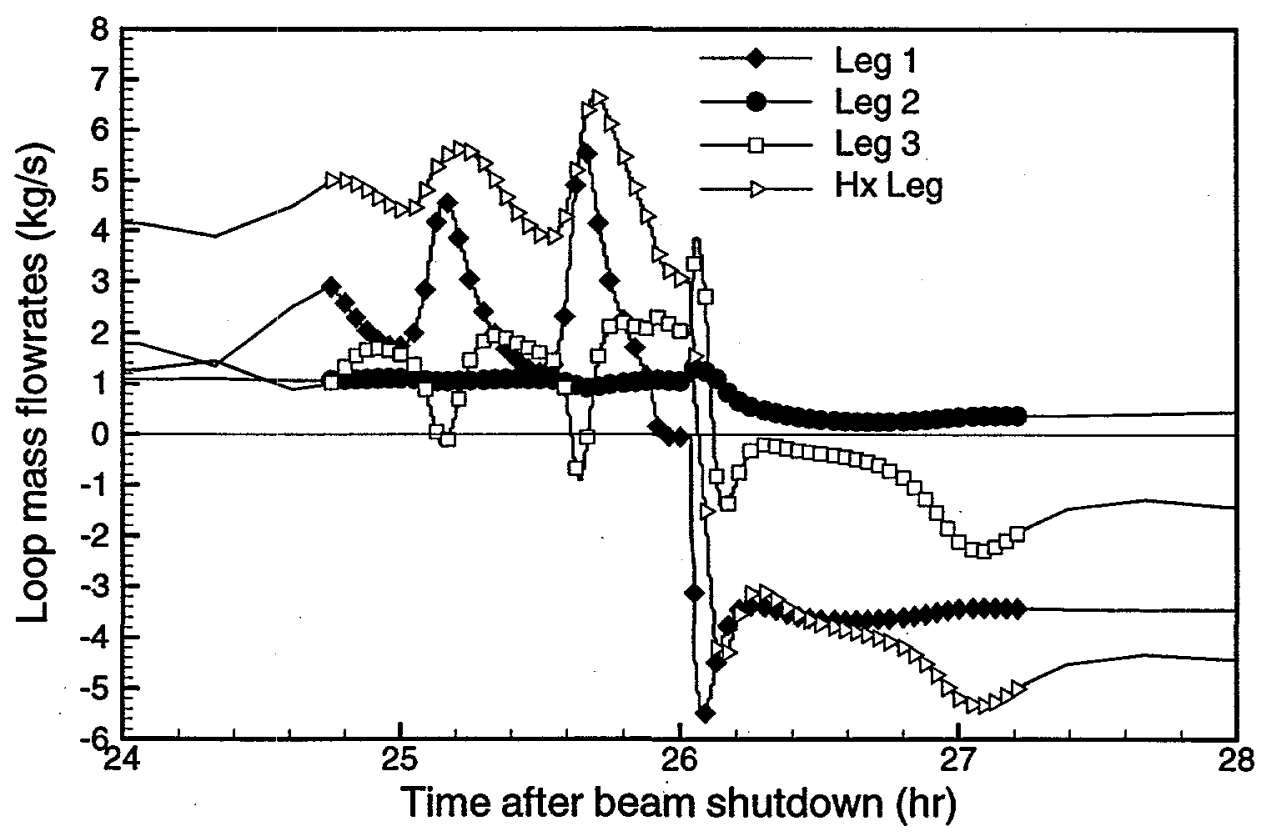

Figure 3 Expanded view of the flowrates during the flow reversal process. 
Figures 5 through 7 show the two header temperatures and the temperatures in the two heated sections of each of the three legs, respectively. Figure 8 shows the two header temperatures and the heat exchanger temperature. The effects of the flow reversals on the relative magnitudes of the temperatures in the heated sections of legs one and three are evident. The flow does not reverse in Leg 2, and therefore, the downstream heated section remains hotter than the upstream heated section throughout the accident scenario. These two temperatures exceed the inlet header temperature after the flow reversals because the flow in this leg occurs from the inlet header to the outlet header. The highest system temperature occurs in this module. The heat exchanger primary (or tube side) temperature is equal to the inlet header temperature prior to the flow reversals, and it is slightly lower than the outlet header temperature after the flow reversals. After the flow reversals, the outlet header temperature is slightly greater than the heat exchanger temperature because Leg 2 continues to discharge into the outlet header.

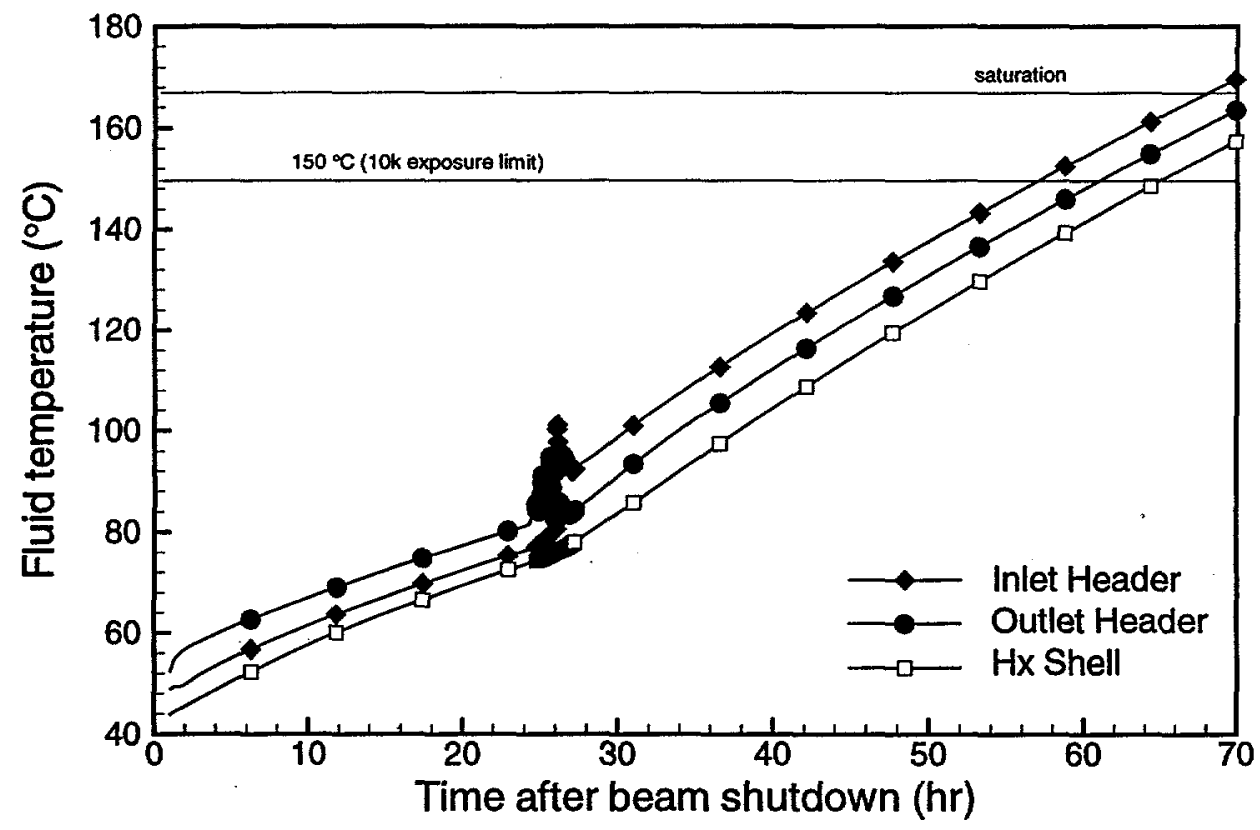

Figure 4 Transient fluid temperatures of the two headers and the shell side of the heat exchanger during a T/B LOFA. 


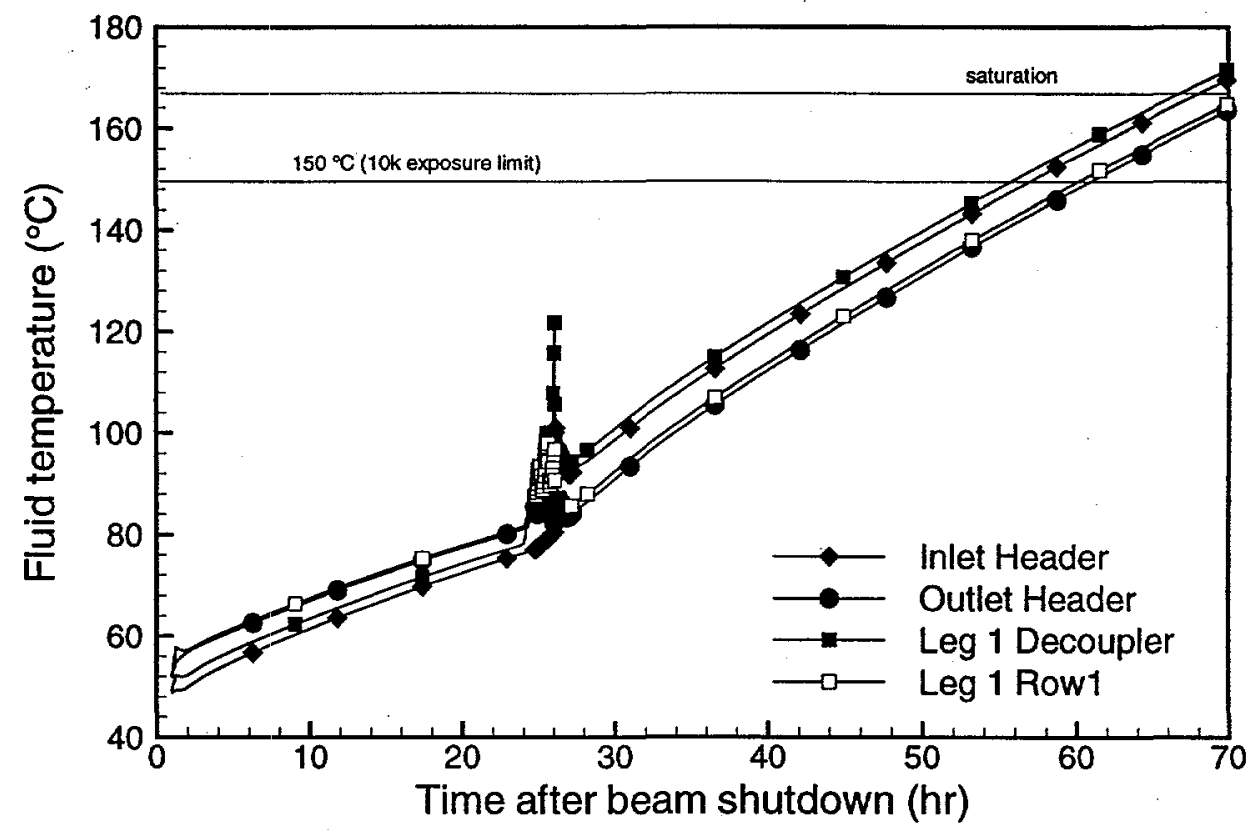

Figure 5 Transient temperatures in the headers and Leg 1 during a T/B LOFA.

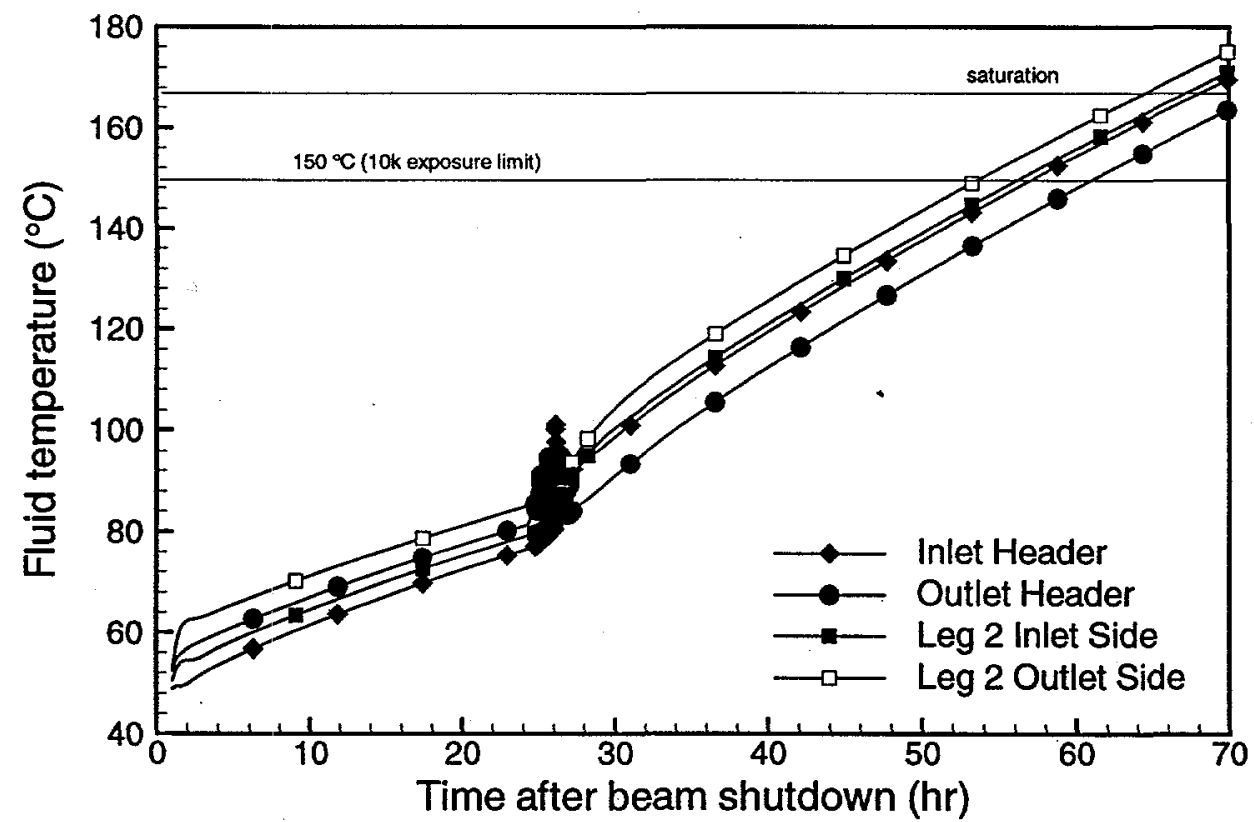

Figure 6 Transient temperatures in the headers and Leg 2 during a T/B LOFA. 


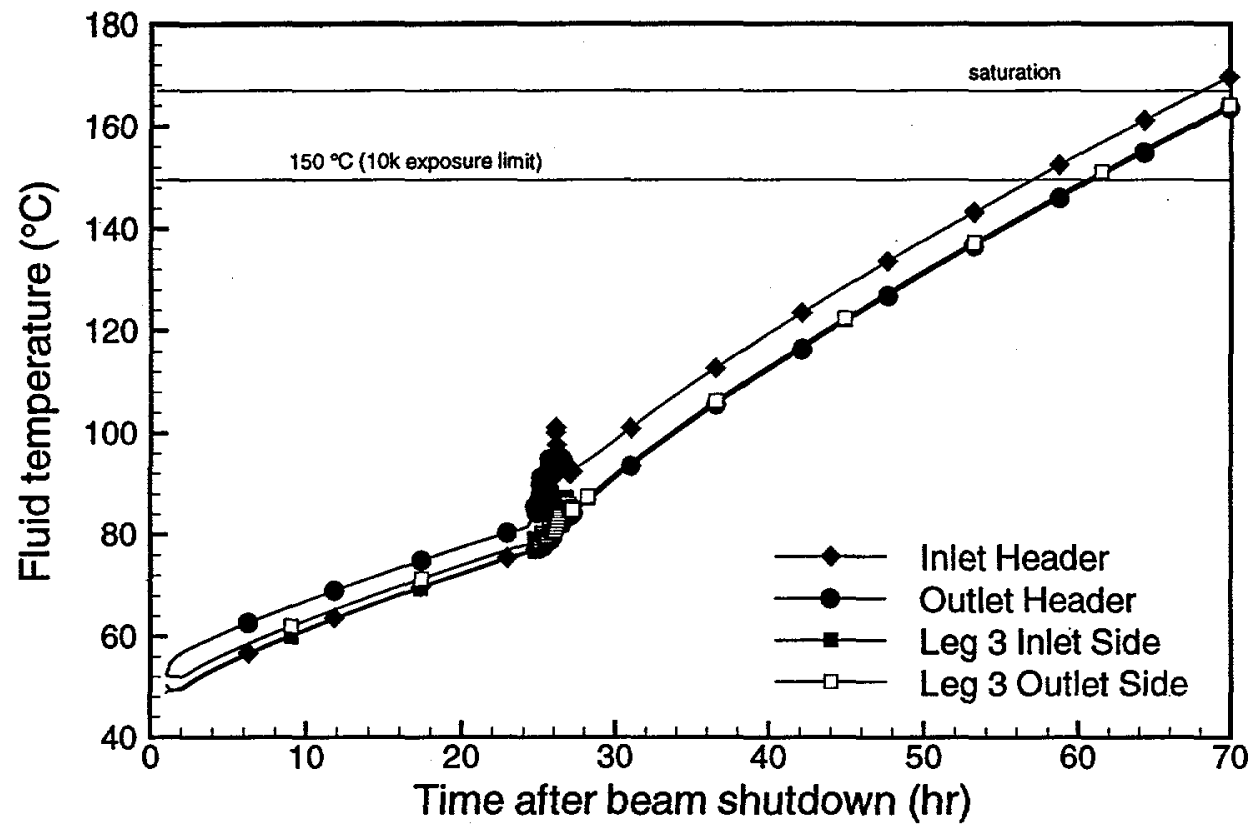

Figure 7 Transient temperatures in the headers and Leg 3 during a T/B LOFA.

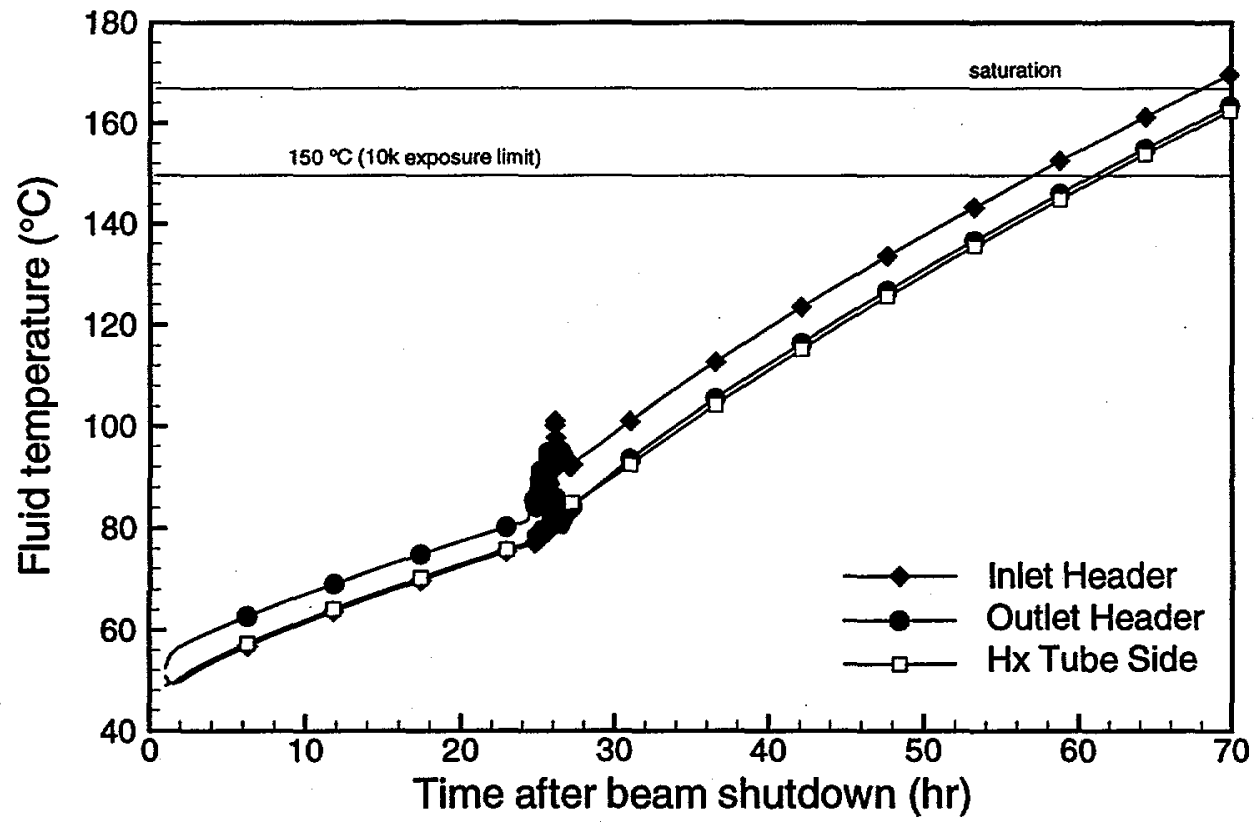

Figure 8 Transient temperatures in the headers and the tube side of the heat exchanger during a T/B LOFA. 
Figure 9 shows the transient outlet header pressure. It is constant at 107.3 psia, given a specified inlet header pressure of 106.24 psia. The difference between the two pressures is hydrostatic. In each leg of the network, the net buoyant force balances the dynamic pressure drop force. At the inlet header pressure the saturation temperature is $166.8^{\circ} \mathrm{C}$ and the inlet header reaches this temperature 67.9 hours after the onset of the accident. Once the mean fluid temperature reaches saturation, bulk boiling will commence and the system will start to pressurize. The primary and secondary coolants will continue to heat up as the saturation temperatures increase due to system pressurization. Since pressurizing the primary blanket HR system would threaten its integrity, bulk boiling should be avoided. The point at which the primary coolant temperature reaches saturation is defined as the limit of effective natural convection cooling by the blanket HR system.

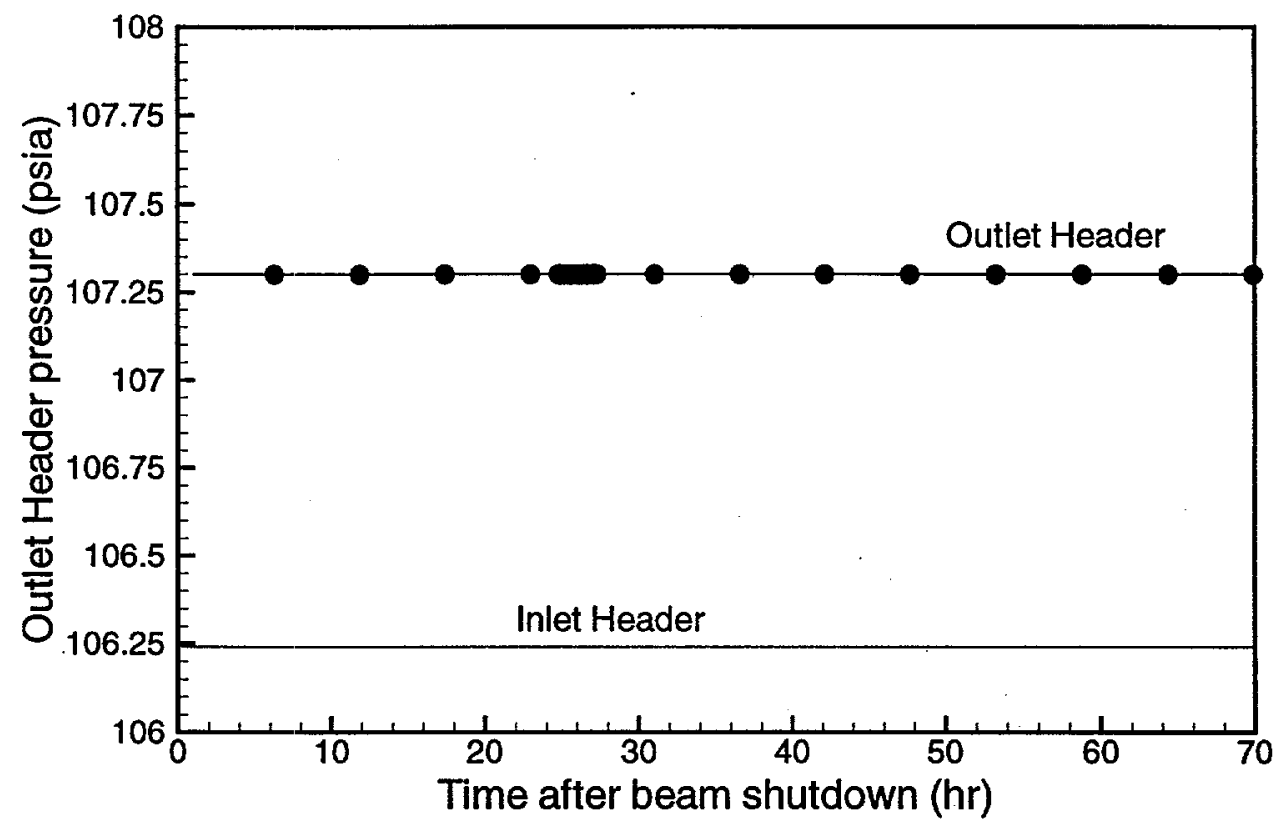

Figure 9 Outlet header pressure during a T/B LOFA.

If the LOFA is confined only to the blanket HR system, the period of adequate natural convection cooling under single-phase flow is significantly longer than for the scenario just considered, in which both the target and blanket systems are involved. As Table 2 shows, the blanket only constitutes $\sim 45 \%$ of the total deposited power being generated in the T/B facility. Figure 10 shows the mass flowrates in the three legs and the $\mathrm{Hx}$ leg of the NC network. The flowrates decrease monotonically due to the decay of the internal heat generation in the blanket modules. There is no flow reversal because the relative power distribution within the blanket modules remains constant. Figure 11 shows the transient fluid temperatures in the inlet header, outlet header, and on the shell side of the heat exchanger. Approximately 210 hours are required for the fluid in the outlet header to reach its saturation temperature of $167.2^{\circ} \mathrm{C}$. This is considerably longer than 68 hours of effective natural convection cooling in the accident scenario that involves the target. 


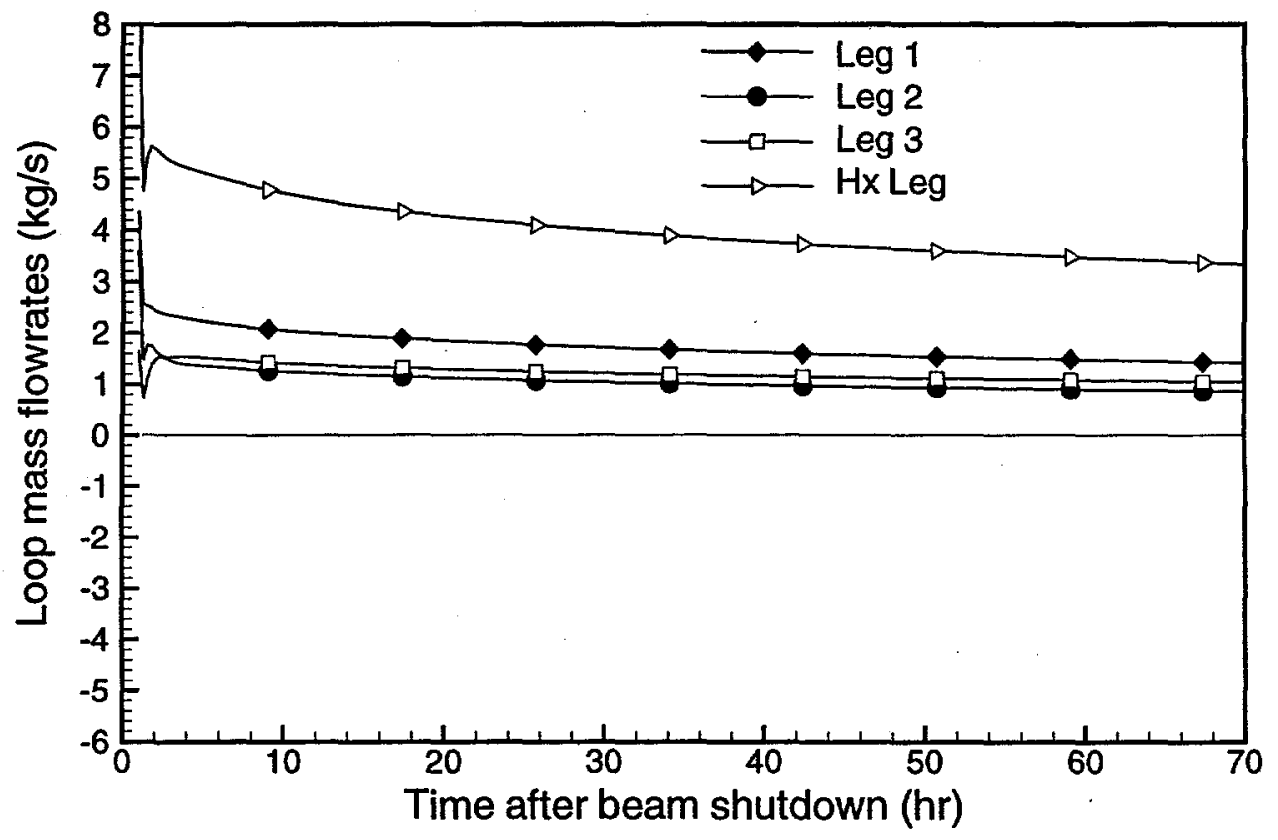

Figure 10 Natural circulation flowrates during a blanket only LOFA.

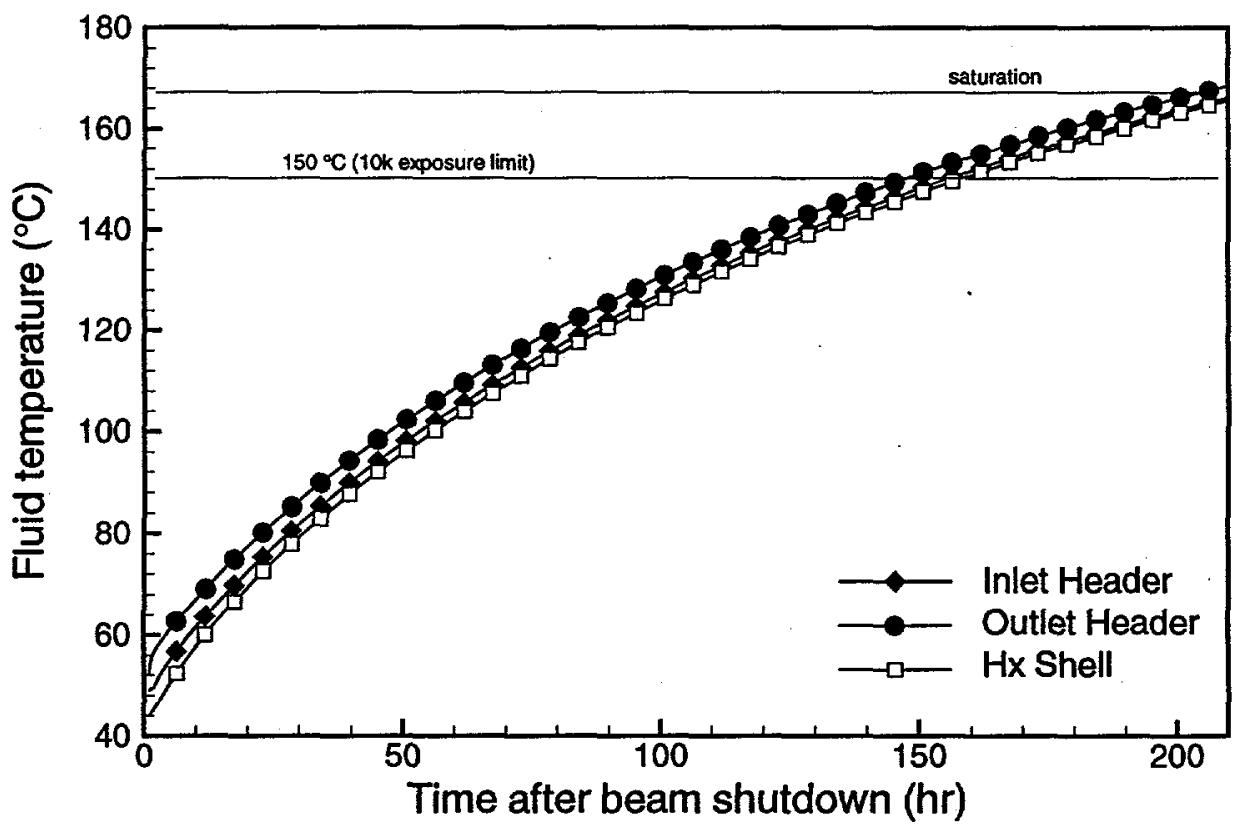

Figure 11 Transient fluid temperatures in the two headers and the shell side of the heat exchanger during a blanket only LOFA. 


\section{Conclusions}

The period of effective single-phase natural convection cooling of the APT blanket, following a facility loss-of-power accident that results in the simultaneous loss of both the T/B primary and secondary pumps, is approximately 68 hours. This is the time required for the coolant to reach its saturation temperature. The transient heat sink for this accident scenario is the stagnant fluid in the shell side of the heat exchanger. If the target HR system is not involved in this accident scenario, the period of effective natural convection cooling is extended to approximately 210 hours. These are the allowable time periods available for restoring electrical power to the pumps or establishing an alternate means for cooling the blanket assemblies.

The volume of assumed stagnant water on the shell sides of the heat exchangers and the masses of metal in the heat exchangers are the heat sinks for the NC model. Other than sensible heating, no other phenomena with respect to the shell side of the heat exchanger were considered in this accident analysis. If the pressure in the blanket secondary HR system is less than that in the primary system, the secondary side fluid would boil before the primary fluid reached saturation. This probably will not be the case since maintaining the secondary side heat exchanger pressure at a higher value than the primary side is desirable for radionuclide containment. This aspect of the accident analysis does warrant further consideration. Boiling on the secondary side could provide effective cooling for a while, but the heat sink would completely lose its effectiveness after dryout. The fluid in the secondary HR system could also circulate by natural convection, thereby, extending the period of time that the system is an effective heat sink for the primary HR system.

\section{References}

1. W. R. Bohl and K. O. Pasamehmetoglu, "Temperature Calculations for a Dry-Rung in a Dry or Flooded Cavity after a LOFA or a LOCA in the Tungsten Neutron Source Primary Heat Removal System," Los Alamos National Laboratory calcnote, CN-APT/TSA10-005 (February 1998).

2. L. L. Hamm, S. Y. Lee, M. A. Shadday, and F. G. Smith, III, "APT Blanket System Model Based On Initial Conceptual Design - Integrated 1D TRAC System Model," Westinghouse Savannah River Company, WSRC-TR-98-0053 (July 1998).

3. S. Kakac, R. K. Shah, and W. Aung, "Handbook of Single-phase Convective Heat Transfer", John Wiley \& Sons, 1987. 


\section{Appendix A: Derivation of the Governing Equations}

The primary HR system flow network consisting of three lumped legs, as shown in Fig. A-1, is divided up into several interconnected discrete control volumes. To derive the governing equations for transient single-phase natural convection for this simplified model, the incompressible continuity, momentum, and thermal energy equations were applied to the control volumes. A Boussinesq fluid was assumed to handle the buoyancy terms in the momentum equations. Four momentum equations, one for each leg, and the continuity equation for the outlet header are solved simultaneously for the mass flowrates in each leg and the outlet header pressure. The thermal energy equations for the header temperatures, the heat exchanger shell side temperature, and the temperature distributions within each network leg are solved separately from the momentum equations.

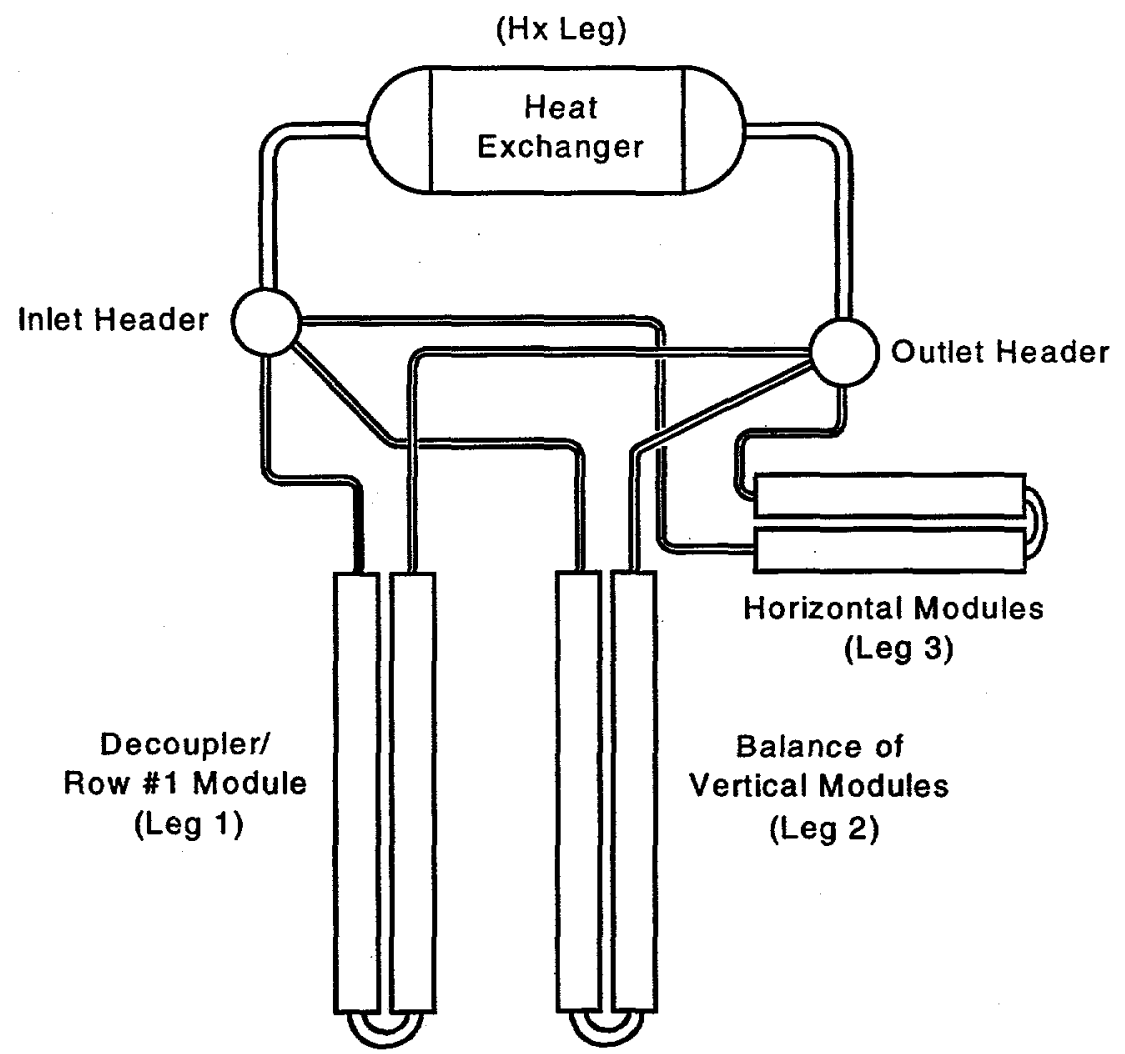

Figure A-1 Schematic of the blanket primary HR system with three lumped modules and one lumped heat exchanger loop.

Figure A-2 shows one of the lumped module legs of the network and a close up of a representative control volume of one of the sections of the leg. The external forces acting on the fluid in the control volume are shown. They are the normal facing pressure forces, the body force, and the wall shear (or frictional force). The linear momentum equation (Eq. a1) is applied to each of the five control volumes within a leg. Equation a2 is the body force term and Eq. a3 is the frictional force term. The " $\mathrm{n}$ " in the subscript refers to the leg number, and the second number refers to the cell number, one through five. Equation a4 is the momentum equation for the first cell of the leg. 
There are four additional equations, one for each of the other cells. If the area changes between cells are neglected, the five momentum equations can be added together to yield a single leg momentum equation (Eq. a5) with the header pressures and the leg mass flowrate as unknowns. At the low flowrates expected under natural convection conditions, the pressure distributions in the network legs will be close to hydrostatic. The flow area expansions/contractions occur in pairs with the same elevation, points 2 and 5 and points 3 and 4 in Fig. A-2. For these reasons the area changes can be neglected. The alternative would be to calculate intermediate pressures at the cell faces, and this would significantly increase the number of simultaneous non-linear equations to be solved and from an accuracy perspective is not warranted.
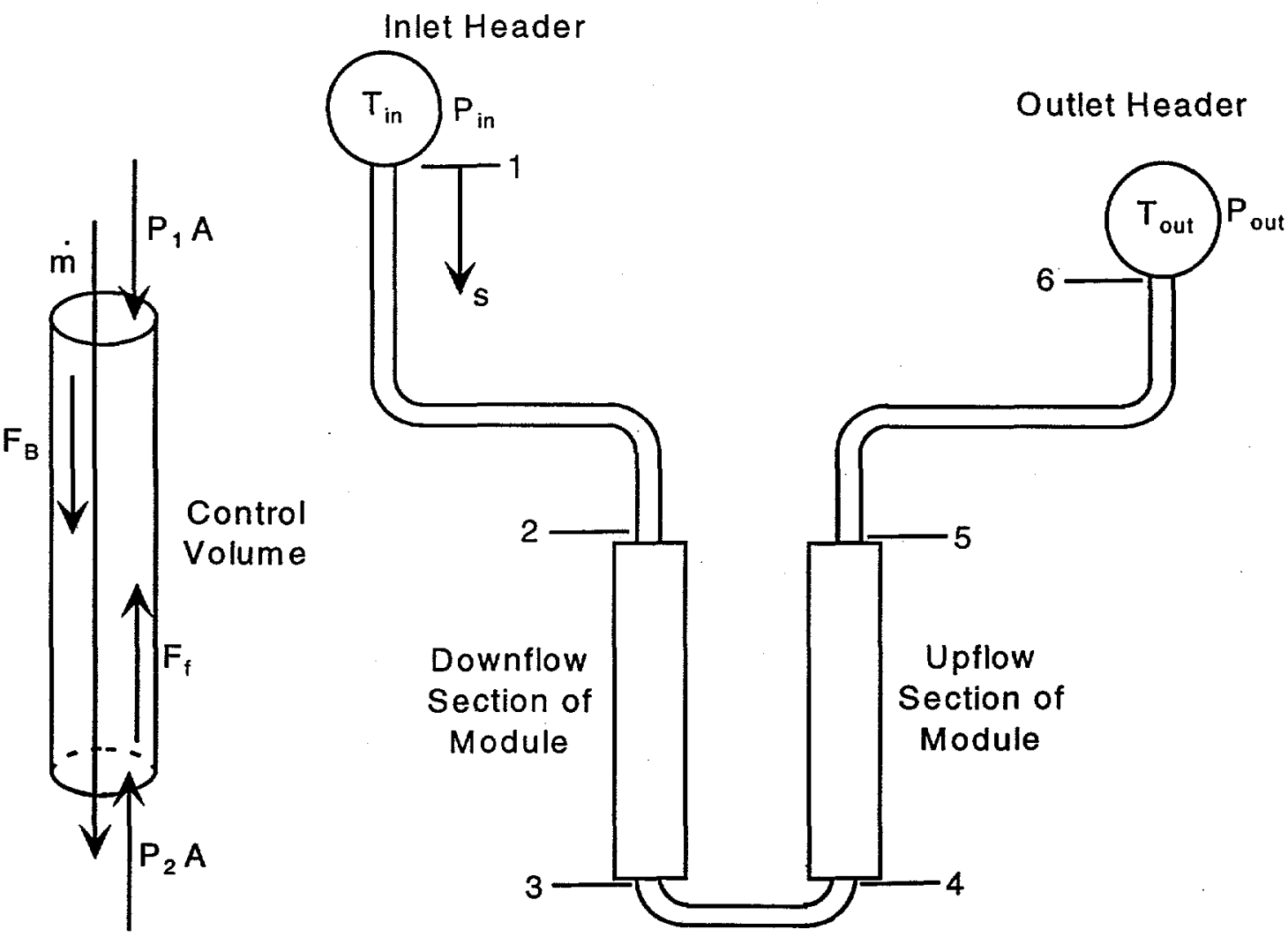

Figure A-2 Schematic of one of the module legs of the natural convection network showing the control volumes used to derive the momentum equation.

$$
\begin{gathered}
\frac{d}{d t}(m \bar{v})+\dot{m}\left(\bar{v}_{\text {out }}-\bar{v}_{i n}\right)=\sum \vec{F} \\
F_{B}=\rho_{o}\left[1-\beta\left(T_{n 1}-T_{o}\right)\right] A_{n 1} g \Delta z_{n 1} \\
F_{f}=\frac{f_{n 1} L_{n 1} \dot{m}_{n}^{2}}{2 \rho_{o} D_{n 1} A_{n 1}} \\
L_{n 1} \frac{d \dot{m}_{n}}{d t}=F_{B}+F_{f}+P_{1} A_{n 1}-P_{2} A_{n 2}
\end{gathered}
$$




$$
\sum_{i} L_{n i} \frac{d \dot{m}_{n}}{d t}=\sum_{i}\left(F_{B n i}+F_{f n i}\right)+P_{i n} A_{n 1}-P_{o u t} A_{n s}
$$

where

$$
\begin{array}{ll}
\text { F } & \text { - force } \\
\rho & \text { - fluid density } \\
\text { f } & \text { - Darcy friction factor } \\
\dot{m} & \text { - mass flowrate } \\
\beta & \text { - coefficient of thermal expansion } \\
\text { P } & \text { - pressure } \\
\text { A } & \text { - flow area } \\
\text { T } & \text { - temperature } \\
\text { L } & \text { - cell length } \\
\text { g } & \text { - gravitational constant } \\
\text { D } & \text { - hydraulic diameter } \\
\Delta z & \text { - elevation difference }
\end{array}
$$

Figure A-3 shows a schematic of the network leg that contains the heat exchanger. This leg is divided into three sections. The overall momentum equation for the mass flowrate in this leg is derived in the same manner as the equations for the module legs.

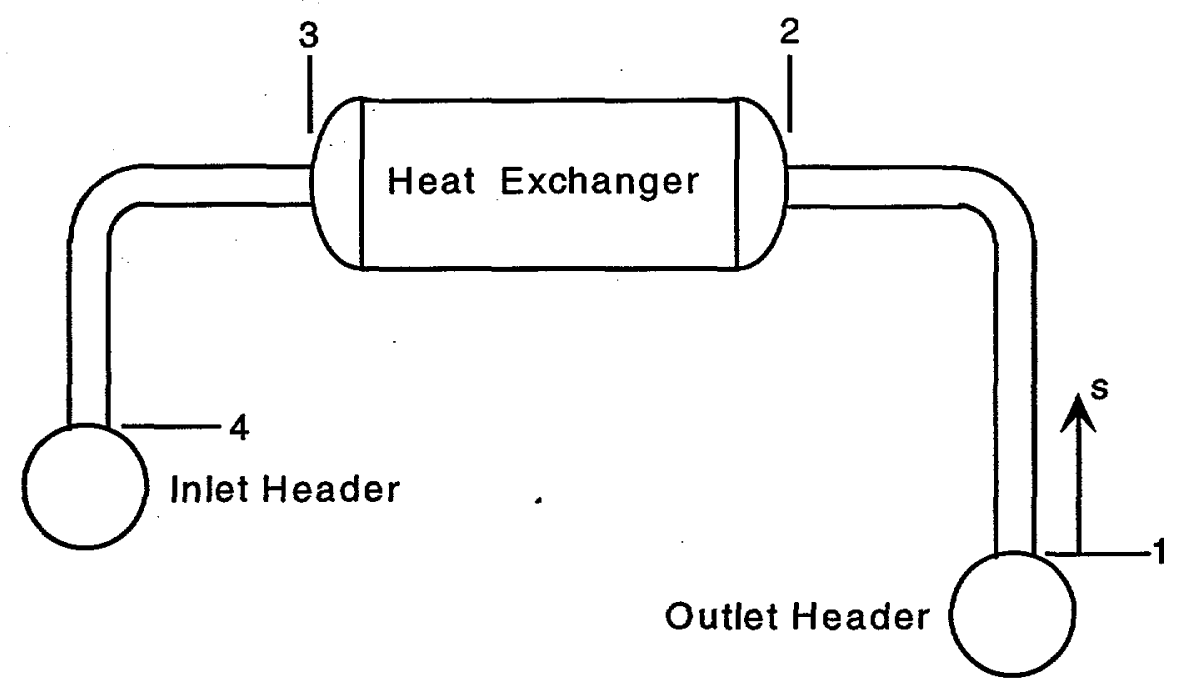

Figure A-3 Schematic of the heat exchanger leg of the natural convection network.

Figure A-4 is a schematic of the outlet header that shows the mass flowrates entering and exiting the header. Positive flowrates are shown. The continuity equation is applied to the control volume to yield Eq. a6. This equation and the four network leg momentum equations are solved simultaneously each time step for the leg mass flowrates and the outlet header pressure. The inlet header pressure is a boundary condition.

A mixed implicitexplicit scheme is used to derive the thermal energy equations. A separate equation is derived for each cell of the network legs and for each header. There is also an energy equation for the secondary side of the heat exchanger. Equation a7 is the thermal energy equation for the second cell of the module leg shown 
in Fig. A-2. This cell is the downflow section of the heated module. Upwind differencing is used, and Eq. a7 applies to the case with positive flow. With negative flow the convective terms would be appropriately modified. The value of the coefficient " $\alpha$ " determines the degree of implicitness of the equation. The equation is fully implicit with " $\alpha$ " set equal to one and fully explicit with " $\alpha$ " set equal to zero. A value of one-half results in the Crank-Nicholson scheme. The superscript " $n$ " denotes the new time level. Equation a8 is the expression for the updated nodal temperature. Note that only upstream temperatures at the new time level appear on the right-hand-side of the equation. Therefore, the temperatures in a specified leg of the network can be updated in a marching scheme starting at its upstream header.

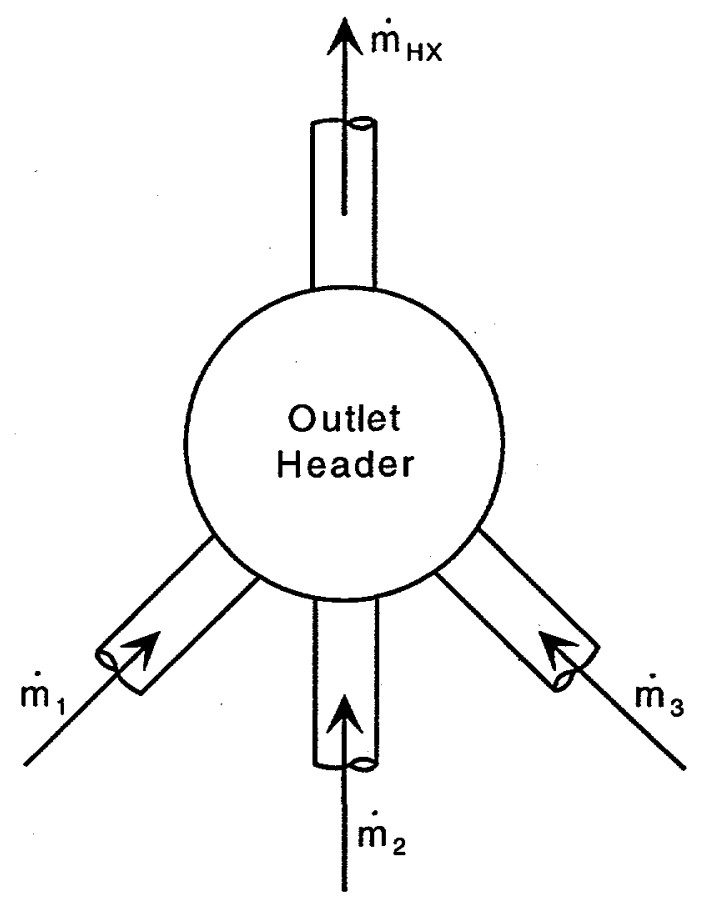

Figure A-4 Schematic of the outlet header showing the mass flowrates.

$$
\begin{gathered}
\dot{\mathrm{m}}_{1}+\dot{\mathrm{m}}_{2}+\dot{\mathrm{m}}_{3}-\dot{\mathrm{m}}_{\mathrm{Hx}}=0 \\
\left(\mathrm{~m}_{\mathrm{s}}+\mathrm{m}\right) \overline{\mathrm{C}}_{\mathrm{p}} \frac{\mathrm{T}_{\mathrm{n} 2}^{\mathrm{n}}-\mathrm{T}_{\mathrm{n} 2}}{\Delta \mathrm{t}}=\dot{\mathrm{m}}_{\mathrm{n}} \mathrm{C}_{\mathrm{p}}\left[\alpha \mathrm{T}_{\mathrm{n} 1}^{\mathrm{n}}+(1-\alpha) \mathrm{T}_{\mathrm{n} 1}\right]-\dot{\mathrm{m}}_{\mathrm{n}} \mathrm{C}_{\mathrm{p}}\left[\alpha \mathrm{T}_{\mathrm{n} 2}^{\mathrm{n}}+(1-\alpha) \mathrm{T}_{\mathrm{n} 2}\right]+\dot{\mathrm{Q}}_{\mathrm{n} 2}(\mathrm{t}) \\
\mathrm{T}_{\mathrm{n} 2}^{\mathrm{n}}=\frac{\frac{\left(\mathrm{m}_{\mathrm{s}}+\mathrm{m}\right) \overline{\mathrm{C}}_{\mathrm{p}}}{\Delta t} \mathrm{~T}_{\mathrm{n} 2}+\dot{\mathrm{m}}_{\mathrm{n}} \mathrm{C}_{\mathrm{p}}\left[\alpha \mathrm{T}_{\mathrm{n} 1}^{\mathrm{n}}+(1-\alpha) \mathrm{T}_{\mathrm{n} 1}\right]-\dot{\mathrm{m}}_{\mathrm{n}} \mathrm{C}_{\mathrm{p}}(1-\alpha) \mathrm{T}_{\mathrm{n} 2}+\dot{\mathrm{Q}}_{\mathrm{n} 2}(\mathrm{t})}{\frac{\left(\mathrm{m}_{\mathrm{s}}+\mathrm{m}\right) \overline{\mathrm{C}}_{\mathrm{p}}}{\Delta \mathrm{t}}+\alpha \dot{\mathrm{m}}_{\mathrm{n}} \mathrm{C}_{\mathrm{p}}}
\end{gathered}
$$

where

$$
\begin{array}{ll}
\mathrm{m} & \text { - fluid mass } \\
\mathrm{m}_{\mathrm{s}} & \text { - solid (metal) mass } \\
\mathrm{C}_{\mathrm{p}} & \text { - fluid specific heat }
\end{array}
$$


$\overline{\mathrm{C}}_{\mathrm{p}} \quad$ - mass weighted liquid/solid composite specific heat

$\dot{\mathrm{Q}}_{\mathrm{n} 2}(\mathrm{t})$ - deposited decay power for cell $\mathrm{n} 2$

$\alpha \quad$ - implicitness parameter

$\Delta \mathrm{t} \quad$ - time step size

Similar equations can be derived for the remaining cells of the module leg shown in Fig. A-2. The storage terms for the two heated cells represent both the masses of the lead/aluminum metal and the fluid in the channels. Their specific heats are composite values. There is also a time dependent internal heat generation source term in each of the two equations representing heated sections.

There are also thermal energy equations for the two headers and the secondary side of the heat exchanger. Equation a9 is the energy equation for the outlet header. The flows are assumed to be positive, as shown in Fig. A-4. If any of the leg flows are negative, the equation would have to be appropriately modified to use the upstream value of temperature. Equation a10 is the expression for the updated outlet header temperature. The inlet header thermal energy equation is derived in a similar fashion.

$$
\begin{gathered}
\mathrm{mC}_{\mathrm{p}} \frac{\mathrm{T}_{\text {out }}^{\mathrm{n}}-\mathrm{T}_{\text {out }}}{\Delta \mathrm{t}}=\sum_{\mathrm{i}=1,3} \dot{\mathrm{m}}_{\mathrm{i}} \mathrm{C}_{\mathrm{p}}\left[\alpha \mathrm{T}_{\mathrm{i}, 5}^{\mathrm{n}}+(1-\alpha) \mathrm{T}_{\mathrm{i}, 5}\right]-\dot{\mathrm{m}}_{\mathrm{Hx}} \mathrm{C}_{\mathrm{p}}\left[\alpha \mathrm{T}_{\text {out }}^{\mathrm{n}}+(1-\alpha) \mathrm{T}_{\text {out }}\right] \\
\mathrm{T}_{\text {out }}^{\mathrm{n}}=\frac{\left[\frac{\mathrm{m \textrm {p } _ { \mathrm { p } }}}{\Delta \mathrm{t}}-\dot{\mathrm{m}}_{\mathrm{Hx}} \mathrm{C}_{\mathrm{p}}(1-\alpha)\right] \mathrm{T}_{\text {out }}+\sum_{\mathrm{i}=1,3} \dot{\mathrm{m}}_{\mathrm{i}} \mathrm{C}_{\mathrm{p}}\left[\alpha \mathrm{T}_{\mathrm{i}, 5}^{\mathrm{n}}+(1-\alpha) \mathrm{T}_{\mathrm{i}, 5}\right]}{\frac{\mathrm{mc}_{\mathrm{p}}}{\Delta t}+\dot{\mathrm{m}}_{\mathrm{Hx}} \mathrm{C}_{\mathrm{p}} \alpha}
\end{gathered}
$$

Figure A-5 is a schematic of the heat transfer between the primary and secondary sides of the heat exchanger. Equation a11 is the thermal energy equation for the tube side of the heat exchanger, and Eq. a12 is the energy equation for the shell side. The shell side of the heat exchanger is assumed to exchange energy only with the tube side. The outer surface of the shell is assumed to be an adiabatic boundary. Equation a13 is the expression for the heat transfer rate between the two sides of the heat exchanger. The heat transfer coefficient accounts for single-phase convective heat transfer on both sides of the heat exchanger and conduction through the tube walls. The mass and specific heat for the secondary side of the heat exchanger are composites of both the metal and the liquid.

$$
\begin{gathered}
\mathrm{mC}_{\mathrm{p}} \frac{\mathrm{T}_{\mathrm{Hx}, 2}^{\mathrm{n}}-\mathrm{T}_{\mathrm{Hx}, 2}}{\Delta \mathrm{t}}=\dot{\mathrm{m}}_{\mathrm{Hx}} \mathrm{C}_{\mathrm{p}}\left[\alpha\left(\mathrm{T}_{\mathrm{Hx}, 1}^{\mathrm{n}}-\mathrm{T}_{\mathrm{Hx}, 2}^{\mathrm{n}}\right)+(1-\alpha)\left(\mathrm{T}_{\mathrm{Hx}, 1}-\mathrm{T}_{\mathrm{Hx}, 2}\right)\right]-\dot{\mathrm{Q}}_{\mathrm{conv}} \\
\left(\mathrm{mC}_{\mathrm{p}}\right)_{\mathrm{sh}} \frac{\mathrm{T}_{\mathrm{sh}}^{\mathrm{n}}-\mathrm{T}_{\mathrm{sh}}}{\Delta \mathrm{t}}=\dot{\mathrm{Q}}_{\mathrm{conv}} \\
\dot{\mathrm{Q}}_{\mathrm{conv}}=\mathrm{h}_{\mathrm{cony}} \mathrm{A}_{\mathrm{Hx}}\left[\alpha \mathrm{T}_{\mathrm{Hx}, 2}^{\mathrm{n}}+(1-\alpha) \mathrm{T}_{\mathrm{Hx}, 2}-\alpha \mathrm{T}_{\mathrm{sh}}^{\mathrm{n}}-(1-\alpha) \mathrm{T}_{\mathrm{sh}}\right]
\end{gathered}
$$


Heat Exchanger Shell Side

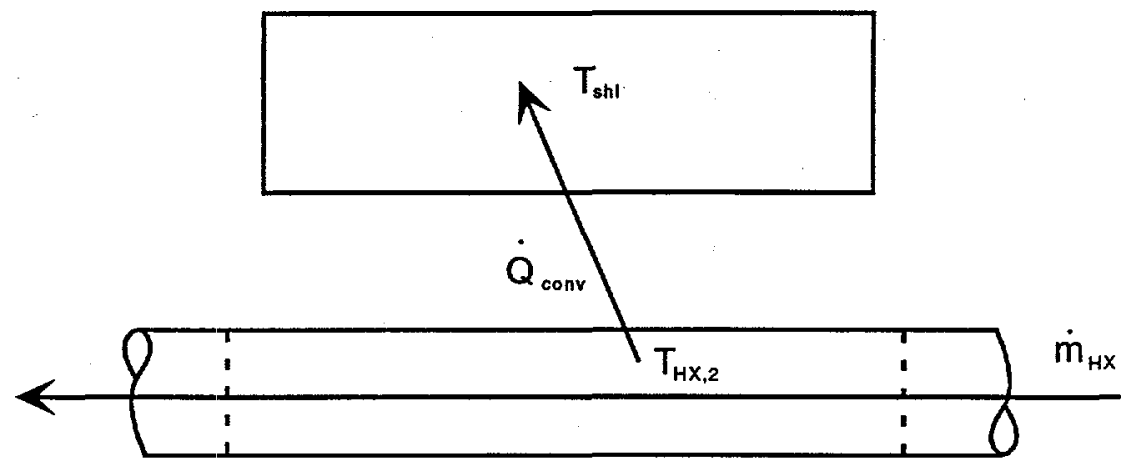

Heat Exchanger Tube Side

Figure A-5 Schematic of the heat exchanger showing the heat transfer to the secondary side. 


\section{Appendix B: Buoyancy-Assisted and Buoyancy- Opposed Friction Factor Multipliers}

To account for the influence of wall heating on the friction factors for flow through the vertical modules, results of an analytical study of fully developed laminar flow between vertical parallel plates were used (see Ref. [3]). A plot of the product of the friction factor and the Reynolds number versus the one-fourth power of a modified Rayleigh number was used to develop functional relations for mixed convection multipliers to friction factors. The modified Rayleigh number used is defined as

$$
\mathrm{Ra}=\frac{g \beta\left(\frac{d T_{w}}{d x}\right) D_{H}^{4} \rho^{2} P r}{\mu^{2}}
$$

For fully developed flow with a constant wall heat flux, the wall and fluid axial temperature gradients are equal. The wall axial temperature gradient can, therefore, be expressed as a function of the wall power and the fluid mass flowrate (Eq. b2).

$$
\frac{\Delta \mathrm{T}}{\mathrm{L}}=\frac{\dot{\mathrm{Q}}_{\mathrm{w}}}{\mathrm{L}_{\mathrm{m} \mathrm{C}_{\mathrm{p}}}}
$$

Substituting Eq. b2 and the definition of the Prandtl number into the expression for the modified Rayleigh number results in Eq. b3, the form of the modified Rayleigh number that is used in the NC model of the primary HR system. The Rayleigh number is directly proportional to the deposited power in the fluid and inversely proportional to the mass flowrate. It expresses the relative importance of buoyancy in vertical mixed convection.

$$
\mathrm{Ra}=\frac{\mathrm{g} \beta \dot{\mathrm{Q}}_{\mathrm{w}} \mathrm{D}_{\mathrm{H}}^{4} \rho^{2}}{\dot{\mathrm{m}} \mu \mathrm{Lk}}
$$

Reference 3 presents results for the range of Rayleigh numbers to the one-fourth power from zero to twelve. Results are presented for both buoyancy-assisted and buoyancyopposed flows. For buoyancy-opposed flow, results are presented for the Rayleigh number to the one-fourth-power range up to four. Beyond this point the buoyancyopposed mixed convection friction behavior is not defined. From the results in Ref. [3], Darcy friction factor multiplier relations were developed. These relations are Eqs. b-4 through b-8, and they are shown graphically by the solid lines in Fig. B-1. The curves are first-order continuous over the entire Rayleigh number to the one-fourth-power range shown. The curve for buoyancy-opposed flow at Rayleigh numbers to the onefourth power greater than four is simply conjecture, and it is included in the model to insure that a reasonable value of the friction factor multiplier is returned in all cases. Having first-order continuous constitutive relations in the model is desirable from a numerical perspective.

$$
\phi \equiv \frac{f_{\text {Mixed }}}{f_{\text {La min ar }}}=1.0 \text { for } \quad \mathrm{Ra}^{1 / 4} \leq 1.5
$$

Buoyancy-Assisted Flow: 


$$
\phi=\left\{\begin{array}{cc}
\mathrm{e}^{\left[\mathrm{C}_{1}\left(\mathrm{Ra}^{1 / 4}-1.5\right)^{2}+\mathrm{C}_{2}\left(\mathrm{Ra}^{1 / 4}-1.5\right)^{3}\right]}, & \text { for } 1.5<\mathrm{Ra}^{1 / 4} \leq 8.0 \\
\mathrm{e}^{\left[\mathrm{C}_{3}+\mathrm{C}_{4}\left(\mathrm{Ra}^{1 / 4}-1.5\right)\right]} & \text { for } \mathrm{Ra}^{1 / 4}>8.0
\end{array}\right\}
$$

(b5 \& b6)

Buoyancy-Opposed Flow:

$$
\phi=\left\{\begin{array}{cc}
\mathrm{e}^{\left[\mathrm{C}_{5}\left(\mathrm{Ra}^{1 / 4}-1.5\right)^{2}+\mathrm{C}_{6}\left(\mathrm{Ra}^{1 / 4}-1.5\right)^{3}+\mathrm{C}_{7}\left(\mathrm{Ra}^{1 / 4}-1.5\right)^{4}\right]} & \text { for } 1.5<\mathrm{Ra}^{1 / 4} \leq 8.0 \\
0.041 \overline{6} & \text { for } \mathrm{Ra}^{1 / 4} \leq 8.0
\end{array}\right\}
$$

where:

$$
\begin{aligned}
& C_{1}=0.11815501 \\
& C_{2}=-.29378955 \times 10^{-2} \\
& C_{3}=-.33784101 \times 10^{1} \\
& C_{4}=0.11636369 \times 10^{1} \\
& C_{5}=-.38259936 \\
& C_{6}=0.71433520 \times 10^{-1} \\
& C_{7}=-.37145261 \times 10^{-2}
\end{aligned}
$$

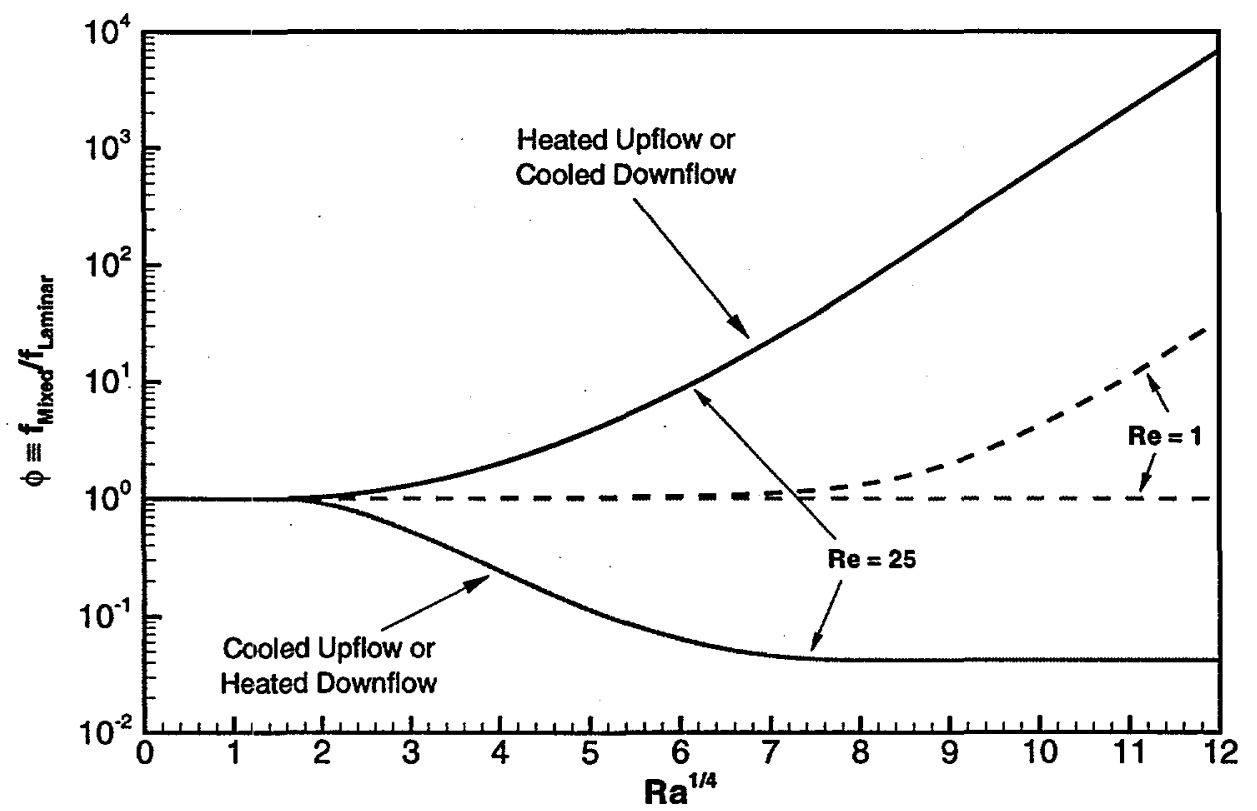

Figure B-1 Friction factor multipliers for buoyancy-assisted and buoyancy-opposed mixed convection in vertical channels. 
WESTINGHOUSE SAVANNAH RIVER COMPANY

BLANKET SAFETY ANALYSIS FOR LOFA (NATURAL CIRCULATION)
Report:

Section:

Date:

Page:
WSRC-FR-98-00207

Appendix B

08/06/98

3 of 4

The Rayleigh number is inversely proportional to the mass flowrate. If the Rayleigh number to the one-fourth power were not limited to a maximum value of twelve in the NC model, it could grow without bound during flow reversals. Even with this restriction on the value of the parameter, there will be a large discontinuity in the values of the friction factor multipliers as the flow direction reverses in a heated vertical passage. To prevent this discontinuity, Eq. b-9 modifies the friction factor multiplier when the Reynolds number is less than twenty-five. This equation interpolates non-linearly between the buoyancy-assisted and buoyancy-opposed values of the friction factor multiplier at a Reynolds number of twenty-five and a value of unity when the Reynolds number is zero. It can easily be seen that, with Eq. by, at a Reynolds number of twentyfive the friction factor multiplier is unaltered, and at zero the friction factor multiplier is unity. This equation insures that the friction factor and its first derivative are continuous as the flow reverses. The dotted lines in Fig. B-1 show the values of the friction factor multiplier at a Reynolds number of one.

$$
\phi_{(\operatorname{Re} 25)}=1-\left[3-2\left(\frac{\operatorname{Re}}{25}\right)\right]\left(\frac{\operatorname{Re}}{25}\right)^{2}+\left[3-2\left(\frac{\operatorname{Re}}{25}\right)\right]\left(\frac{\operatorname{Re}}{25}\right)^{2} \phi .
$$


Date: 08/06/98

Page: 4 of 4 


\section{Appendix C: Sample Input Deck}

A sample-input file for the NCLOFA code (see Appendix D) is provided below. The input file applies to the LOFA in which both the target and blanket HR system pumps are lost and the target power is deposited into the Module 1 Decoupler 24 hours after beam shutdown. The input is structured such that data unique to a specific leg is grouped together and comment lines are provided describing the input variables.

\section{Input file data.in}

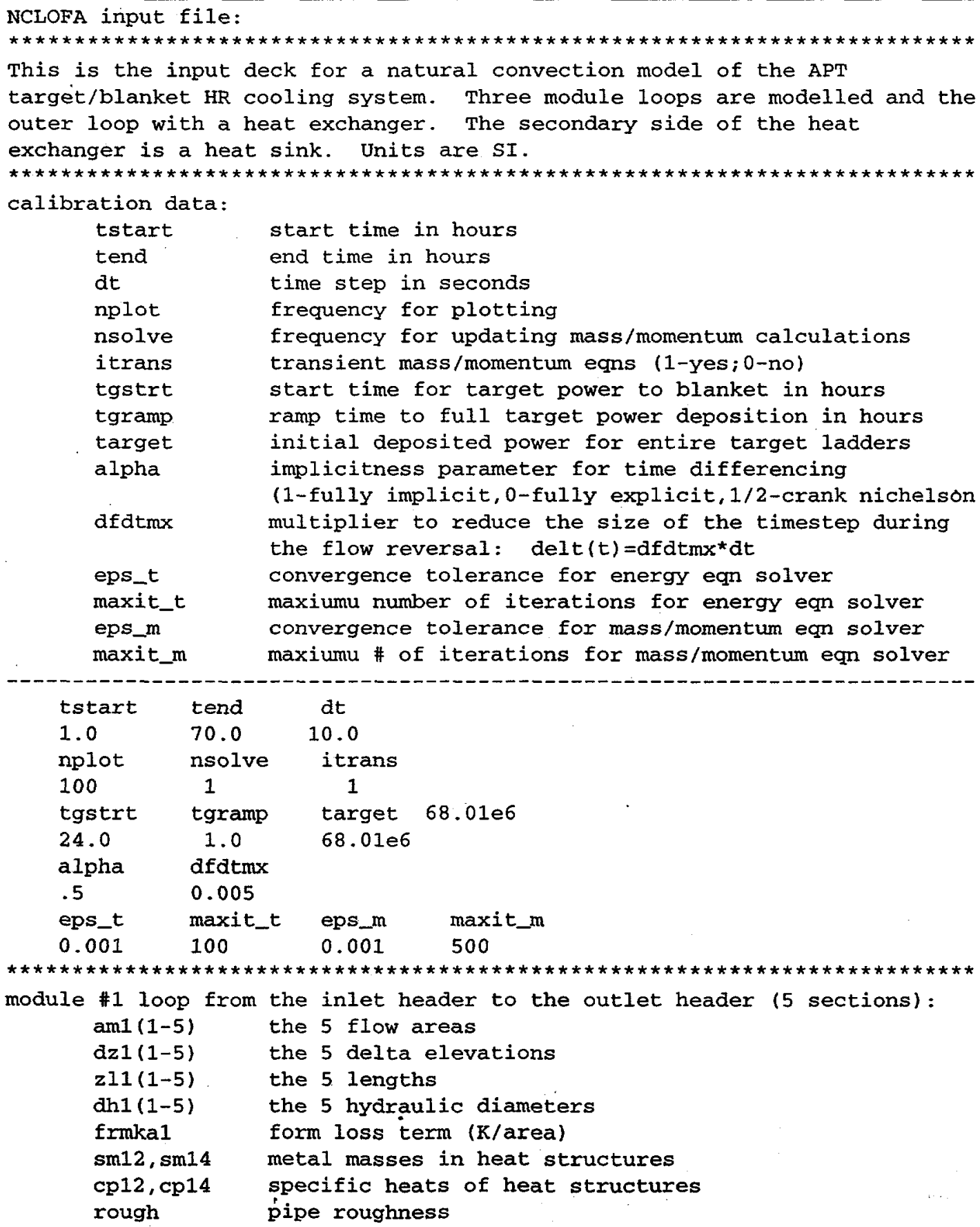




$\begin{array}{llllll}\text { am11 } & \text { am12 } & \text { am13 } & \text { am14 } & \text { am15 } & \\ 0.0609 & 0.199 & 1.64 & 0.199 & 0.0609 & \\ \text { dz11 } & \text { dz12 } & \text { dz13 } & \text { dz14 } & \text { dz15 } & \\ 6.1506 & 2.7582 & 0.0 & -2.7582 & -5.3886 & \\ \text { z111 } & \text { z112 } & \text { zl13 } & \text { zl14 } & \text { zl15 } & \\ 10.77 & 2.7582 & 0.3048 & 2.7582 & 10.77 & \\ \text { dh11 } & \text { dh12 } & \text { dh13 } & \text { dh14 } & \text { dh15 } & \text { frmka1 } \\ 0.1905 & 0.00861 & 0.289 & 0.005063 & 0.1905 & 0.0 \\ \text { sm12 } & \text { cp12 } & \text { sm14 } & \text { cp14 } & \text { rough } & \\ 177.01 & 925.0 & 2748.48 & 188.02 & 1.0 \text { e-5 } & \\ \end{array}$

module \#2 loop from the inlet header to the outlet header ( 5 sections):

am2 (1-5) the 5 flow areas

dz2 (1-5) the 5 delta elevations

$z 12(1-5)$ the 5 lengths

dh2 (1-5) the 5 hydraulic diameters

frmka2 form loss term ( $\mathrm{K} /$ area)

$\operatorname{sm} 22-\sin 24$ metal masses in heat structures

$\operatorname{cp} 22-\operatorname{cp} 24 \quad$ specific heats of heat structures

\begin{tabular}{|c|c|c|c|c|c|}
\hline $\operatorname{arn} 21$ & $\operatorname{am} 22$ & $\operatorname{am} 23$ & $\operatorname{am} 24$ & $\operatorname{am} 25$ & \\
\hline 0.08574 & 0.34647 & 6.5617 & 0.34647 & 0.08574 & \\
\hline$d z 21$ & $\mathrm{dz22}$ & $\mathrm{dz} 23$ & $\mathrm{dz} 24$ & $\mathrm{dz25}$ & \\
\hline 6.1506 & 3.5 & 0.0 & -3.5 & -5.3886 & \\
\hline z121 & $\mathrm{z} 122$ & $z 123$ & $z 124$ & $z 125$ & \\
\hline 10.777 & 3.5 & 0.3048 & 3.5 & 10.0152 & \\
\hline dh21 & dh22 & dh23 & dh24 & dh25 & frmka2 \\
\hline 0.1524 & 0.00311 & 0.289 & 0.00311 & 0.1524 & 0.0 \\
\hline $\sin 22$ & $\mathrm{cp} 22$ & $\sin 24$ & $\operatorname{cp} 24$ & & \\
\hline 34007.86 & 171.23 & 28539.52 & 173.29 & & \\
\hline
\end{tabular}

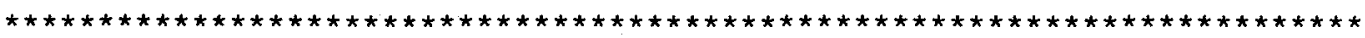

module \#3 loop from the inlet header to the outlet header (5 sections):

am $3(1-5)$ the 5 flow areas

$\mathrm{dz} 3(1-5) \quad$ the 5 delta elevations

$z 13(1-5)$ the 5 lengths

dh3 (1-5) the 5 hydraulic diameters

frmka3 form loss term (K/area)

$\operatorname{sm} 32-\operatorname{sm} 34$ metal masses in heat structures

cp32-cp34 specific heats of heat structures

\begin{tabular}{|c|c|c|c|c|c|}
\hline $\operatorname{am} 31$ & $\operatorname{am} 32$ & $\operatorname{am} 33$ & $\operatorname{am} 34$ & $\operatorname{am} 35$ & \\
\hline 0.06236 & 0.16017 & 1.64 & 0.16017 & 0.06236 & \\
\hline$d z 31$ & $d z 32$ & dz33 & $d z 34$ & dz35 & \\
\hline 9.07 & 0.0 & 0.0 & 0.0 & -8.308 & \\
\hline$z 131$ & $\mathrm{z} 132$ & $z 133$ & $z 134$ & z135 & \\
\hline 13.73 & 2.479 & 0.3048 & 2.479 & 13.05 & \\
\hline dh31 & dh32 & dh33 & dh34 & dh35 & frmka3 \\
\hline 0.09843 & 0.09526 & 0.289 & 0.09526 & 0.09843 & 143.4 \\
\hline $\operatorname{sm} 32$ & $\operatorname{cp} 32$ & $\operatorname{sm} 34$ & $\operatorname{cp} 34$ & & \\
\hline 0.0 & 925.0 & 2751.65 & 167.58 & & \\
\hline
\end{tabular}

heat exchanger loop (inlet to outlet headers 3 sections):

ahx $(1-5)$ the 3 flow areas

dzhx(1-5) the 3 delta elevations

$\operatorname{zlhx}(1-5) \quad$ the 3 lengths

dhhx(1-5) the 3 hydraulic diameters 
frmkax form loss term ( $\mathrm{K} /$ area)

wmssh1 mass of HX secondary shell side

arshl heat transfer area of $\mathrm{HX}$ secondary shell side

convh convection hT coef. of HX secondary shell side

cpshl specific heat of $\mathrm{HX}$ secondary shell side

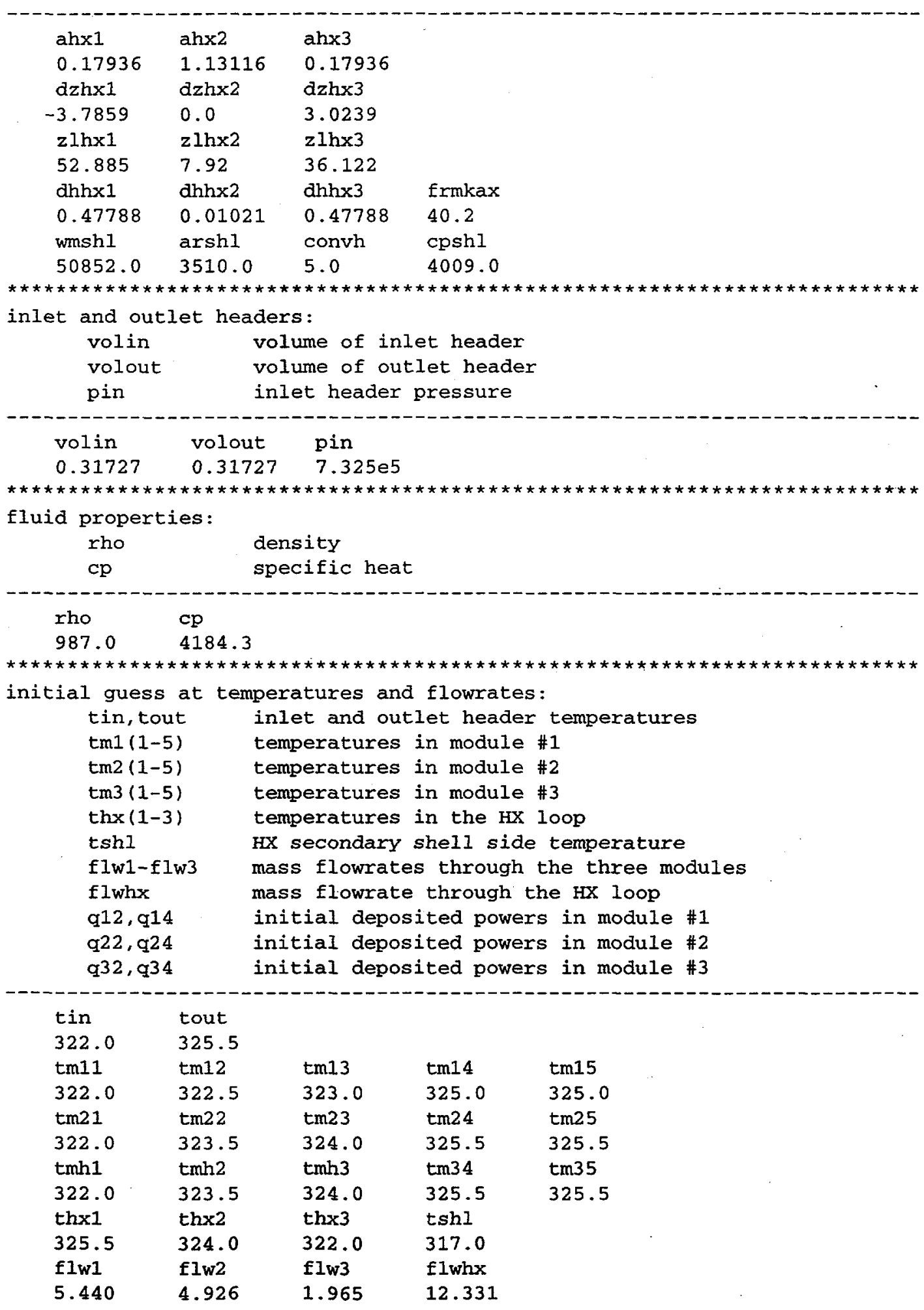


WESTINGHOUSE SAVANNAH RIVER COMPANY

BLANKET SAFETY ANALYSIS FOR LOFA (NATURAL CIRCULATION)
Report: WSRC-TR-98-00207

Section:

Date:

Page:

Appendix C

08/06/98

4 of 4

q12

q14

q22

q24

q34

$8.222 \mathrm{e} 6 \quad 15.768 \mathrm{eb} \quad 9.083 \mathrm{e} 6 \quad 17.695 \mathrm{e} 6 \quad 0.0 \mathrm{e} 6$

$5.712 \mathrm{e} 6$

calibration data:

icalib calibration flag (1-yes;0-no)

pincal,poutcal inlet and outlet header calibration pressures ( $\mathrm{Pa}$ )

pmpcal

pump pressure drop ( $\mathrm{Pa}$ )

flwcal $(1-4)$

initial guess $(\mathrm{kg} / \mathrm{s})$

icalib pincal poutcal pmpcal

$0 \quad 7.325 e 5 \quad 4.5671 e 5 \quad 7.6048 \mathrm{e} 5$ (40 and 110 psid pres drop)

flw1 flw2 flw3 flwhx

$544.0 \quad 615.0 \quad 410.0 \quad 1569.0$

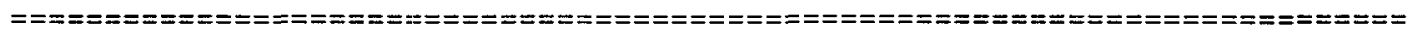

\begin{tabular}{llllll} 
flw1 & flw2 & flw3 & flwhx & & \\
5.440 & 4.926 & 1.965 & 12.331 & & \\
0.0 & 0.0 & 0.0 & 0.0 & & \\
& & & & & \\
q12 & q14 & $q 22$ & $q 24$ & $q 32$ & $q 34$ \\
$8.222 e 6$ & $15.768 e 6$ & $9.083 e 6$ & $17.695 e 6$ & $0.0 e 6$ & $5.712 \mathrm{e} 6$ \\
\hline
\end{tabular}




\section{Appendix D: Code Listing}

A code listing of the fortran program NCLOFA and its associated fortran subroutines is presented below. A algorithm description is provided at the front of each routine. The following is a listing of the routines:

- nclofa.f - main program that reads in the input and writes out the output.

- momtm.f - performs Newton iterations for momentum equations.

- momloop.f - generates each leg's momentum equation and Jacobian.

- rayleigh.f - computes Rayleigh number and heating orientation.

- frict.f - computes multiplier and friction factor.

- outhdr.f - generates header Jacobian terms.

- tmean.f - computes mean fluid temperatures.

- condlq.f - computes fluid thermal conductivity.

- dpower.f - computes deposited decay power levels.

- ludcmp.f - generates LUD decomposition of linearized equation set.

- lubksb.f - performs forward/backward passes of LUD process.

\section{Main program nclofa.f}

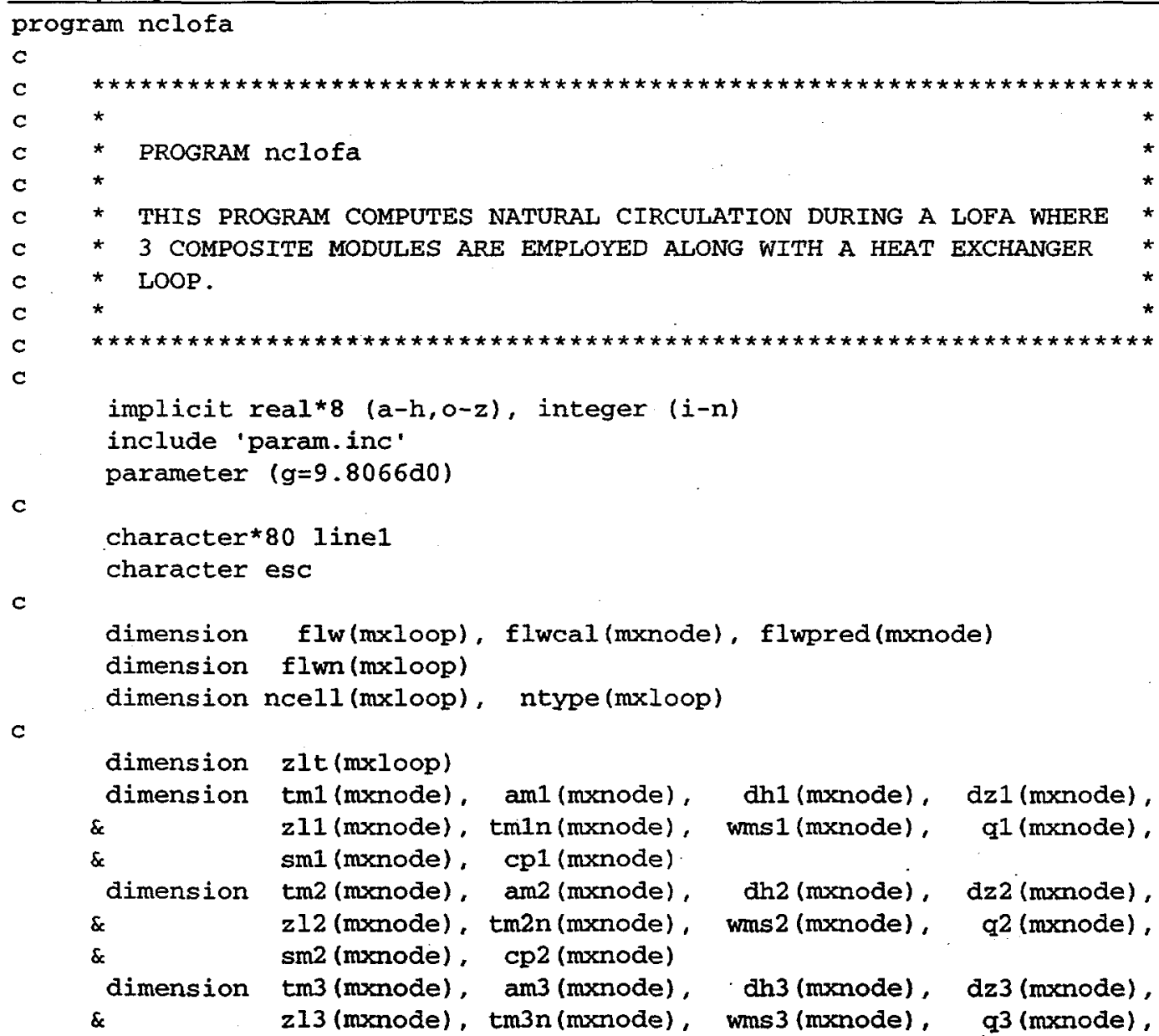


$\&$ $\&$

$\operatorname{sm} 3$ (mxnode), $\operatorname{cp} 3$ (mxnode) dimension thx(mxnode), ahx(mxnode), dhhx (mxnode), dzhx(mxnode), dimension $\&$ $\mathrm{zlhx}$ (mxnode), thxn (mxnode), wmshx (mxnode)

c fold1 (mxnode), fold2 (mxnode), qd3 (mxnode), qdhx (mxnode),

data ncel $1 / 5,5,5,3 /$

$c$

data ntype/1, 1, 1,2/

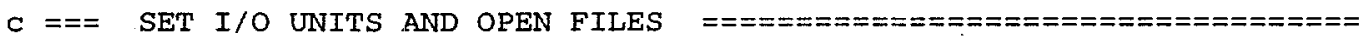

c

iin1 $=5$

iout $1=7$

iout $2=8$

iout3 $=17$

iout $4=19$

iout $5=22$

iout $6=23$

iout7 $=26$

itec $=12$

itecl $=13$

itec2 $=14$

itec $3=15$

itec4 $=16$

convt $=273.15 \mathrm{~d} 0$

convp $=14.696 \mathrm{~d} 0 / 101325.0 \mathrm{do}$

conv_tim $=3600.0 \mathrm{do}$

$\mathrm{C}$

C INITIALIZE TIME COUNTERS

c

esc $=\operatorname{char}(27)$

write $(*, 10)$ esc

c

c open files:

c

open (unit=iin1, file='data.in', status='old')

open (unit=iout1, file='results.out', status='unknown')

open (unit=iout2, file='cal.out', status='unknown')

open (unit=iout3, file='rayl.out', status='unknown')

open (unit=iout4, file='rayfrct.out', status='unknown')

open (unit=iout5, file='jacob.out', status='unknown')

open (unit=iout6, file='convg.out', status='unknown')

open (unit=iout7, file='restrt.out', status='unknown')

open (unit=itec, file='tec.dat', status='unknown')

open (unit=itec1, file='tec1.dat', status='unknown")

open (unit=itec2, file='tec2.dat', status='unknown')

open (unit=itec3, file='tec3.dat', status='unknown')

C

open (unit=itec4, file='tec4.dat',

status = ' unknown')

C

c

Read in the input

C Print input data for 1-D 3-module model.

write (iout 1,1000 )

write (iout 1,901 )

write (iout 1,1000 ) 
c --- CONTROL PARAMETER INPUT:

c

do $i=1,26$

read (iin1,900) linel

write (iout1,900) line1

enddo

C TIME STEP AND RUN TIME:

read $($ in 1,900$)$ linel

write (iout 1,900$)$ linel

read (iin $1, *)$ tstart, tend, at

write (iout $1,{ }^{*}$ ) tstart, tend, dt

C FREQUENCIES FOR PLOTTING AND MASS/MOM SOLVING:

read (iin1,900) line1

write (iout 1,900$)$ line1

read (iin1,*) nplot, nsolve, itrans

write (iout1,*) nplot, nsolve, itrans

C

c TARGET POWER TIMING:

read (iin1,900) line1

write (iout 1,900 ) linel

read (iin1,*) tgstrt, tgramp, target

write (iout $1{ }^{*}$ ) tgstrt, tgramp, target

$\mathrm{C}$

C IMPLICITNESS PARAMETER FOR TIME DIFFERENCING \& FF RATE CHANGE:

read (iin1,900) linel

write (iout 1,900 ) linel

read (iin1,*) alpha, dfdtmx

write (iout $1, *$ ) alpha, dfdtmx

C

C CHECK (AND LIMIT) RANGE OF ALPHA

alpha $=\operatorname{dmax} 1($ alpha, zero)

alpha $=\operatorname{dminl}($ alpha, one)

C ENERGY AND MASS/MOMENTUM SOLVERS CONVERGENCE TOLERANCES AND

C MAXIMUM NUMBER OF ITERATIONS ALLOWED:

read (iin 1,900$)$ linel

write (iout 1,900 ) linel

read $(i$ in1,*) eps_t, maxit_t,eps_m,maxit_m

c

write (iout1,*) eps_t,maxit_t,eps_m,maxit_m

C -- MODULE \#1 INPUT (VERTICAL LATERAL MODULES) :

c

do $i=1,11$

read (iin1,900) linel

write (iout 1,900 ) line1

enddo

c

read $(i$ in 1,900$)$ line 1

write (iout 1,900 ) linel

read (iin1,*) (am1(i), $i=1, \operatorname{ncell}(1)$ )

write (iout1,*) (am1(i), $i=1, \operatorname{ncel} 1(1))$

read (iin1,900) line1

write (iout 1,900$)$ linel

read $(i \operatorname{in1}, *) \quad(\mathrm{dz} 1(i), i=1, \operatorname{ncel} 1(1))$ 
write (iout $1, *)$ (dz1(i), $i=1$, ncell(1))

read (iin1,900) line 1

write (iout 1,900 ) linel

read (iin1,*) (zl1(i), $i=1, \operatorname{ncel1}(1))$

write (iout $1, *)$ (z11(i), $i=1, \operatorname{ncell}(1)$ )

read (iin1,900) line1

write (iout 1,900 ) linel

read (iin1,*) (ah1(i), $i=1$, ncell(1)), frmkal

write (iout $1, *)($ dhl $(i), i=1$, ncell(1)), frmkal

read (iinl,900) linel

write (iout 1,900 ) line1

read (iin1,*) sm12,cp12, sm14, cp14,rough

write (iout1,*) $\mathrm{sm} 12, \mathrm{cp} 12, \operatorname{sm} 14, \mathrm{cp} 14$, rough

C

$\mathrm{C}$

c

C

C

C --- MODULE \#3 INPUT (ALI HORIZONTAL MODULES) :

c

do $i=1,10$

read (iin1,900) linel

write (iout1,900) linel

enddo

c

do $i=1,10$

read (iin1,900) linel

write (iout1,900) line1

enddo

read (iin1,900) Iine1

write (iout 1,900 ) line1

read (iin1,*) (am2(i), $i=1, \operatorname{ricell}(2)$ )

write (iout1,*) (am2(i), $i=1, \operatorname{ncel} 1(2)$ )

read (iin1,900) linel

write (iout 1,900 ) linel

read $\left(i \operatorname{in} 1,{ }^{*}\right)(\mathrm{dz} 2(i), i=1, \operatorname{ncel} 1(2))$

write (iout1,*) (dz2(i), $i=1, \operatorname{ncel} 1(2))$

read $($ iin 1,900$)$ line1

write (iout1,900) line1

read (iin1,*) (z12(i), $i=1, \operatorname{ncel} 1(2))$

write (iout1,*) (zl2(i), $i=1, \operatorname{ncell}(2))$

read $(i$ in 1,900$)$ linel

write (iout 1,900$)$ line1

read (iin1,*) (dh2(i), $i=1, \operatorname{ncel} 1(2))$, frmka2

write (iout1, $\left.{ }^{*}\right)$ (dh2(i), $\left.i=1, \operatorname{ncel1}(2)\right)$, frmka2

read (iin 1,900$)$ line1

write (iout 1,900$)$ linel

read $($ iin $1, *) \quad \operatorname{sm} 22, \operatorname{cp} 22, \operatorname{sm} 24, \mathrm{cp} 24$

write (iout1, *) sm22, cp22, sm24, cp24

read (iin 1,900$)$ line 1

write (iout 1,900$)$ line1

read (iin1,*) (am3(i), $i=1, \operatorname{ncel1}(3))$

write (iout $1, *)$ (am3(i), i=1, ncell(3))

read (iin 1,900$)$ line1

write (iout 1,900$)$ line 1

read $(i \operatorname{in} 1, *) \quad(d z 3(i), i=1, \operatorname{ncell}(3))$

write (iout $1, *)$ (az3(i), $i=1, \operatorname{ncell}(3)$ ) 
read (iinl,900) line1

write (iout 1,900 ) line 1

read (iin1,*) (z13(i), $i=1, \operatorname{ncell}(3))$

write (iout $\left.1,{ }^{*}\right)(z 13(i), i=1$, ncell $(3))$

read (iinl, 900) linel

write (iout 1,900 ) line1

read (iinl,*) (ah3(i), $i=1, n c e 11(3))$, frmka3

write (iout $\left.1,{ }^{*}\right)(\operatorname{dh} 3(i), i=1, \operatorname{ncell}(3))$, frmka3

read (iin 1,900$)$ line1

write (iout 1,900 ) linel

read (iin1, *) $\operatorname{sm} 32, \operatorname{cp} 32, \operatorname{sm} 34, \mathrm{cp} 34$

write (iout1,*) $\operatorname{sm} 32, \mathrm{cp} 32, \operatorname{sm} 34, \mathrm{cp} 34$

$\mathrm{c}$

HEAT EXCHANGER LOOP INPUT \#4:

c

do $i=1,12$

read (iin1,900) line1

write (iout 1,900 ) line1

enddo

c

read (iin1,900) linel

write (iout1,900) linel

read (iinl, $\left.{ }^{*}\right) \quad(\operatorname{ahx}(i), i=1, \operatorname{ncell}(4))$

write (iout $1, *)(\operatorname{ahx}(i), i=1, \operatorname{ncell}(4))$

read $(i$ in 1,900$)$ line 1

write (iout1, 900) linel

read (iin1,*) (dzhx(i), $i=1, \operatorname{ncell}(4))$

write (iout $\left.1,{ }^{*}\right)(\operatorname{dzhx}(i), i=1, \operatorname{ncell}(4))$

read (iin1,900) linel

write (iout1,900) line1

read (iin1,*) (z1hx(i), $i=1, \operatorname{ncell}(4))$

write (iout $\left.1,{ }^{*}\right)(z \operatorname{lhx}(i), i=1, \operatorname{ncell}(4)$ )

read (iin1,900) linel

write (iout 1,900$)$ line1

read $\left(i \operatorname{in} 1,{ }^{*}\right)(\operatorname{dhhx}(i), i=1, \operatorname{ncell}(4))$, frmkax

write (iout $\left.1,{ }^{*}\right)$ (dhhx(i), $i=1$, ncell(4)), frmkax

read (iin1,900) line1

write (iout1,900) line1

read (iin1,*) wmssh1, arsh1, convh, cpsh1

write (iout $1{ }^{\star}$ ) wmssh1, arsh1, convh, $\operatorname{cpsh} 1$

c

c - FIXED HEADER INPUT:

c

do $i=1,6$

read (iin1,900) line1

write (iout1,900) line1

enddo

c

read (iin1,900) line1

write (iout1,900) linel

read (iin1,*) volin, volout, pin

write (iout $1, *$ ) volin, volout, pin

$c$

c --- FLUID PROPERTIES INPUT:

c

do $i=1,5$

read (iin1,900) linel 


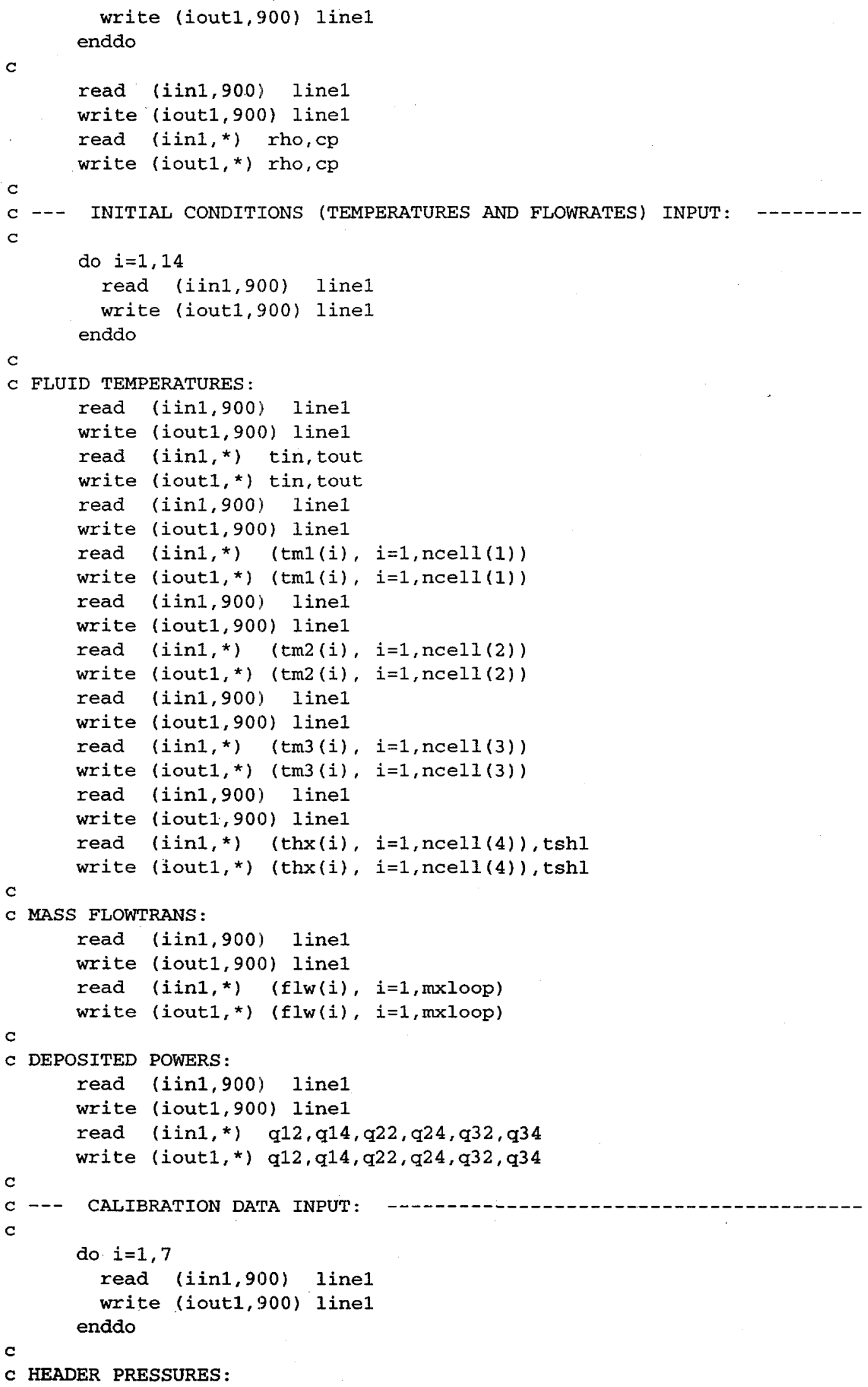


read (iin1,900) linel

write (iout1,900) line1

read (iinl, *) icalib,pincal,poutcal,pmpcal

write (iout $1,{ }^{*}$ ) icalib,pincal, poutcal,pmpcal

$c$

c INITIAL GUESS FOR MASS FLOWRATES:

read (iin1,900) line 1

write (iout1,900) line1

read (iinl,*) (flwcal(i), $i=1$, mxloop)

write (iout $1, *$ ) (flwcal( $i$ ), $i=1$, mxloop)

C

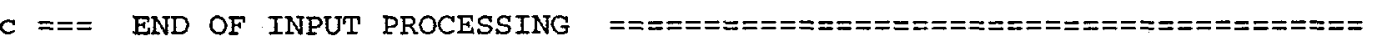

$\mathrm{C}$

$\mathrm{C}$

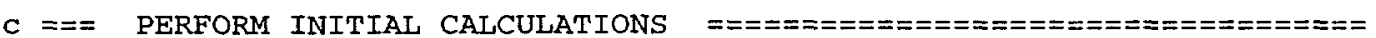

$c$

c print the header for output file.

write (iout 1,1000 )

write (iout 1,902$)$

write (iout 1,1000$)$

$\mathrm{C}$

C COMPUTE FLUID CELL MASSES FOR EACH LOOP, HEADERS, AND SHELL.

c ALSO COMPUTE TOTAL LENGTH OF EACH LOOP.

c

do $j=1$, mxloop

$z l t(j)=$ zero

enddo

c

do $i=1$, ncell (1)

wms $1(i)=\operatorname{rho*} \operatorname{am} 1(i) * z 11(i)$

$\operatorname{zlt}(1)=\operatorname{zlt}(1)+\operatorname{zll}(i)$

enddo

C

do $i=1$, ncel1 (2)

wms $2(i)=\operatorname{rho}$ am $2(i) * z 12(i)$

$z 1 t(2)=z 1 t(2)+z 12(i)$

enddo

c

do $i=1, \operatorname{ncel1}(3)$

wms $3(i)=\operatorname{rho} \operatorname{am}^{2}(i) * z 13(i)$

$z 1 t(3)=z 1 t(3)+z 13(i)$

enddo

c

do $i=1$, ncel1 (4)

wmshx $(i)=\operatorname{rho}{ }^{*} \operatorname{ahx}(i) * z \operatorname{lhx}(i)$

$\operatorname{zIt}(4)=\operatorname{zIt}(4)+\operatorname{zlhx}(i)$

enddo

$\mathrm{c}$

wmsin $=$ rho*volin

wmsout $=$ rho*volout

pout $=$ pin +7360.50

C

C SET SOLID CELL MASSES AND SPECIFIC HEATS FOR EACH MODULE LOOP:

C

do $i=1, \operatorname{ncel} 1(1)$
$\operatorname{sm} 1(i)=$ zero
$\operatorname{cp} 1(i)=$ zero 
enddo

$\operatorname{sm} 1(2)=\operatorname{sm} 12$

$\operatorname{sm} 1(4)=\operatorname{sm} 14$

$\operatorname{cp} 1(2)=\operatorname{cp} 12$

c

$\operatorname{cp} 1(4)=\operatorname{cp} 14$

do $i=1, \operatorname{ncel} 1(2)$
$\operatorname{sm} 2(i)=$ zero
$\operatorname{cp} 2(i)=$ zero

enddo

$\operatorname{sm} 2(2)=\operatorname{sm} 22$

$\sin 2(4)=\operatorname{sm} 24$

$\operatorname{cp} 2(2)=\operatorname{cp} 22$

c

$\mathrm{cp} 2(4)=\mathrm{cp} 24$

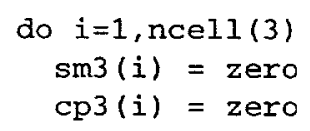

enddo

$\operatorname{sm} 3(2)=\operatorname{sm} 32$

$\operatorname{sm} 3(4)=\operatorname{sm} 34$

$\operatorname{cp} 3(2)=\operatorname{cp} 32$

c

$\operatorname{cp} 3(4)=\operatorname{cp} 34$

C COMPUTE INITIAL AVERAGE FLUID TEMPERATURE, BETA, AND VISCOSITY:

$\mathrm{c}$

iskip $=0$

call tmean (wms in, wmsout, wms 1 , wms 2 , wms 3 , wmshx,

$\&$

tin, tout, tm1, tm2, tm3, thx, tnot, beta, vis,

$\mathscr{\&}$

iskip, ncell)

COMPUTE FLUID THERMAL CONDUCTIVITY:

$\mathrm{c}$

ifld $=1$

call condlq (tnot, ifld, condl, dummy)

C

c INITIAL TARGET POWER PARAMETER SETTINGS AND TIMING POINTS:

$\mathrm{C}$

tstart $=$ conv_tim ${ }^{\star}$ start

tendhr $=$ tend

tend $=$ conv_tim*tend

ccc nstep $=$ int ( (tend-tstart) $/ d t)+1$

tgstrt $=$ conv_tim*tgstrt

tgramp $=$ conv_tim ${ }^{*}$ tgramp

tgdry = tgstrt + tgramp

nstep $=\operatorname{int}((($ tend-tstart $-2.5 *$ tgramp $) / d t)+$

$\&$

$(2.5 *$ tgramp $) /(d f d t m x * d t))+1$

c

eps_p $=1.0 \mathrm{~d}-3$

do $i=1$, ncel1 ( 1 )

$q 1(i)=$ zero

enddo

$\mathrm{q} 1(2)=\mathrm{q} 12$

$q 1(4)=q 14$

c

do $i=1$, ncell (2) 
$c$

$$
\begin{aligned}
& q 2(i)=\text { zero } \\
& \text { enddo } \\
& q 2(2)=q 22 \\
& q 2(4)=q 24 \\
& \text { do } i=1, \operatorname{ncel} 1(3) \\
& q 3(i)=\text { zero } \\
& \text { enddo } \\
& q 3(2)=q 32 \\
& q 3(4)=q 34
\end{aligned}
$$


$c==$ WRITE INITIAL CONDITIONS TO TECPLOT FILES $===================$ 
$$
c
$$$$
\text { c }
$$$$
\text { c }
$$

$$
\begin{aligned}
& \text { c enddo } \\
& \text { c }
\end{aligned}
$$

Page:

$\mathrm{c}$

C COMPUTE BLANKET/TARGET POWER DEPOSITED TO FLUID. CELLS

$\mathrm{C}$

$\mathrm{C}$

c

$\mathrm{c}$

$\&$

$\&$

$\delta$

$\&$

C UPDATE TEMPERATURE ARRAYS:

$\mathrm{C}$

C

c

c

C UPDATE MEAN TEMPERATURE (LOOP AVERAGE) AND BETA:

c $\&$ $\&$ iskip $=1$

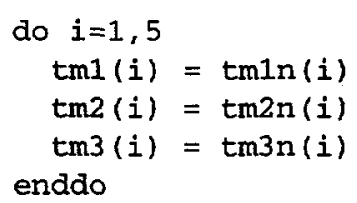
, wi, qd1, qd2, qd3, qdhx, convh, arsh1, $n c e l l, a l$ pha, eps_t,maxit_t) tinn, toutn, tmin, tm2n, tm $3 n, t h \times n, t s h l n$, target, q1, q2, q3, qd1, qd2, qd3, qdhx,

dtshrt $=$ dfdtmx ${ }^{\star} d t$
dtreg $=d t$
tshst $=$ tgstrt $+.75 *$ tgramp

tshstp $=$ tshst $+2.5^{\star}$ tgramp

eltim $=$ tstart

end if

eltim_p $=$ eltim + half $d_{d t}$

call dpower (eltim_p, tgstrt, tgdry, 
c

endif

c

c $===$ WRITE RESULTS OUT TO TECPLOT AND OUTPUT FILES $=================$

$\mathrm{c}$

if $(\bmod (i t, n p l o t) . e q .0)$ then

C

c write results to graphics tecplot file:

$\mathrm{c}$

write(itec, '(17d12.4)') eltim/conv_tim, flw(1), flw(2), flw(3),

$\& \quad$ flw (4), tin-convt, tout-convt, thx (2)-convt,

$\& \quad \operatorname{tsh} 1-\operatorname{convt}, \operatorname{tm} 1(2)-\operatorname{convt}, \operatorname{tm} 1(4)-$ convt, $\operatorname{tm} 2(2)$-convt,

$\& \quad \operatorname{tm} 2(4)$-convt, $\operatorname{tm} 3(2)$-convt, $\operatorname{tm} 3(4)$-convt, tnot-convt,

c

\&. pout * convp

c MODULE \#1 FILE:

write (itec1, '(8d12.4)') eltim/conv_tim,tin-convt,

$\&$

$\operatorname{tm} 1(1)$-convt, $\operatorname{tm} 1(2)$-convt, tm1 (3)-convt,

$\mathrm{c}$

tml (4)-convt, tml (5)-convt, tout-convt

C MODULE \#2 FILE:

write (itec2, '(8d12.4)') eltim/conv_tim,tin-convt,

$\&$

$\varepsilon$

C

C MODULE \#3 FILE:

write (itec3,'(8d12.4)') eltim/conv_tim,tin-convt,

se

$\alpha$

c

write (itec4,' (7d12.4)') eltim/conv_tim, tout-convt,

$\&$

$\&$ $\operatorname{tm} 2(1)$-convt, $\operatorname{tm} 2(2)$-convt, $\operatorname{tm} 2(3)$-convt, tm2 (4)-convt, tm2 (5)-convt, tout-convt

c

c write time results to output file:

$c$

write (iout 1,1000 )

tmhr $=$ eltim/conv_tim

write (iout1, 1015) tmhr

write (iout1,1020) $\operatorname{tm} 1(1), \operatorname{tm} 1(2), \operatorname{tm} 1(3), \operatorname{tm} 1(4), \operatorname{tm} 1(5)$

write (iout 1,1020$) \operatorname{tm} 2(1), \operatorname{tm} 2(2), \operatorname{tm} 2(3), \operatorname{tm} 2(4), \operatorname{tm} 2(5)$

write (iout 1,1020$) \operatorname{tm} 3(1), \operatorname{tm} 3(2), \operatorname{tm} 3(3), \operatorname{tm} 3(4), \operatorname{tm} 3(5)$

write (iout 1,1020$) \operatorname{thx}(1), \operatorname{thx}(2), \operatorname{thx}(3), \operatorname{tsh} 1$

write (iout 1,1030 ) tin, tout, tnot

write (iout 1,1025$) \mathrm{flw}(1), \mathrm{fl}(2), f 1 \mathrm{w}(3), \mathrm{flw}(4)$, pout endif

c

enddo

c

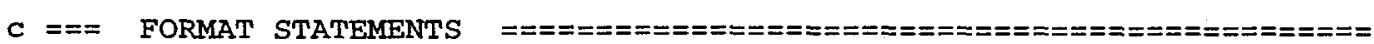

c

10 format $\left(1 \mathrm{x}, \mathrm{a} 1, \cdot\left[2 \mathrm{~J}^{\prime}\right)\right.$

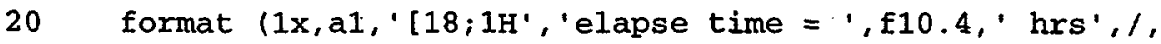

$\&$ ' end time $=1, f 10.4,{ }^{\prime}$ hrs', $/ / 1$

210 format (' VARIABLES $=t$, Mod-1, Mod-2, Mod-3, Hx, tin, tout,,

\& 'thx, tshl, t1dwn, t1up, t2dwn, t2up, t3in, t3out, '.

\& 'tavg, pout') 


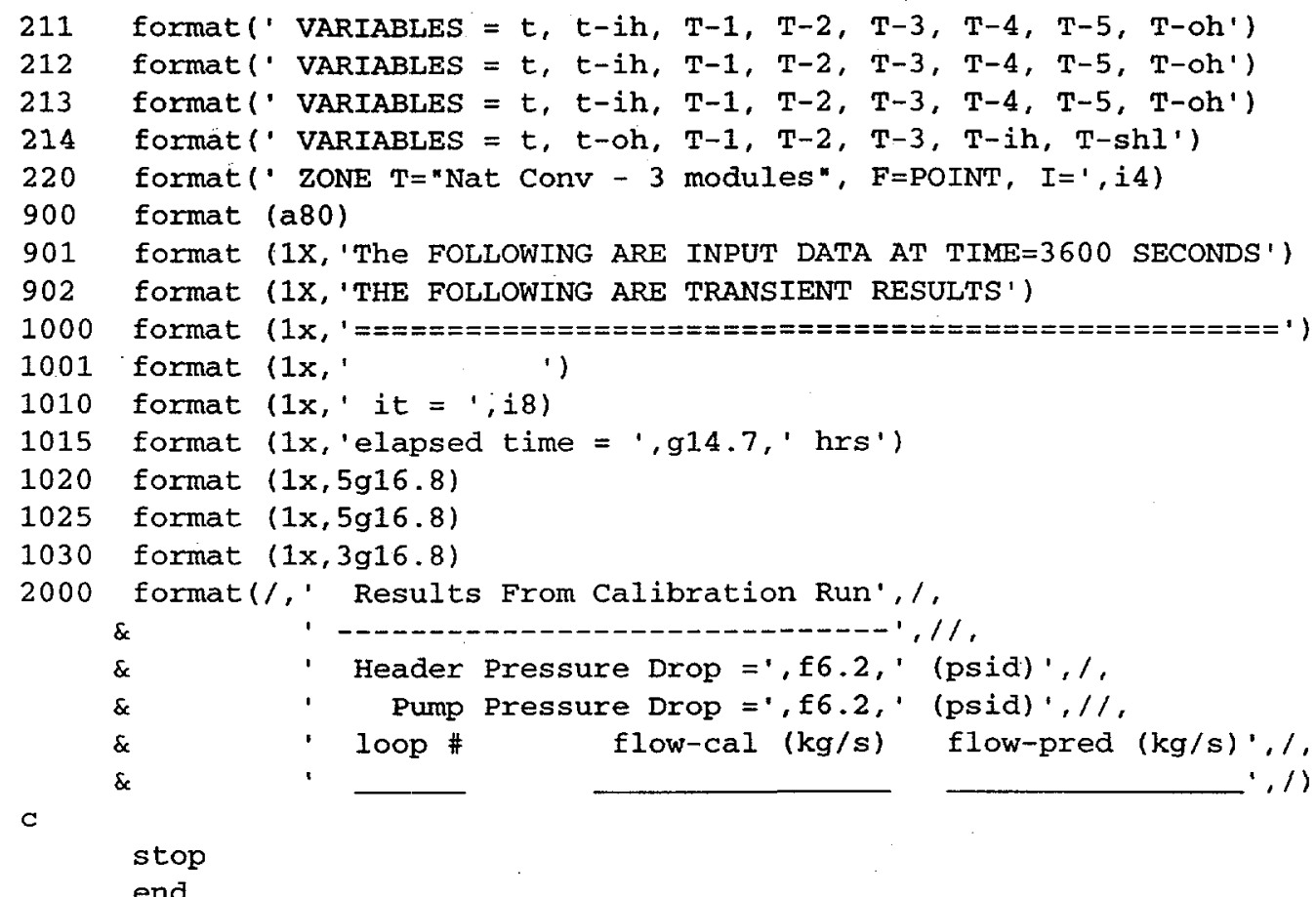

\section{Subroutine energy.f}

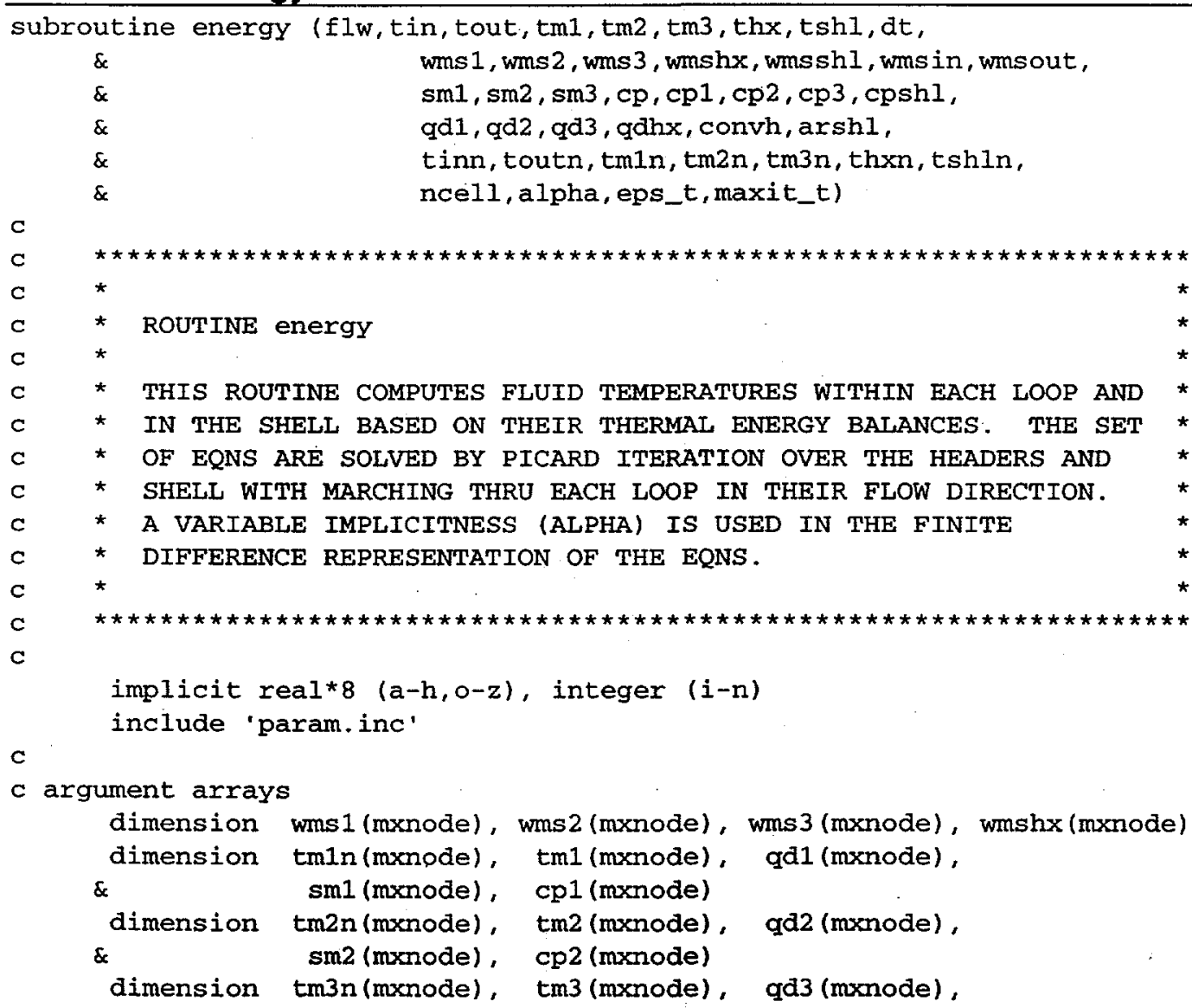


\& $\quad \sin 3$ (mxnode), $\operatorname{cp} 3$ (mxnode)

dimension thxn(mxnode), thx(mxnode), qdhx(mxnode)

dimension $\mathrm{flw}(\mathrm{mxloop})$

dimension ncell ( $m \times 10 o p)$

c

c local arrays

dimension gama (mxnode), gamal (mxnode)

dimension tm1i(mxnode), tm2i (mxnode), tm3i (mxnode), thxi (mxnode)

dimension err (mxloop)

c

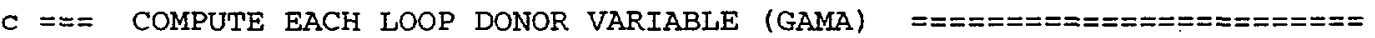

$c$

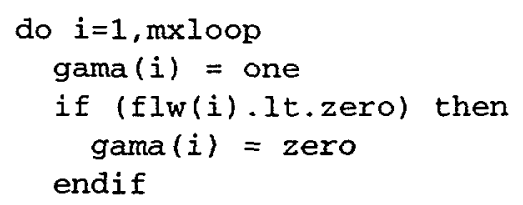




$$
\text { write }\left(23,{ }^{\prime}()^{\prime}\right)
$$

C

c INLET HEADER:

c

$\&$

termo $=\operatorname{gama}(1) * f l w(1)+\operatorname{gama}(2) * f l w(2)+\operatorname{gama}(3) * f l w(3)$ $-\operatorname{gama1}(4) \star f \operatorname{lw}(4)$

term $1=\operatorname{gama} 1(1){ }^{*} \mathrm{cp} * \mathrm{flw}(1) *\left(\operatorname{alpha}{ }^{*} \operatorname{tm} 1 i(1)+\operatorname{alpha} 1 * \operatorname{tm} 1(1)\right)$

term2 $=\operatorname{gama} 1(2) * c p * f 1 w(2) *\left(a \operatorname{lpha} * \operatorname{tm} 2 i(1)+\operatorname{alpha}{ }^{*} \operatorname{tm} 2(1)\right)$

$\operatorname{term} 3=\operatorname{gama1}(3) * \mathrm{cp} * \mathrm{flw}(3) *\left(\operatorname{alpha} * \operatorname{tm} 2 i(1)+\operatorname{alpha}{ }^{*} \operatorname{tm} 3(1)\right)$

term4 $=\operatorname{gama}(4) * c p * f l w(4) *\left(a \operatorname{lpha} * \operatorname{thxi}(\mathrm{m} 4)+\operatorname{alpha}{ }^{*} \operatorname{thx}(\mathrm{m} 4)\right)$

hcap $=\mathrm{cp}^{\star}$ Wmsin $/ \mathrm{dt}$

coef $=$ hcap - alpha $1 * c p *$ termo

coefn $=$ hcap + alpha* $\mathrm{cp}^{\star}$ term0

$\mathrm{C}$

tini $=($ coef*tin $-\operatorname{term} 1-\operatorname{term} 2-\operatorname{term} 3+\operatorname{term} 4) / \operatorname{coefn}$

c

c $\quad$ sum $=f \operatorname{lw}(4)-(f \operatorname{lw}(1)+f \operatorname{lw}(2)+f \operatorname{lw}(3))$

c write $(23,322)$ iter, sum, tm1i(1), tm2 $i(1), \operatorname{tm} 2 i(1), \operatorname{thx} i(m 4)$,

$\mathrm{C}$

$\&$ (gama $(k), k=1,4)$

c 8

format(" iter, sum, tm1i(1), tm2i(1),tm2i(1), thxi (m4), gama.',

C OUTLET HEADER:

c

$\operatorname{term} 0=\operatorname{gama1}(1) * f \operatorname{lw}(1)+\operatorname{gama} 1(2) * f l w(2)+\operatorname{gama} 1(3) * f l w(3)$

$\varepsilon$ $-\operatorname{gama}(4) * f l w(4)$

term1 $=\operatorname{gama}(1) * c p * f l w(1) *(a l p h a * \operatorname{tm} 1 i(m 1)+a l p h a 1 * \operatorname{tm} 1(m 1))$

term2 $=\operatorname{gama}(2) * \mathrm{cp} * \mathrm{f} 1 \mathrm{w}(2) *\left(\operatorname{alpha} * \operatorname{tm} 2 i(\mathrm{~m} 2)+\operatorname{alpha}{ }^{*} \operatorname{tm} 2(\mathrm{~m} 2)\right)$

term3 $=\operatorname{gama}(3) * c p * f l w(3) *(a l p h a * \operatorname{tm} 3 i(m 3)+\operatorname{alpha} * \operatorname{tm} 3(\mathrm{~m} 3))$

term4 $\left.=\operatorname{gama1}(4) * c p * f l w(4) *(a) p h a * \operatorname{thxi}(1)+\operatorname{alphal}{ }^{*} \operatorname{thx}(1)\right)$

hcap $=\mathrm{cp}^{*}$ wmsout $/ \mathrm{dt}$

coef $=$ hcap + alpha $1 * c p *$ term 0

c

coefn $=$ hcap - alpha*cp*term0

touti $=($ coef*tout + term $1+\operatorname{term} 2+\operatorname{term} 3-\operatorname{term} 4) / \operatorname{coefn}$

C

C SHELL OF HEAT EXCHANGER:

C

term4 $=$ htc $(a I p h a * t h x i(2)+\operatorname{alpha1} * \operatorname{thx}(2))$

hcap $=\operatorname{cpshl}{ }^{*}$ wmsshl $/ \mathrm{dt}$

coef $=$ hcap - alphal*htc

coefn $=$ hcap + alpha*htc

c

$\operatorname{tshli}=(\operatorname{coef} * \operatorname{tsh} l+\operatorname{term} 4) / \operatorname{coefn}$

C

c write $(24,422)$ iter, thxi (2), tshl, tshli

c422 format(' iter, thxi(2), tshl,tshli ',i4,3f10.5)

$\mathrm{C}$

C MODULE \#1 (VERTICAL LATERAL MODULES) :

C

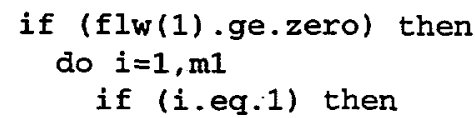


c

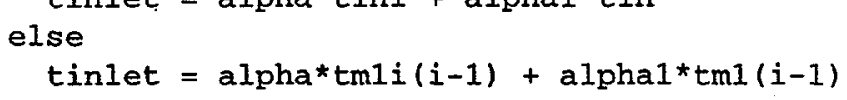

c

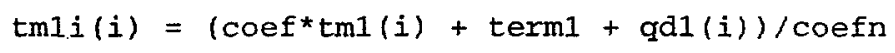

$\operatorname{tmli}(i)=\left(\operatorname{coef}{ }^{*} \operatorname{tm} 1(i)-\operatorname{term} 1+\right.$ qd1(i)) $/$ coefn enddo

endif

C

c MODULE \#2 (ALL REMAINING VERTICAL MODULES):

c

if ( $f l_{w}(2)$.ge.zero) then

do $i=1, \mathrm{~m} 2$

if (i.eq.1) then

tinlet $=$ alpha $*$ tini + alphal $*$ in

else

tinlet $=\operatorname{alpha}{ }^{\star} \operatorname{tm} 2 i(i-1)+\operatorname{alpha}{ }^{*} \operatorname{tm} 2(i-1)$

endif

term $1=\mathrm{cp}^{\star}$ flw $(2) *$ tinlet

hcap $=(\operatorname{sm} 2(i) * c p 2(i)+w m s 2(i) * c p) / d t$

coef $=$ hcap - alpha1* $\mathrm{cp}^{*} \mathrm{flw}(2)$

c

coefn $=$ hcap + alpha ${ }^{*} \mathrm{cp}^{\star} \mathrm{flw}(2)$

$\underset{\text { enddo }}{\operatorname{tm} 2 i(i)=(\operatorname{coef} * \operatorname{tm} 2(i)+\operatorname{term} 1+q d 2(i)) / \operatorname{coefn}}$ else

do $i=1, \mathrm{~m} 2$

if (i.eq.m2) then

tinlet $=$ alpha*touti + alphal ${ }^{*}$ tout

else

tinlet $=\operatorname{alpha}{ }^{*} \operatorname{tm} 2 i(i+1)+\operatorname{alpha} 1 * \operatorname{tm} 2(i+1)$

endif

term $1=\mathrm{cp} * \mathrm{flw}(2) *$ tinlet

hcap $=\left(\mathrm{sm} 2(i){ }^{*} \mathrm{cp} 2(i)+w m s 2(i){ }^{*} \mathrm{cp}\right) / d t$

coef $=$ hcap + alphal* $\mathrm{cp}^{*} \mathrm{fl} w(2)$

coefn $=$ hcap - alpha* $\mathrm{Cp}^{*} \mathrm{flw}(2)$

c

$\operatorname{tm} 2 i(i)=\left(\operatorname{coef}^{\star} \operatorname{tm} 2(i)-\operatorname{term} 1+q d 2(i)\right) / \operatorname{coefn}$ enddo 


\section{endif}

$c$

C MODULE \#3 (ALL HORIZONTAL MODULES):

c

if (flw(3).ge.zero) then

do $i=1, \mathrm{~m} 3$

if (i.eq.1.) then

tinlet $=$ alpha*tini $+\operatorname{alpha} 1 * \operatorname{tin}$

else

tinlet $=$ alpha*tm3i $(i-1)+\operatorname{alpha} 1 * \operatorname{tm} 3(i-1)$

endif

$\operatorname{term} 1=c p * f l w(3) *$ tinlet

hcap $=(\operatorname{sm} 3(i) * \operatorname{cp} 3(i)+w m s 3(i) * c p) / d t$

coef $=$ hcap - alphal*cp*flw (3)

coefn $=$ hcap + alpha* $\mathrm{cp}^{*} \mathrm{flw}(3)$

c

$\operatorname{tm} 3 i(i)=(\operatorname{coef} * \operatorname{tm} 3(i)+\operatorname{term} 1+q d 3(i)) / \operatorname{coefn}$

c write $(23,322)$ iter, $i, t i n i, t i n l e t, \operatorname{tm} 3 i(i), \operatorname{tm} 3(i)$

c322 format('+ iter, $i, t i n i, t i n l e t, \operatorname{tm} 3 i(i), \operatorname{tm} 3(i) \cdot, 2 i 4,4 f 10.5)$ enddo

else

do $i=1, \mathrm{~m} 3$

if (i.eq.m3) then

tinlet $=$ alpha*touti + alphal*tout

else

tinlet $=\operatorname{alpha}{ }^{*} \operatorname{tm} 3 i(i+1)+\operatorname{alpha} 1 * \operatorname{tm} 3(i+1)$

endif

terml $=c p * f l w(3) * t i n l e t$

hcap $=(\operatorname{sm} 3(i) * \operatorname{cp} 3(i)+\operatorname{wms} 3(i) * c p) / d t$

coef $=$ hcap + alpha ${ }^{*} \mathrm{cp}^{*} \mathrm{flw}$ (3)

coefn $=$ hcap - alpha* cp* $f I w(3)$

C

$\operatorname{tm} 3 i(i)=(\operatorname{coef} \operatorname{tm} 3(i)-\operatorname{term} 1+q d 3(i)) / \operatorname{coefn}$

c write $(23,323)$ iter, $i$, tout $i, t i n l e t, t m 3 i(i), t m 3$ (i)

c323 format('- iter, $i$, tout $i, t i n l e t, t m 3 i(i), t m 3(i),, 2 i 4,4 f 10.5)$ enddo endif

$c$

c HEAT EXCHANGER LOOP \#4:

c

if (flw(4).ge.zero) then

do $i=1, \mathrm{~m} 4$

if $(i . e q .2)$ then

tinlet $=$ alpha*thxi $(i-1)+$ alphal $* \operatorname{thx}(i-1)$

term0 $=c p^{*} f 1 w(4)+h t c$

term1 $=c p^{*} f 1 w(4) * t i n l e t$

term2 $=$ htc* $(a l p h a * t s h l i+a l p h a l * t s h 1)$

hcap $=w m s h x(i) * c p / d t$

coef $=$ hcap - alpha1*termo

coefn $=$ hcap + alpha*term0

c

$\operatorname{thxi}(i)=\left(\operatorname{coe}{ }^{*} \operatorname{thx}(i)+\operatorname{term} 1+\operatorname{term} 2+q d h x(i)\right) / \operatorname{coefn}$ else

if (i.eq.1) then tinlet $=$ alpha*touti + alphal*tout

else

tinlet $=$ alpha*thxi $(i-1)+\operatorname{alpha} * \operatorname{th} x(i-1)$ 


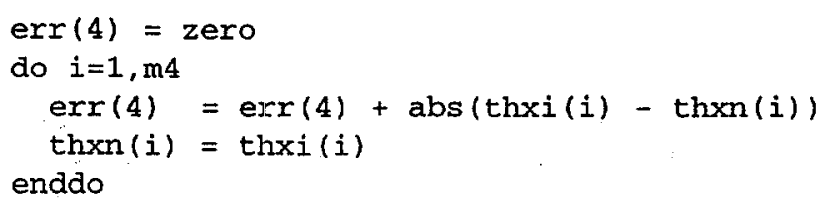

c

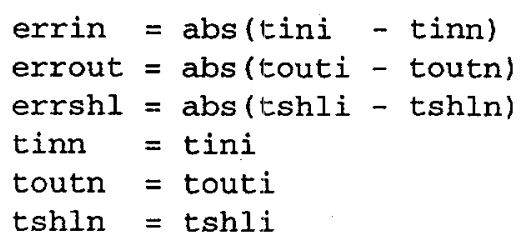




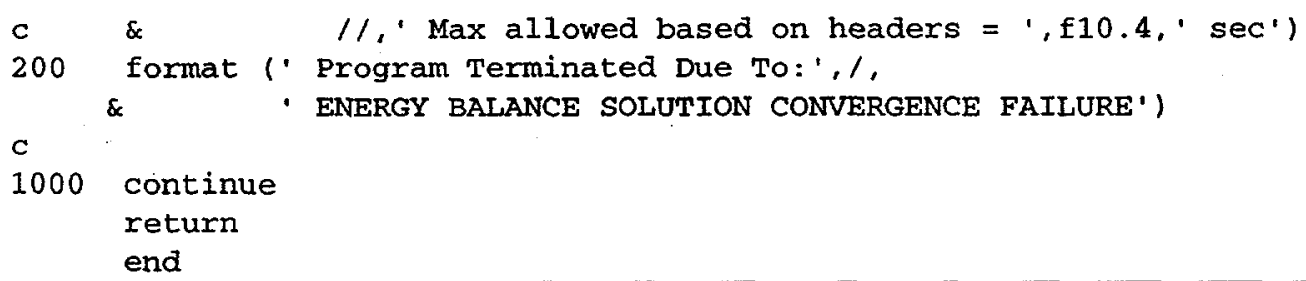

\section{Subroutine momtm.f}

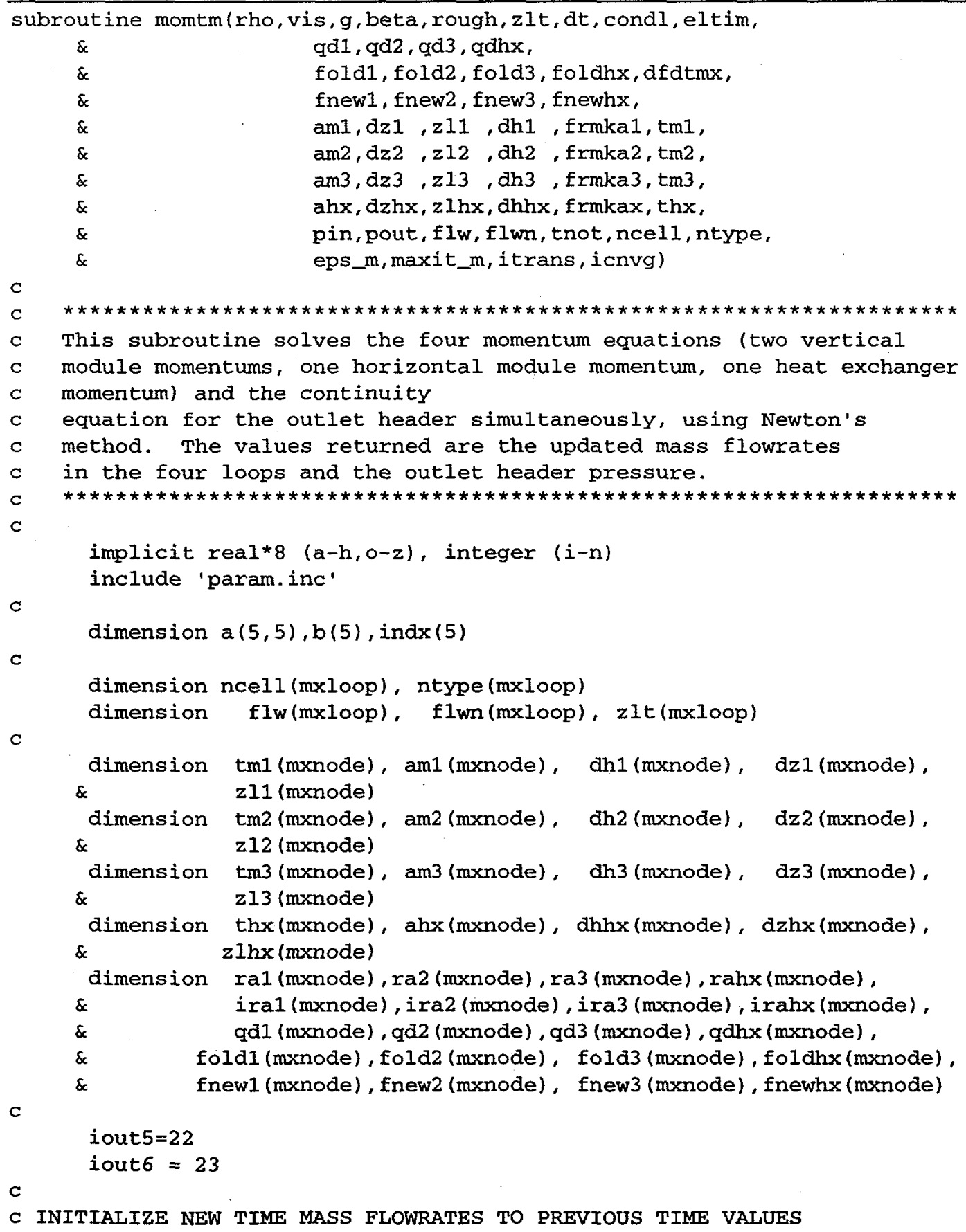


c

do, $j=1, \mathrm{mxloop}$

$f l w n(j)=f l w(j)$

enddo

$\mathrm{C}$

$c==$ SOLVE NON-LINEAR SET OF MASS/MOMENTUN EQNS $====================$

c

do iter=1, maxit_m

call rayleigh ( $f$ lwn, g, beta, condl, rho, vis, qd1, qd2, qd3, qdhx,

$\&$

$\&$

$\&$

$\mathrm{C}$

c MODULE \#1 (VERTICAL LATERAL MODULES):

c

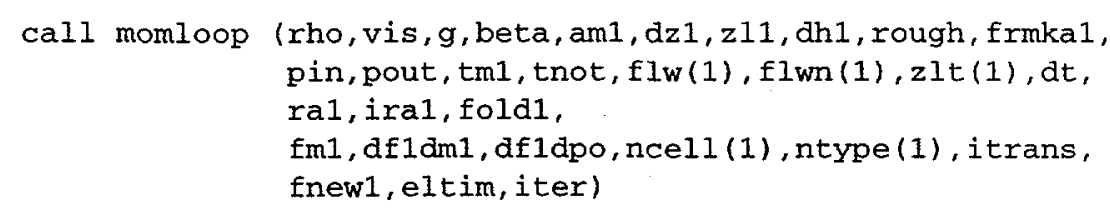

$c$

C

c MODULE \#2 (ALL REMAINING VERTICAL MODULES):

C

$a(1,1)=d f 1 d m 1$

$a(1,2)=$ zero

$\mathrm{a}(1,3)=$ zero

$\mathrm{a}(1,4)=$ zero

$a(1,5)=\operatorname{af} 1 d p o$

$\mathrm{b}(1)=-\mathrm{fm} 1$

elthrs $=$ eltim $/ 3600.0$ d0

write (iout5,500)

write (iout5, 502) iter, elthrs

write (iout5, 505) fm1, df1dm1, df1dpo

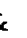
call momloop (rho, vis, g, beta, am2, dz2, z12, dh2, rough, frmka2, pin, pout, tm2, tnot, flw(2), flwn (2), zlt (2), dt, ra2, ira2, fold2, fm2, df2dm2, af2dpo, ncel1 (2) , ntype (2), itrans , fnew2, eltim, iter)

c

c

c MODULE \#3 (ALL HORIZONTAL MODULES):

c

$a(2,1)=$ zero

$a(2,2)=d f 2 d m 2$

$\mathrm{a}(2,3)=$ zero

$a(2,4)=$ zero

$a(2,5)=d f 2 d p o$

$\mathrm{b}(2)=-\mathrm{fm} 2$

write (iout5, 505) fm2, df $2 \mathrm{dm} 2, \mathrm{df} 2 \mathrm{dpo}$

$\&$

$\&$

$\&$

c

call momloop (rho, vis, $g$, beta, am $, \mathrm{dz} 3, \mathrm{z} 13$, dh3 , rough, frmka3, pin, pout, tm $3, \operatorname{tnot}, f \operatorname{lw}(3), f \operatorname{lwn}(3), \mathrm{zlt}(3), d t$, ra3, ira3, fold3,

fm3, df3dm3, df3dpo, ncel1 (3), ntype (3), itrans, fnew3, eltim, iter)

$a(3,1)=$ zero 
$a(3,2)=$ zero

$a(3,3)=d f 3 d m 3$

$a(3,4)=$ zero

$\mathrm{a}(3,5)=\mathrm{df} 3 \mathrm{dpo}$

$\mathrm{b}(3)=-\mathrm{fm} 3$

$c$

write (iout5, 505) fm3, df $3 \mathrm{dm} 3, \mathrm{df} 3 \mathrm{dpo}$

c

HEAT EXCHANGER LOOP \#4:

call momloop (rho, vis, g, beta, ahx, dzhx, zlhx, dhhx, rough, frmkax, pin, pout, thx, tnot, flw (4), flwn (4), zlt (4), at, rahx, irahx, foldhx,

fmhx, dfxdmx, dfxdpo, ncel1 (4), ntype (4), itrans, fnewhx, eltim, iter)

c

$a(4,1)=$ zero

$a(4,2)=$ zero

$a(4,3)=$ zero

$\mathrm{a}(4,4)=\mathrm{d} f \mathrm{xdmx}$

$a(4,5)=d f x d p o$

$\mathrm{b}(4)=-\mathrm{fmhx}$

write $($ iout5, 505) fmhx, dfxdmx, dfxdpo

c

C OUTLET HEADER CONTINUITY BALANCE:

C

c

call outhdr ( $f$ lwn, fmout, dfotd1, dfotd2, dfotd3, dfotdx)
$a(5,1)=$ dfotd 1
$a(5,2)=$ dfotd2
$a(5,3)=d$ fotd 3
$a(5,4)=d f o t d x$
$a(5,5)=$ zero
$\mathrm{b}(5)=-$ fmout

write $($ iout 5,511$) f \operatorname{lwn}(1), f \operatorname{lwn}(2), f \operatorname{lwn}(3), f \operatorname{lwn}(4)$, fmout

write (iout5, 511) fmout, dfotd1, dfotd2, dfotd3, dfotdx

$\mathrm{c}$

C SOLVE FOR NEWTON ITERATE BY LU DECOMPOSITION:

c

$\mathrm{n}=5$

$\mathrm{np}=5$

call ludemp $(a, n, n p$, ind $x, d)$

call lubksb $(a, n, n p$, ind $x, b)$

$c$

C UPDATE NEW TIME MASS FLOWRATE ARRAY AND OUTLET HEADER PRESSURE:

c

write (iout6, 510) iter, $f \operatorname{lwn}(1), f \operatorname{lwn}(2), f \operatorname{wn}(3), f \operatorname{lwn}(4)$, pout

write (iout6,510) iter, $(b(i), i=1,5)$

Cc

do $i=1, \mathrm{mxl}$ loop

$\mathrm{Cc}$

if $(j .1 t, 20)$ then

$f \operatorname{lw}(i)=f l w n(i)+b(i)$

$\mathrm{Cc}$

else

$$
f \operatorname{lwn}(i)=f l w n(i)+0.5 * b(i)
$$

enddo

cc if (j.1t. 20)then endif

cc else 


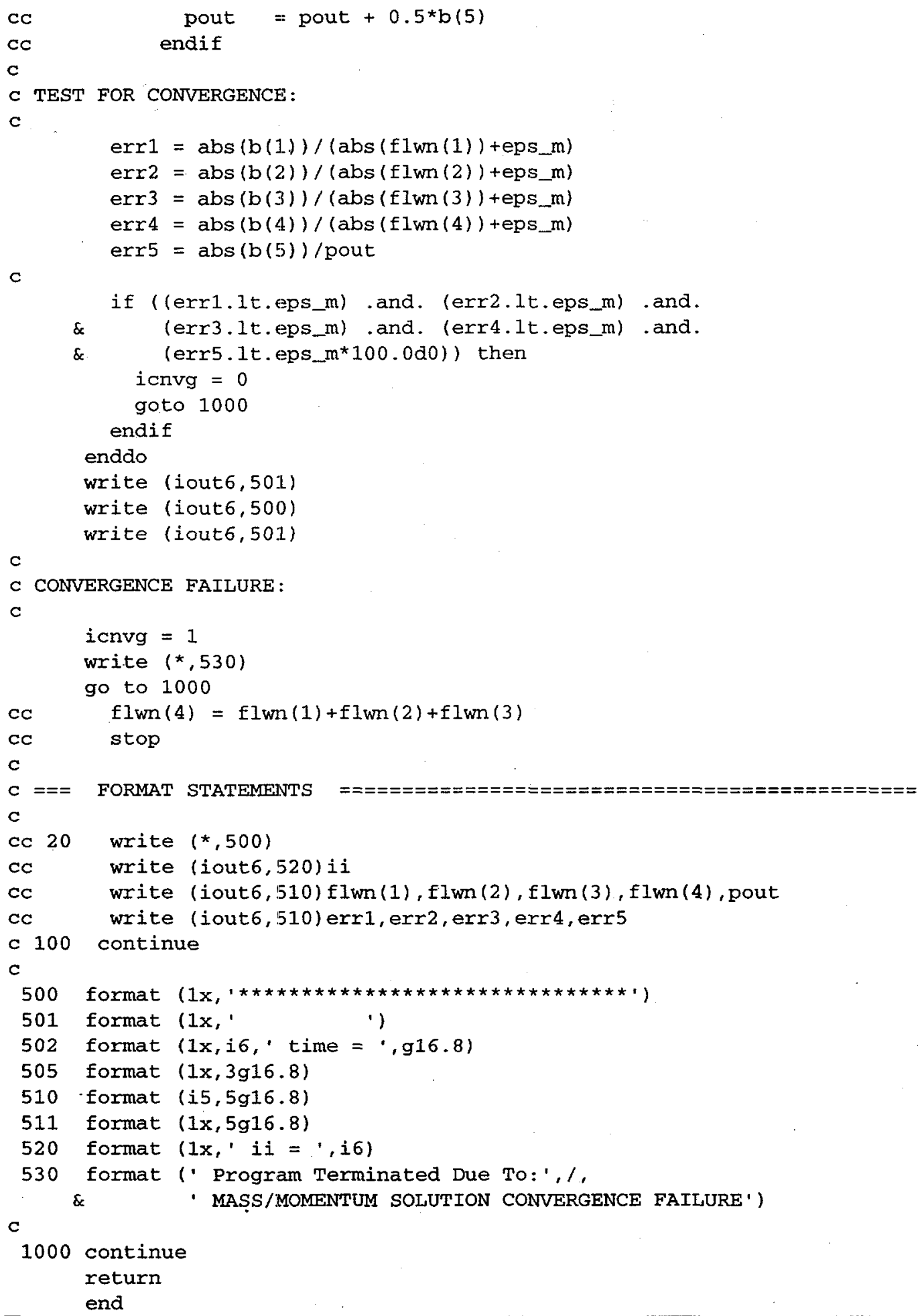

\section{Subroutine momloop.f}

subroutine momloop (rho, vis, g, beta, am, dz, zl, dh, rough, frmka, 
fnew, eltim, iter)

$C$
$C$
$C$
$C$
$C$
$C$
$C$
$C$
$C$
$C$
$C$
$C$
$C$
$C$
$C$
$C$
$C$


C ESTIMATE FUNCTION DERIVATIVE NUMERICALLY BY SIMPLE FORWARD

C DIFFERENCING FOR FLOW TERM AND ANALYTICALLY FOR PRESSURE TERM:

C

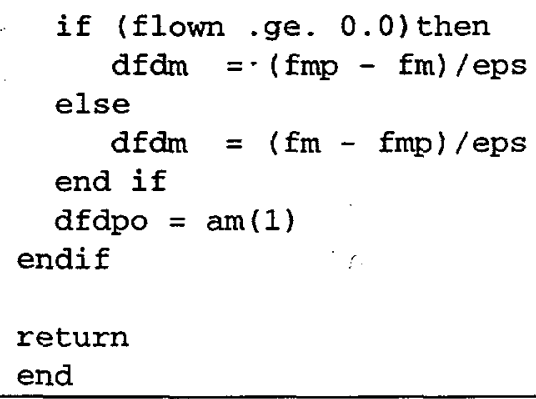

\section{Subroutine rayleigh.f}

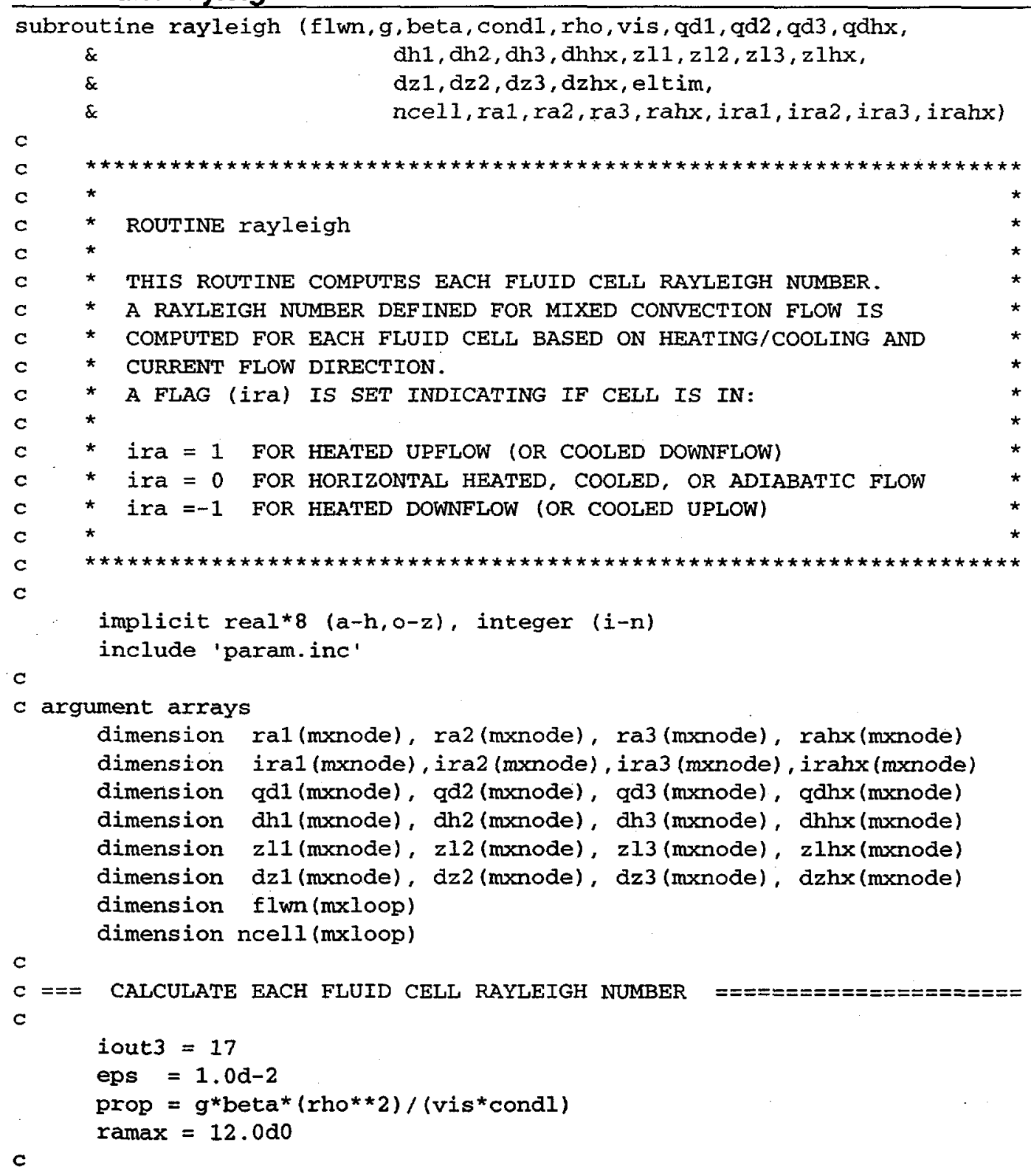




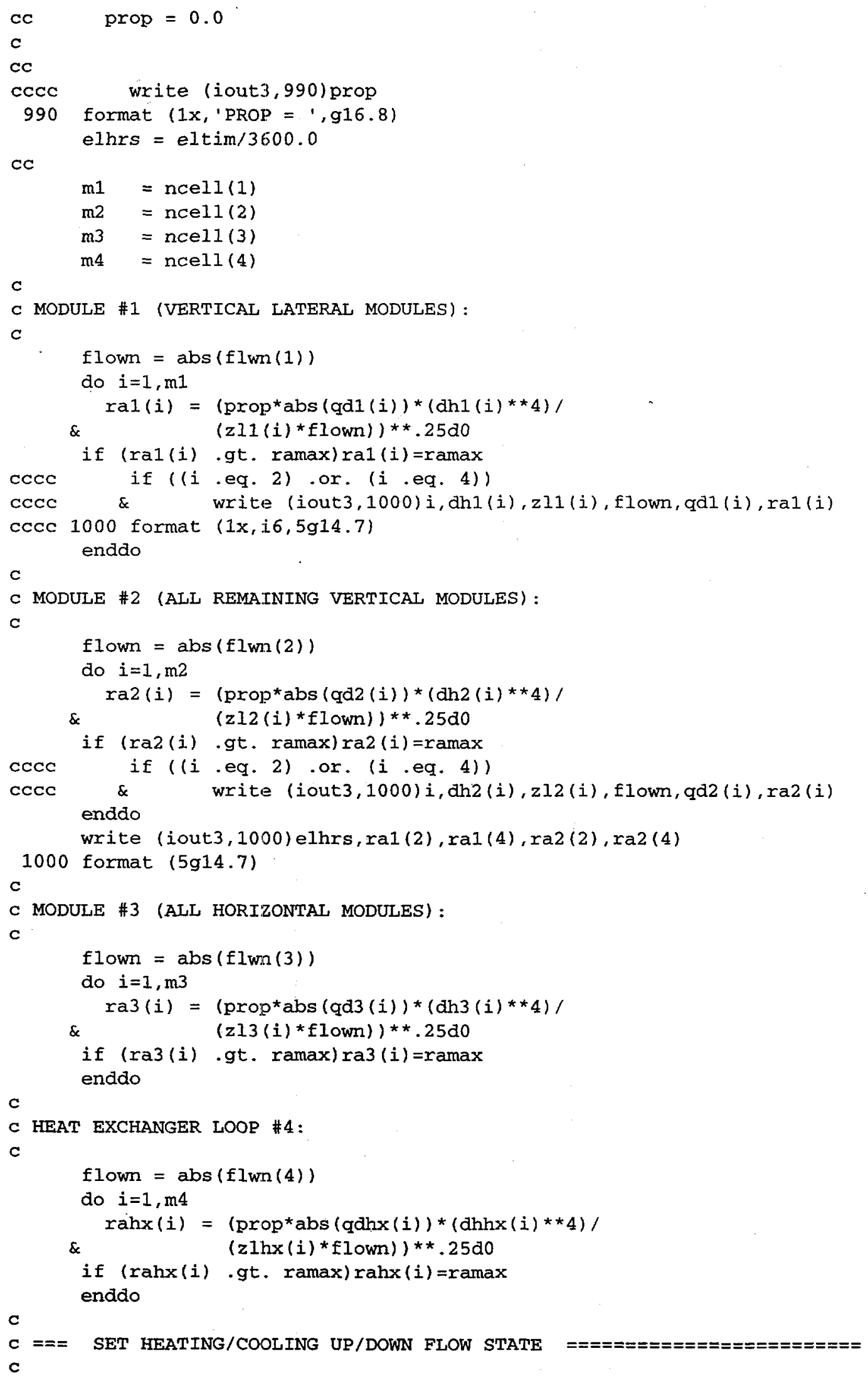


$\mathrm{C}$

c MODULE \#1 (VERTICAI LATERAI MODULES) :

$\mathrm{c}$

flown $=$ flwn $(1)$

do $i=1, \mathrm{~m} 1$

point $=\mathrm{dz} 1(\mathrm{i})$

c

if (qd1(i).gt.zero) then

if (point.lt.zero) then

if (flown.ge.zero) then

c --- heated upflow

$$
\underset{\text { else }}{\operatorname{iral}(i)=1}
$$

c --- heated downflow

$$
\operatorname{ira1}(i)=-1
$$
endif

elseif (point.gt.zero) then if (flown.ge.zero) then

c --- heated downflow

$$
\operatorname{iral}(i)=-1
$$

else

c --- heated upflow

$$
\operatorname{ira1}(i)=1
$$

$$
\text { endif }
$$

c --- horizontal

$$
\operatorname{iral}(i)=0
$$

endif

c --- COOLED

elseif (qd1(i).1t.zero) then

if (point.lt.zero) then

if (flown.ge.zero) then

c --- cooled upflow

$$
\operatorname{ira1}(i)=-1
$$

else

c --- cooled downflow

$$
\operatorname{ira1}(i)=1
$$

$$
\text { endif }
$$

elseif (point.gt.zero) then if (flown.ge.zero) then

c --- cooled downflow

$$
\operatorname{iral}(i)=1
$$

$$
\text { else }
$$

c --- cooled upflow

$$
\operatorname{ira1}(i)=-1
$$

$$
\text { endif }
$$

$$
\text { else }
$$

c --- horizontal

$\operatorname{iral}(i)=0$

$$
\text { endif }
$$

$$
\text { else }
$$

c

$$
\begin{array}{r}
\text { ADIABATIC } \\
\text { iral(i) }=0
\end{array}
$$

endif

enddo

C

C MODULE \#2 (VERTICAL LATERAL MODULES) : 
C

flown $=f l w n(2)$

do $i=1, \mathrm{~m} 2$

point $=\mathrm{dz2}(i)$

C --- HEATED

Page:

$$
\text { c - }
$$

if (point.1t.zero) then

if (flown.ge.zero) then

--- heated upflow

$$
\operatorname{ira2}(i)=1
$$

$$
\text { else }
$$

c --- heated downflow

$$
\operatorname{ira} 2(i)=-1
$$
endif

elseif (point.gt.zero) then

if (flown,ge,zero) then

c --- heated downflow

$$
\operatorname{ira} 2(i)=-1
$$

$$
\text { else }
$$

c --- heated upflow

$$
\operatorname{ira} 2(i)=1
$$

$$
\text { endif }
$$

$$
\text { else }
$$

c --- horizontal

$$
\operatorname{ira2}(i)=0
$$

$$
\text { endif }
$$

elseif (qd2(i).1t.zero) then
elsel

if (point.1t.zero) then

c --- cooled upflow

$$
\text { if (flown.ge.zero) then }
$$

$$
\operatorname{ira} 2(i)=-1
$$$$
\text { else }
$$

c --- cooled downflow $\operatorname{ira} 2(i)=1$ endif

elseif (point.gt.zero) then

if (flown.ge.zero) then

c --- cooled downflow

$$
\operatorname{ira} 2(i)=1
$$

$$
\text { else }
$$

c --- cooled upflow

$$
\operatorname{ira2}(i)=-1
$$

$$
\text { endif }
$$

$$
\text { else }
$$

c --- horizontal

$$
\operatorname{ira} 2(i)=0
$$

$$
\text { endif }
$$

$$
\text { else }
$$

c

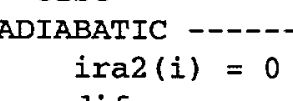

$c$

$c$

c MODULE \#3 (HORIZONTAL LATERAL MODULES) :

C 
flown $=f l w n(3)$

do $i=1, \mathrm{~m} 3$

$$
\text { point }=\mathrm{dz} 3(i)
$$

c - - HEATED

$$
\begin{aligned}
& \text { if (qd3(i).gt.zero) then } \\
& \text { if (point.lt.zero) then } \\
& \text { if (flown.ge.zero) then }
\end{aligned}
$$

c --- heated upflow

$$
\operatorname{ira} 3(i)=1
$$

else

c --- heated downflow

$$
\operatorname{ira} 3(i)=-1
$$
endif

elseif (point.gt.zero) then if (flown,ge.zero) then

c --- heated downflow

$$
\operatorname{ira} 3(i)=-1
$$

else

c --- heated upflow

$$
\operatorname{ira} 3(i)=1
$$

$$
\text { endif }
$$

c --- horizontal

$$
\operatorname{ira} 3(i)=0
$$

$$
\text { endif }
$$

c --- COOLED

$$
\text { elseif (qd3(i).1t.zero) then }
$$

if (point.1t.zero) then if (flown.ge.zero) then

c --- cooled upflow

$$
\text { ira3 }(i)=-1
$$

c --- cooled downflow

$$
\operatorname{ira3}(i)=1
$$

$$
\text { endif }
$$

elseif (point.gt.zero) then if (flown.ge.zero) then

c --- cooled downflow

$$
\operatorname{ira3}(i)=1
$$

$$
\text { else }
$$

c --- cooled upflow

$$
\operatorname{ira3}(i)=-1
$$

$$
\text { endif }
$$

c --- horizontal

$$
\operatorname{ira} 3(i)=0
$$

endif

$$
\text { else }
$$

c --- ADIABATIC

$\operatorname{ira} 3(i)=0$

endif

enddo

c

C

c MODULE \#4 (HEAT EXCHANGER LOOP) :

C

flown $=f \operatorname{lwn}(4)$ 
do $i=1, m 4$

point $=\mathrm{dzhx}(\mathrm{i})$

$c$

HEATED -...-

if ( $q d h x(i) \cdot g t$.zero) then

if (point.1t.zero) then

if (flown.ge.zero) then

c --- heated upflow

$$
\operatorname{irahx}(i)=1
$$

else

c --- heated downflow

$$
\operatorname{irahx}(i)=-1
$$
endif

elseif (point.gt.zero) then if (flown.ge.zero) then

c --- heated downflow

$$
\operatorname{irahx}(i)=-1
$$

else

c --- heated upflow

$\operatorname{irahx}(i)=1$

$$
\text { endif }
$$

else

c --- horizontal

$$
\operatorname{irahx}(i)=0
$$

endif

C - - COOLED

$$
\text { elseif (qdhx(i).lt.zero) then }
$$

if (point.lt.zero) then if (flown.ge.zero) then

c --- cooled upflow

$$
\operatorname{irahx}(i)=-1
$$

$$
\text { else }
$$

c --- cooled downflow

$$
i \operatorname{rahx}(i)=1
$$

$$
\text { endif }
$$

elseif (point.gt.zero) then

if (flown.ge.zero) then

c --- cooled downflow

$$
\operatorname{irahx}(i)=1
$$

$$
\text { else }
$$

c --- cooled upflow

$$
\operatorname{irahx}(i)=-1
$$

$$
\text { endif }
$$

else

c --- horizontal

$$
i \operatorname{rahx}(i)=0
$$

endif

$$
\text { else }
$$

c --- ADIABATIC

$$
\operatorname{irahx}(i)=0
$$

endif

$$
\text { enddo }
$$

$c$

return

end 


\section{Subroutine frict.f}

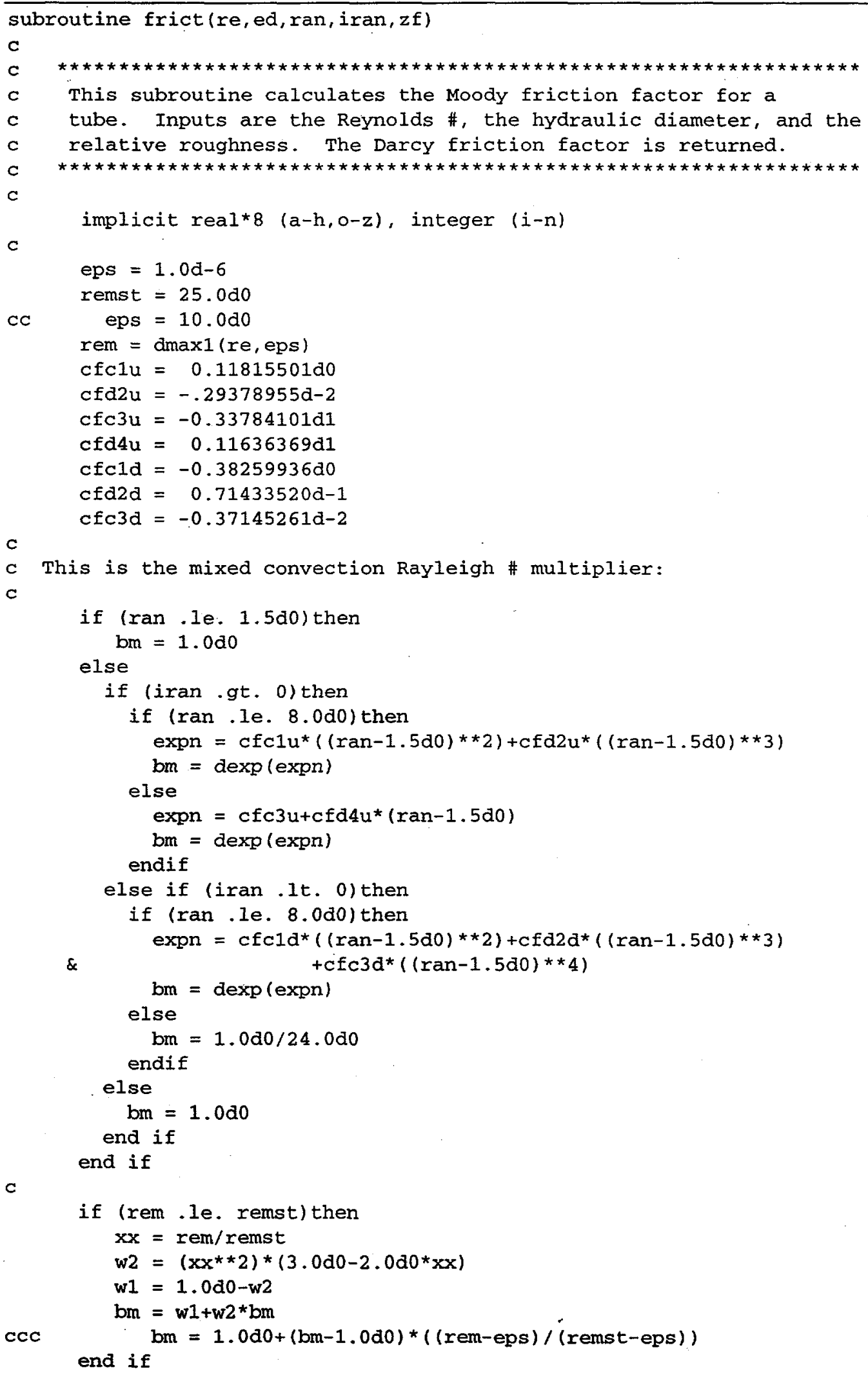


c

c Calc. standard friction factor

c

if (rem.1e.2300.0d0) then

$\mathrm{zf}=64.0 \mathrm{do} /$ rem

elseif (rem.ge.4000.0d0) then

$z f=1.0 \mathrm{~d} 0 /((1.14 \mathrm{~d} 0$

$\left.\left.-2.0 \mathrm{do} * \log 10\left(\mathrm{ed}+21.25 \mathrm{do} /\left(\mathrm{rem}^{\star *} 0.9 \mathrm{~d} 0\right)\right)\right) * * 2\right)$

else

$z f=0.23158 \mathrm{~d} 0-2.0549 \mathrm{~d}-4^{*} \mathrm{rem}$

$\&$

$+6.6351 d-8 *\left(\mathrm{rem}^{* * 2}\right)-6.7336 \mathrm{~d}-12 *(\mathrm{rem} * * 3)$

endif

$z f=b m * z f$

$\mathrm{C}$

iout $4=19$

if (iran .ne. 0)write (iout4, 1000) iran, ran, re, bm, zf

1000 format. $(1 \mathrm{x}, \mathrm{i5}, 4 \mathrm{~g} 16.8)$

return

end

\section{Subroutine outhdr.f}

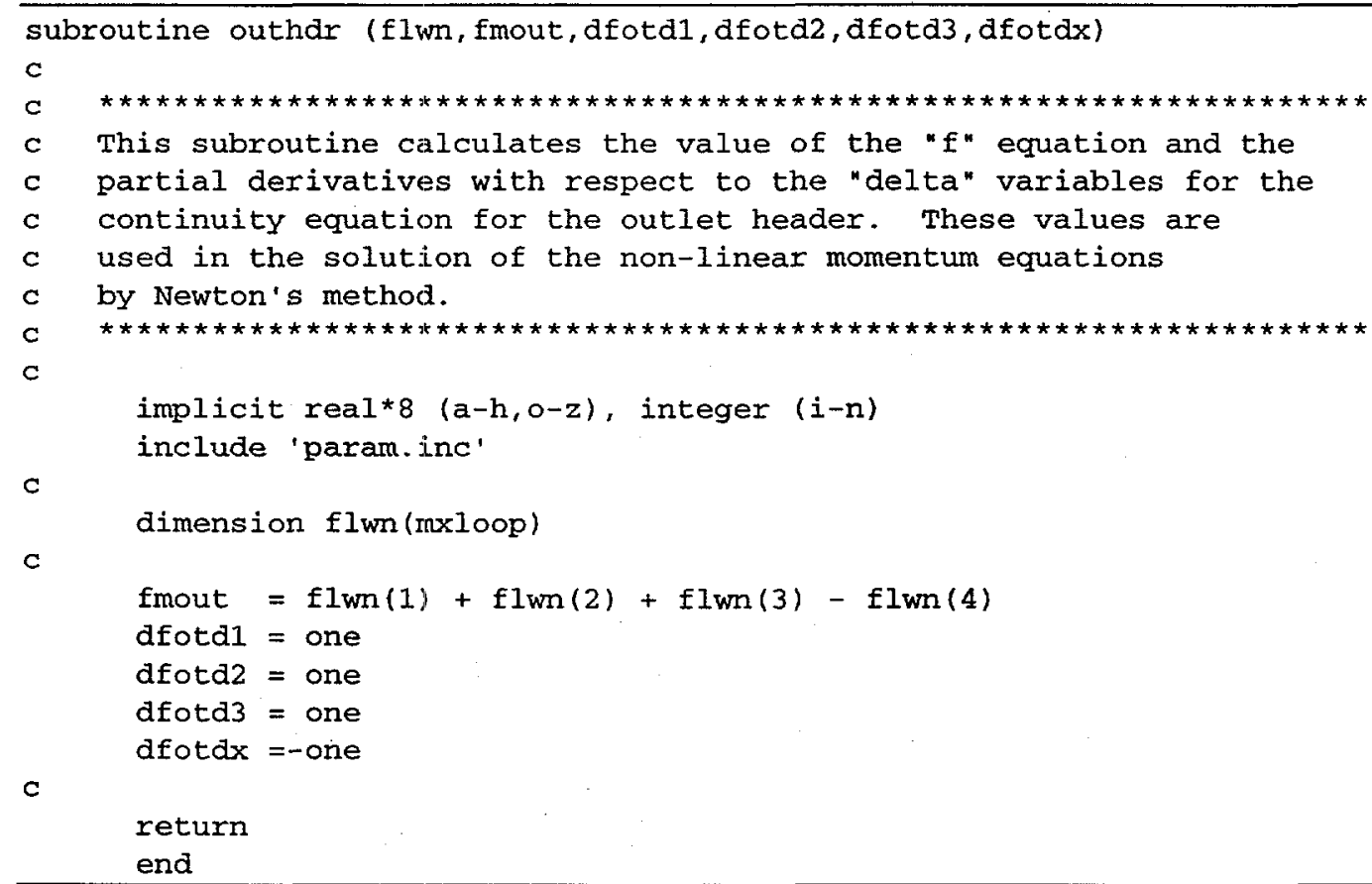

\section{Subroutine tmean.f}

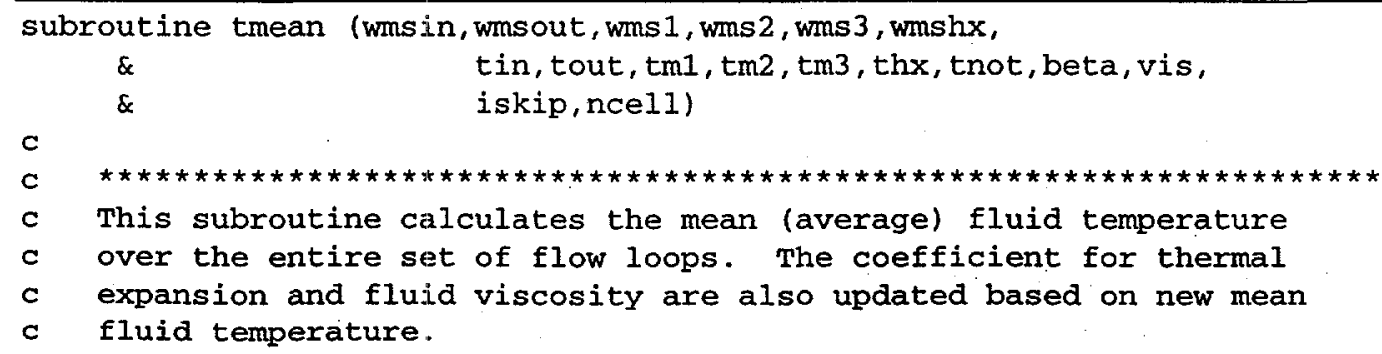


c

c

implicit real*8 $(a-h, o-z)$, integer $(i-n)$

$c$

include 'param.inc'

dimension ncel1(mxloop), coefb(5), coefv (8)

dimension tml (mxnode), wms I (mxnode)

dimension tm2 (mxnode), wms2 (mxnode)

dimension $\operatorname{tm} 3$ (mxnode), wms3 (mxnode)

dimension thx(mxnode), wmshx(mxnode)

c

data coefb/ $4.9323453 d-03,-6.3224634 d-05,2.8526660 d-07$,

c

$\& \quad-5.4026781 d-10,3.7406938 d-13 /$

data coefv/ $2.5217246 \mathrm{~d}+00,-4.3320035 \mathrm{~d}-02,3.1823267 \mathrm{~d}-04$,

\& $\quad-1.2943418 d-06,3.1456297 d-09,-4.5657684 d-12$,

\& $\quad 3.6636052 d-15,-1.2534347 d-18 /$

c

c CALCULATE MEAN TEMPERATURE (LOOP AVERAGE):

$\mathrm{C}$

if (iskip.eq.0) then

totmas = wmsin + wmsout

do $i=1, \operatorname{ncell}(1)$

totmas $=$ totmas $+\operatorname{wms} 1(i)$

enddo

do $i=1$, ncell (2)

totmas $=$ totmas + wms $2(i)$

enddo

do $i=1$, ncell (3)

totmas $=$ totmas + wms $3(i)$

enddo

do $i=1$, ncell (4)

totmas $=$ totmas $+w m s h x(i)$

enddo

$\mathrm{C}$

totemas $=$ wmsin*tin + wmsout* tout

do $i=1$, ncell (1)

totemas $=$ totemas $+w m s 1(i) * \operatorname{tm} 1(i)$

enddo

do $i=1$, ncell (2)

totemas $=$ totemas $+w m s 2(i) * t m 2(i)$

enddo

do $i=1$, ncell (3)

totemas $=$ totemas $+w m s 3(i) * \operatorname{tm} 3(i)$

enddo

do $i=1$, ncel1 (3)

totemas $=$ totemas $+\operatorname{wmshx}(i) * \operatorname{thx}(i)$ enddo

C

tnot $=$ totemas $/$ totmas

c

C CALCULATE NEW BETA:

c

$\&$

beta $=\operatorname{coefb}(1)+(\operatorname{coefb}(2)+(\operatorname{coefb}(3)+(\operatorname{coefb}(4)$

endif

$+\operatorname{coefb}(5) *$ tnot $) *$ tnot $) *$ tnot $) *$ tnot

c 
c CALCULATE NEW ABSOLUTE VISCOSITY $(\mathrm{kg} / \mathrm{m}-\mathrm{s})$ :

c

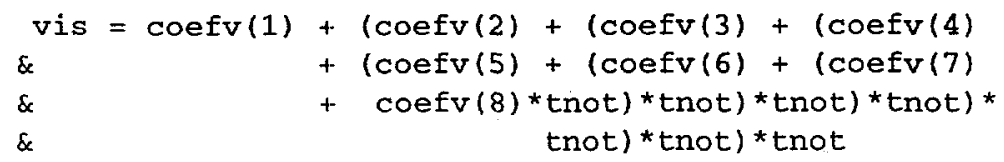

c

return

end

\section{Subroutine condlq.f}

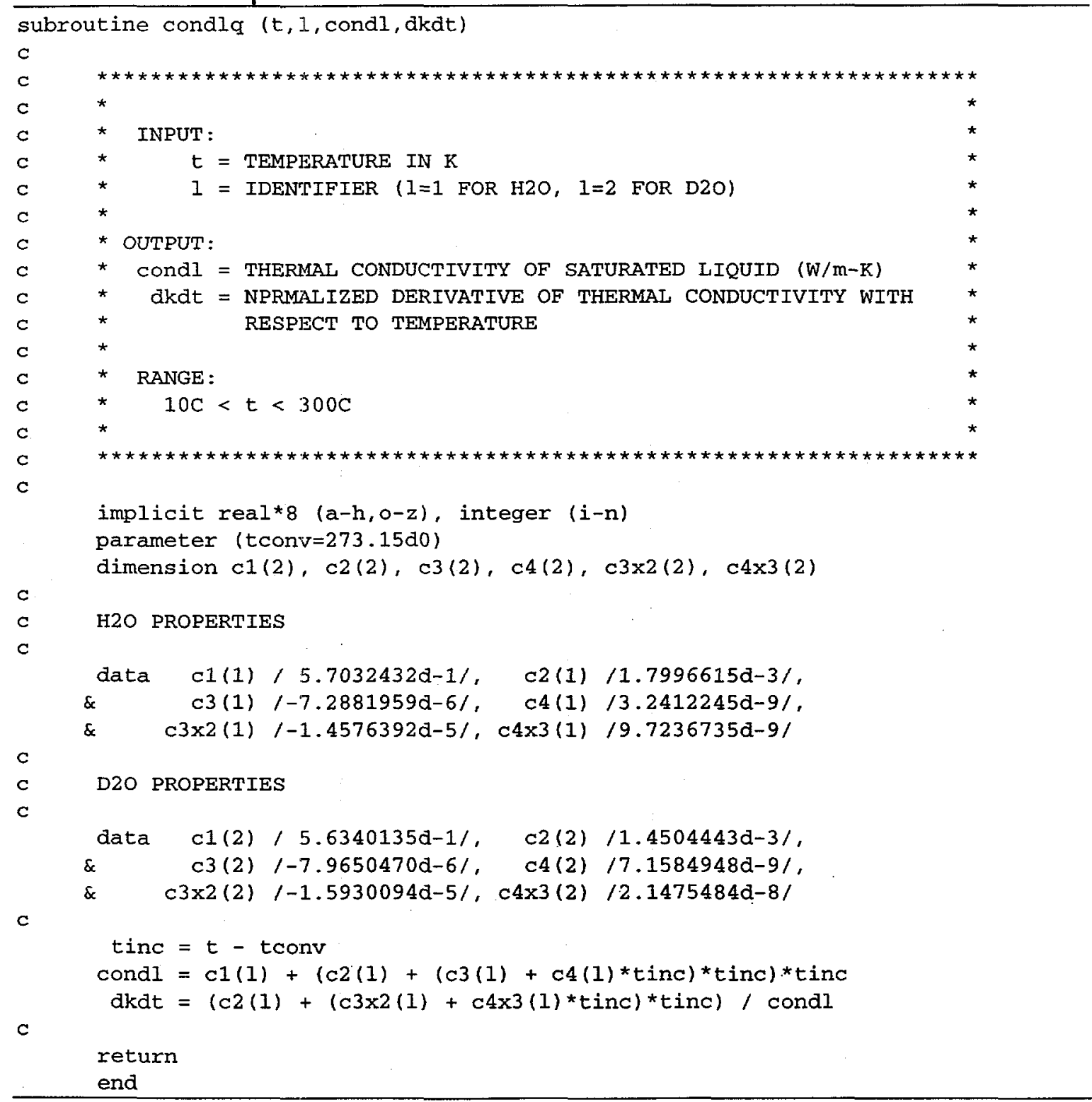

\section{Subroutine dpower.f}

subroutine dpower (eltim_p,tgstrt,tgdry, 
WESTINGHOUSE SAVANNAH RIVER COMPANY

BLANKET SAFETY ANALYSIS FOR LOFA

(NATURAL CIRCULATION))
Report: WSRC-TR-98-00207

Section: - Appendix D

Date:

Page:

ncell)

c

c

c

C

C

C

c

c

C

c argument arrays

dimension qd1 (mxnode), qd2 (mxnode), qd3 (mxnode), qdhx (mxnode)

dimension q1 (mxnode), q2 (mxnode), q3 (mxnode)

dimension ncell (mxloop)

c

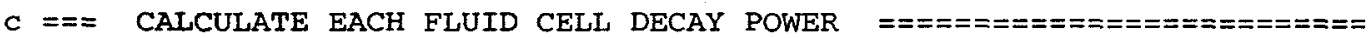

c

conv_tim $=3600.0 \mathrm{d0}$

$\mathrm{m} 1=\operatorname{ncel1}(1)$

$\mathrm{m} 2 \quad=\operatorname{ncell}(2)$

$\mathrm{m} 3=\operatorname{ncel} 1(3)$

$\mathrm{m} 4=\operatorname{ncel1}(4)$

tau = eltim_p/conv_tim

c

C COMPUTE DECAY FRACTION

$c$

if (tau.le.one) then

write $(*, 200)$ tau

stop

else

decay $=3.849 d-3 *(0.96 d 0-0.363 d 0 * \log 10($ tau $))$

endif

c

C COMPUTE TARGET POWER DEPOSITED TO DECOUPLER

c

if (eltim_p.1t.tgstrt) then qtgt $=$ zero

elseif (eltim_p.gt.tgdry) then

qtgt $=$ target

else

qtgt $=\operatorname{target}^{*}($ eltim_p-tgstrt $) /(\operatorname{tgdry}-\operatorname{tgstrt})$ endif

c

C COMPUTE BLANKET MODULE POWER DEPOSTTED

c

c MODULE \#1

do $i=1, \mathrm{~m} 1$

$q d l(i)=\operatorname{decay}^{*} q 1(i)$

enddo

qd1 (2) $=$ qd1 (2) + decay* qtgt

c

c MODULE \#2

do $i=1, \mathrm{~m} 2$

$q d 2(i)=\operatorname{decay}^{*} q 2(i)$ 
enddo

$\mathrm{c}$

C MODULE \#3

do $i=1, \mathrm{~m} 3$

qd3 $(i)=\operatorname{decay}^{\star} \mathrm{q} 3(i)$

enddo

$\mathrm{C}$

c HEAT EXCHANGER \#4

do $i=1, m 4$

gdhx $(i)=$ zero

enddo

C

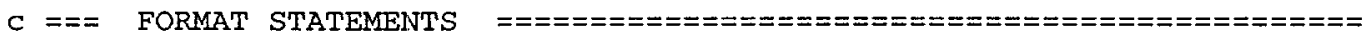

$\mathrm{C}$

200 format (' Program Terminated Due To: ', /,

$\&$ ' INITIAL START TIME MUST BE GREATER THAN OR',

\& ' EQUAL TO ONE HOUR', //,

\& $\quad$ CURRENT ELAPSED TIME $=\prime, \pm 10.3$,' hours')

C

return

end

\section{Subroutine ludemp.f}

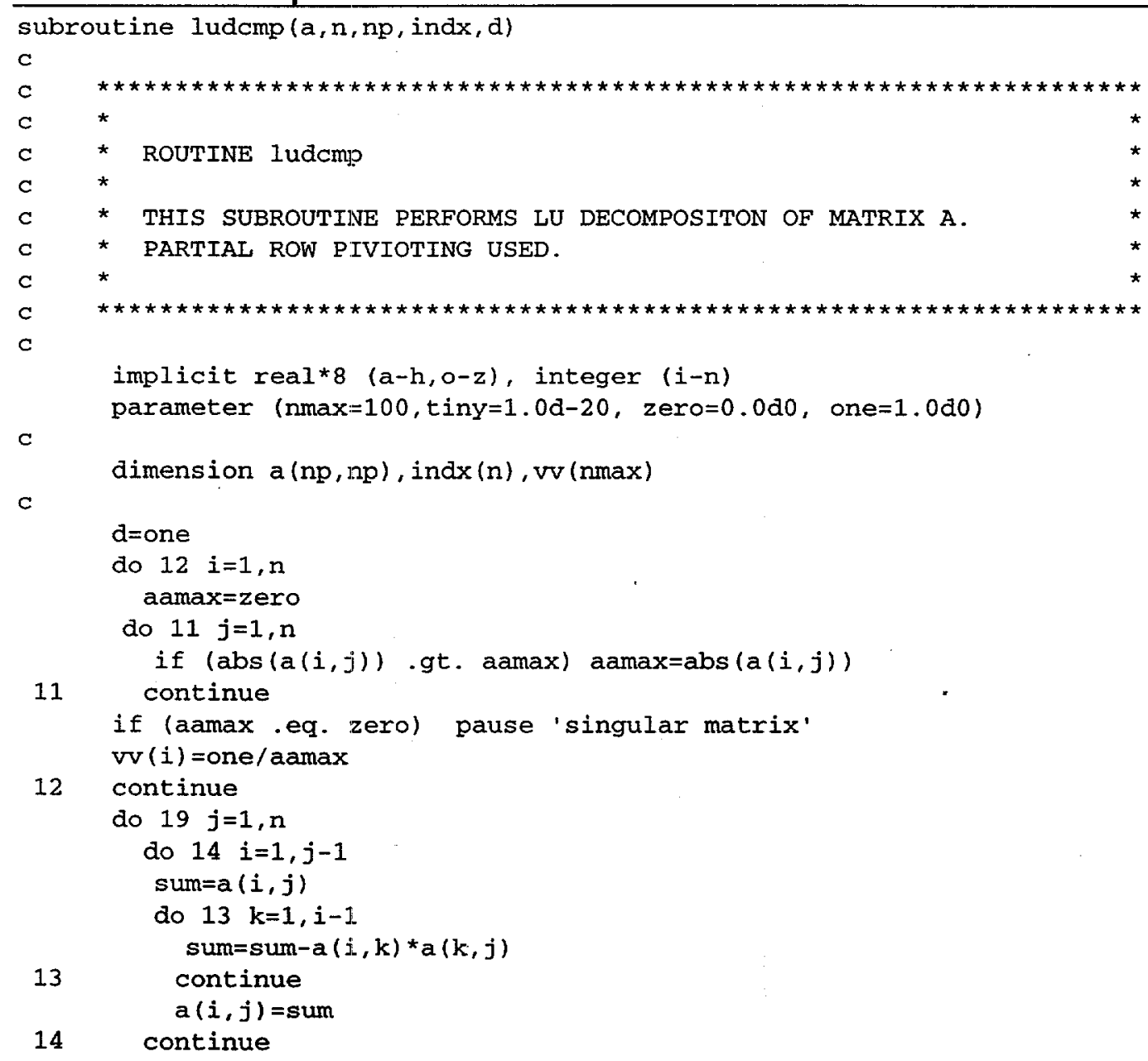


15

aamax $=$ zero

do $16 i=j, n$

sum $=a(i, j)$

do $15 \mathrm{k}=1, j-1$

sum $=\operatorname{sum}-a(i, k) * a(k, j)$

continue

$a(i, j)=$ sum

dum $=v v(i) * a b s$ (sum)

if (dum .ge. aamax) then

$i \max =i$

aamax $=$ dum

endif

16 continue

if ( $j$.ne. imax) then

do $17 \mathrm{k}=1, \mathrm{n}$

dum $=a(i \max , k)$

$a(i \max , k)=a(j, k)$

$a(j, k)=$ dum

17 continue

$$
d=-d
$$

$v v(i \max )=v v(j)$

endif

$\operatorname{indx}(j)=i \max$

if $(a(j, j)$.eq. zero) $a(j, j)=$ tiny

if $(j$.ne. $n)$ then

dum=one $/ a(j, j)$

do $18 i=j+1, n$

$a(i, j)=a(i, j) * d u m$

18 continue

endif

19 continue

return

end

\section{Subroutine lubksb.f}

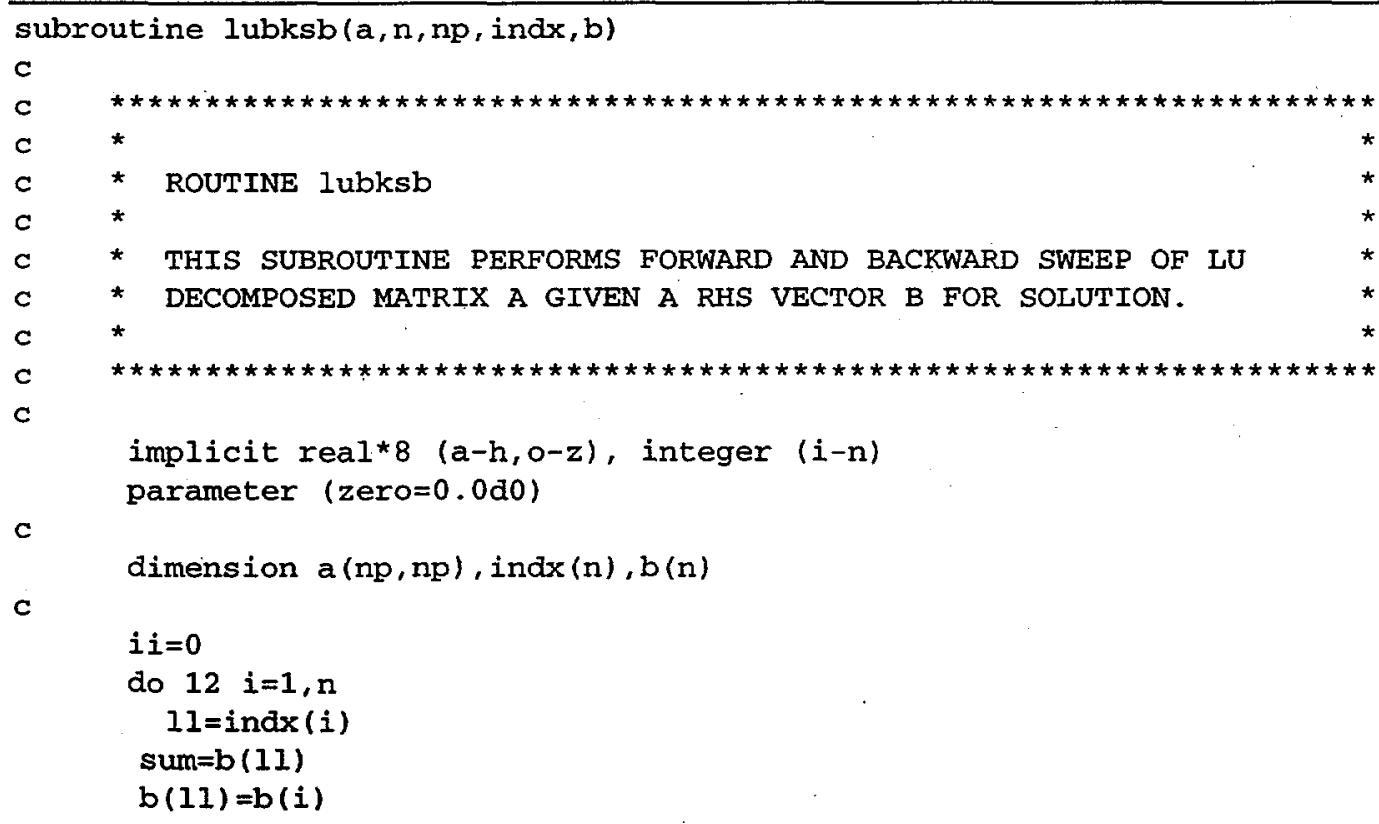

c

c

c

* THIS SUBROUTINE PERFORMS FORWARD AND BACKWARD SWEEP OF LU

* DECOMPOSED MATRIX A GIVEN A RHS VECTOR B FOR SOLUTION.

*

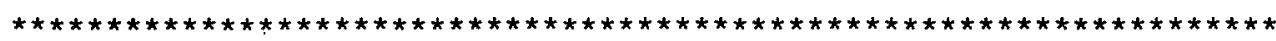

implicit real*8 $(a-h, o-z)$, integer $(i-n)$

parameter $(z e r o=0.0 \mathrm{~d} 0)$

c

dimension $a(n p, n p)$, ind $x(n), b(n)$

c

$$
\begin{aligned}
& i i=0 \\
& \text { do } 12 \quad i=1, n \\
& 11=i \operatorname{ndx}(i) \\
& \text { sum=b(11) } \\
& b(11)=b(i)
\end{aligned}
$$


if (ii ne. 0 ) then

do $11 j=i i, i-1$

sum $=\operatorname{sum}-a(j, j) * b(j)$

11

$$
\text { continue }
$$

else if (sum ne. zero) then $i i=i$

endif

$b(i)=$ sum

12. . continue

do $14 i=n, 1,-1$

sum=b(i)

do $13 j=i+1, n$

sum $=\operatorname{sum}-a(i, j) * b(j)$

13 continue

$b(i)=\operatorname{sum} / a(i, i)$

14 continue

return

end 